\title{
Evaluation of Experimental and Predicted Vapor-Liquid Equilibrium Data for Systems Relevant to Biomass Fast Pyrolysis and Catalytic Upgrading
}

Eugene Paulechka

Vladimir Diky Abhijit Dutta

This publication is available free of charge from:

https://doi.org/10.6028/NIST.IR.8357 


\title{
Evaluation of Experimental and Predicted Vapor-Liquid Equilibrium Data for Systems Relevant to Biomass Fast Pyrolysis and Catalytic Upgrading
}

\author{
Eugene Paulechka \\ Vladimir Diky \\ Applied Chemicals and Materials Division \\ Material Measurement Laboratory \\ Abhijit Dutta \\ Catalytic Carbon Transformation and Scale-up Center \\ National Renewable Energy Laboratory
}

This publication is available free of charge from:

https://doi.org/10.6028/NIST.IR.8357

March 2021

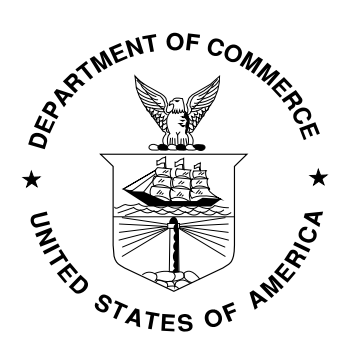

U.S. Department of Commerce

Gina M. Raimondo, Secretary

National Institute of Standards and Technology James K. Olthoff, Performing the Non-Exclusive Functions and Duties of the Under Secretary of Commerce for Standards and Technology \& Director, National Institute of Standards and Technology 
Certain commercial entities, equipment, or materials may be identified in this document in order to describe an experimental procedure or concept adequately. Such identification is not intended to imply recommendation or endorsement by the National Institute of Standards and Technology, nor is it intended to imply that the entities, materials, or equipment are necessarily the best available for the purpose.

National Institute of Standards and Technology Interagency or Internal Report 8357

Natl. Inst. Stand. Technol. Interag. Intern. Rep. 8357, 75 pages (March 2021)

This publication is available free of charge from: https://doi.org/10.6028/NIST.IR.8357 


\begin{abstract}
The experimental vapor-liquid equilibrium (VLE) data for the binaries relevant to the catalytic fast pyrolysis of biomass have been collected and analyzed using the NIST-COSMO-SAC and NIST-modified UNIFAC models. The existing inconsistencies in the experimental data and the predicted values are discussed. For VLE with furan derivatives, PTxy data are normally reported, and the predicted values are in good agreement with them. For phenolic compounds, the gas phase compositions are available for only $36 \%$ of the points, most results originate from a few laboratories, and each system has been typically studied in a single laboratory. The binaries are identified where more experimental VLE data are required to evaluate quality of the existing experimental and predicted results.
\end{abstract}

\title{
Key words
}

Catalytic fast pyrolysis; predictive models; vapor-liquid equilibria. 


\section{Table of Contents}

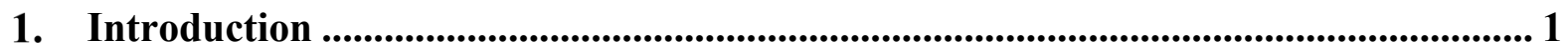

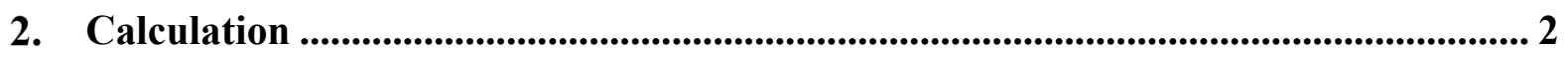

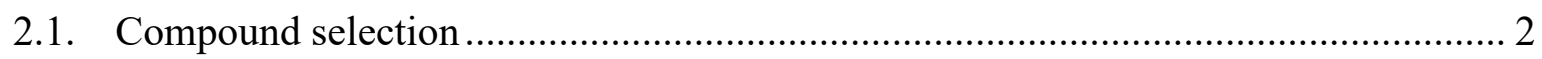

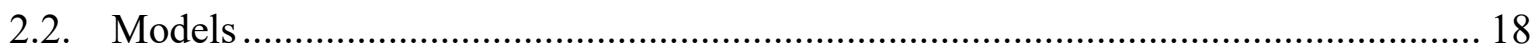

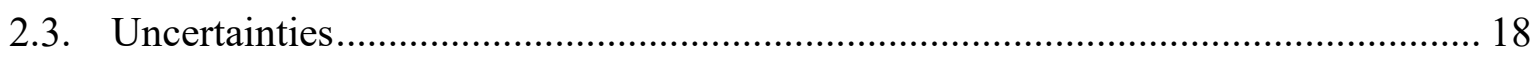

2.4. Criteria for analysis of the experimental and predicted data.................................. 19

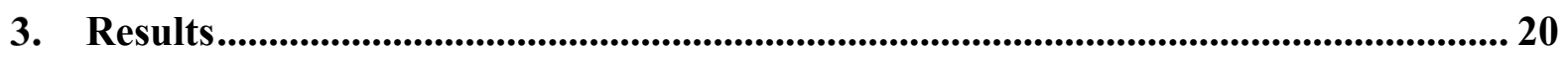

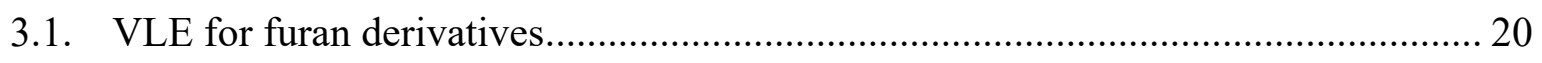

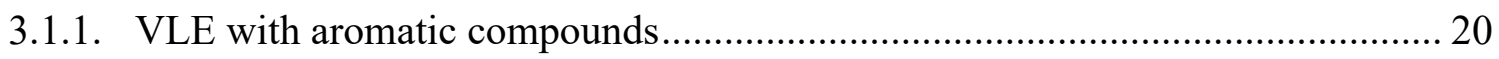

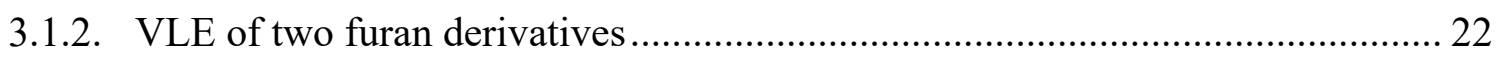

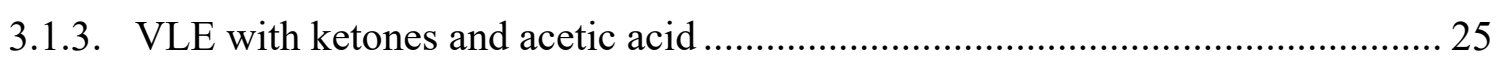

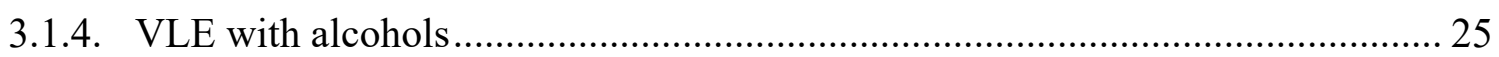

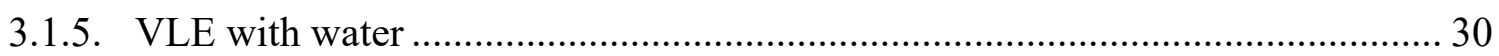

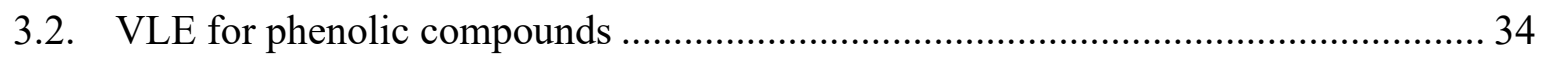

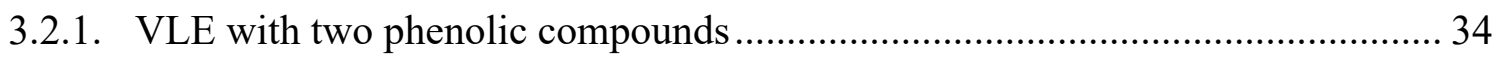

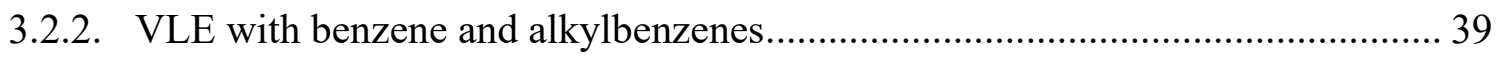

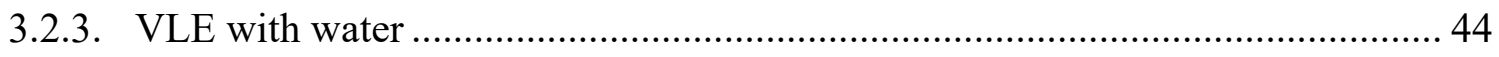

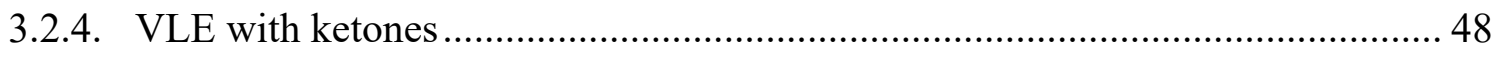

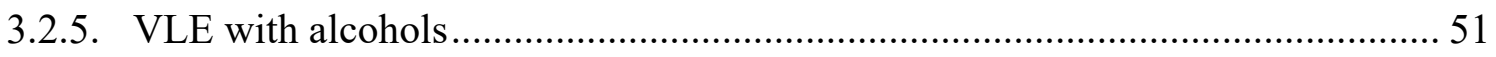

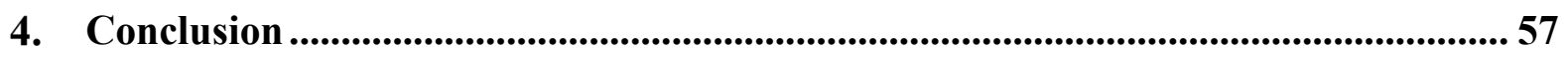

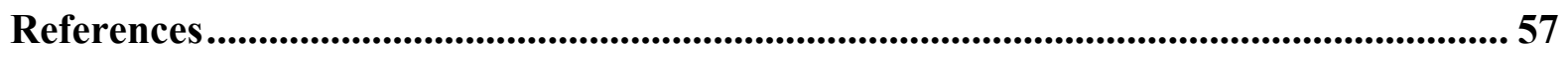

\section{List of Tables}

Table 1. Principal and secondary components considered in this work. ...................................... 3

Table 2. Binary mixtures with VLE data evaluated in this work............................................ 5

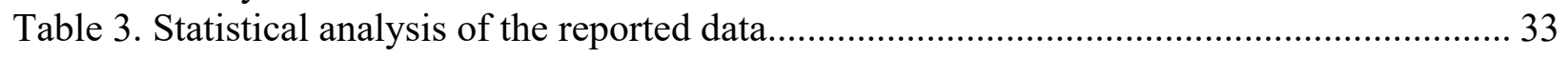

\section{List of Figures}

Fig. 1. Comparison of the predicted and experimental pressures $P$ and first-component mole fractions $y_{1}$ in the gas phase at different first-component mole fractions in the liquid phase $x_{1}$ for the binaries of furan derivatives with aromatic compounds: a, c, NIST-COSMO-SAC; $b, d$ : NIST-Modified UNIFAC.

Fig. 2. Comparison of the predicted and experimental pressures $P$ and first-component mole fractions $y_{1}$ in the gas phase at different first-component mole fractions in the liquid phase $x_{1}$ for 
the binaries of furan derivatives one of which is furan or methylfuranes: a, c, NIST-COSMOSAC; $b$, d: NIST-Modified UNIFAC.

Fig. 3. Comparison of the predicted and experimental pressures $P$ and first-component mole fractions $y_{1}$ in the gas phase at different first-component mole fractions in the liquid phase $x_{1}$ for the binaries of furan derivatives: a, c, NIST-COSMO-SAC; b, d: NIST-Modified UNIFAC. .... 24 Fig. 4. Comparison of the predicted and experimental pressures $P$ and first-component mole fractions $y_{1}$ in the gas phase at different first-component mole fractions in the liquid phase $x_{1}$ for the binaries of furan derivatives with ketones and acetic acid: a, c, NIST-COSMO-SAC; b, d: NIST-Modified UNIFAC.....

Fig. 5. Comparison of the predicted and experimental pressures $P$ and first-component mole fractions $y_{1}$ in the gas phase at different first-component mole fractions in the liquid phase $x_{1}$ for the binaries of furan and methylfuranes with methanol and ethanol: $a, c$, NIST-COSMO-SAC; $b$, d: NIST-Modified UNIFAC. 27

Fig. 6. Comparison of the predicted and experimental pressures $P$ and first-component mole fractions $y_{1}$ in the gas phase at different first-component mole fractions in the liquid phase $x_{1}$ for the binaries of furan derivatives with methanol and ethanol: a, c, NIST-COSMO-SAC; $b$, d: NIST-Modified UNIFAC.

Fig. 7. Comparison of the predicted and experimental pressures $P$ and first-component mole fractions $y_{1}$ in the gas phase at different first-component mole fractions in the liquid phase $x_{1}$ for the binaries of furan derivatives with longer-chain alcohols: a, c, NIST-COSMO-SAC; $b$, d: NIST-Modified UNIFAC....

Fig. 8. Comparison of the predicted and experimental pressures $P$ and first-component mole fractions $y_{1}$ in the gas phase at different first-component mole fractions in the liquid phase $x_{1}$ for the binaries of furan derivatives with water: a, c, NIST-COSMO-SAC; b, d: NIST-Modified UNIFAC.

Fig. 9. Comparison of the predicted and experimental pressures $P$ and first-component mole fractions $y_{1}$ in the gas phase at different first-component mole fractions in the liquid phase $x_{1}$ for the binaries of phenol with methylphenols: a, c, NIST-COSMO-SAC; b, d: NIST-Modified UNIFAC.

Fig. 10. Comparison of the predicted and experimental pressures $P$ and first-component mole fractions $y_{1}$ in the gas phase at different first-component mole fractions in the liquid phase $x_{1}$ for the 1,2-benzenediol binaries: a, c, NIST-COSMO-SAC; b, d: NIST-Modified UNIFAC........... 36 Fig. 11. Comparison of the predicted and experimental pressures $P$ and first-component mole fractions $y_{1}$ in the gas phase at different first-component mole fractions in the liquid phase $x_{1}$ for the 2-methylphenol binaries: a, c, NIST-COSMO-SAC; b, d: NIST-Modified UNIFAC. 37 Fig. 12. Comparison of the predicted and experimental pressures $P$ and first-component mole fractions $y_{1}$ in the gas phase at different first-component mole fractions in the liquid phase $x_{1}$ for the binaries with methylphenols: a, c, NIST-COSMO-SAC; b, d: NIST-Modified UNIFAC..... 38 Fig. 13. Comparison of the predicted and experimental pressures $P$ and first-component mole fractions $y_{1}$ in the gas phase at different first-component mole fractions in the liquid phase $x_{1}$ for the binaries of phenol with alkylbenzenes: a, c, NIST-COSMO-SAC; $b$, d: NIST-Modified UNIFAC.

Fig. 14. Comparison of the predicted and experimental pressures $P$ and first-component mole fractions $y_{1}$ in the gas phase at different first-component mole fractions in the liquid phase $x_{1}$ for the binaries of 2-methylphenol with alkylbenzenes: a, c, NIST-COSMO-SAC; b, d: NISTModified UNIFAC. 
Fig. 15. Comparison of the predicted and experimental pressures $P$ and first-component mole fractions $y_{1}$ in the gas phase at different first-component mole fractions in the liquid phase $x_{1}$ for the binaries of 3-methylphenol with alkylbenzenes and 2-methylnaphthalene: a, c, NISTCOSMO-SAC; $b$, d: NIST-Modified UNIFAC.

Fig. 16. Comparison of the predicted and experimental pressures $P$ and first-component mole fractions $y_{1}$ in the gas phase at different first-component mole fractions in the liquid phase $x_{1}$ for the binaries of 4-methylphenol and 2-methoxyphenol with alkylbenzenes: a, c, NIST-COSMOSAC; $b$, d: NIST-Modified UNIFAC.

Fig. 17. Comparison of the predicted and experimental pressures $P$ and first-component mole fractions $y_{1}$ in the gas phase at different first-component mole fractions in the liquid phase $x_{1}$ for the binaries with methoxybenzene: a, c, NIST-COSMO-SAC; b, d: NIST-Modified UNIFAC. 45 Fig. 18. Comparison of the predicted and experimental pressures $P$ and first-component mole fractions $y_{1}$ in the gas phase at different first-component mole fractions in the liquid phase $x_{1}$ for (phenol + water): a, c, NIST-COSMO-SAC; b, d: NIST-Modified UNIFAC. 46

Fig. 19. Comparison of the predicted and experimental pressures $P$ and first-component mole fractions $y_{1}$ in the gas phase at different first-component mole fractions in the liquid phase $x_{1}$ for the binaries with water: a, c, NIST-COSMO-SAC; b, d: NIST-Modified UNIFAC..... 47 Fig. 20. Comparison of the predicted and experimental pressures $P$ and first-component mole fractions $y_{1}$ in the gas phase at different first-component mole fractions in the liquid phase $x_{1}$ for the binaries of phenol with ketones: a, c, NIST-COSMO-SAC; b, d: NIST-Modified UNIFAC.49 Fig. 21. Comparison of the predicted and experimental pressures $P$ and first-component mole fractions $y_{1}$ in the gas phase at different first-component mole fractions in the liquid phase $x_{1}$ for the binaries of phenolic compounds with ketones: a, c, NIST-COSMO-SAC; b, d: NISTModified UNIFAC.

Fig. 22. Comparison of the predicted and experimental pressures $P$ and first-component mole fractions $y_{1}$ in the gas phase at different first-component mole fractions in the liquid phase $x_{1}$ for the binaries of phenol with alcohols: a, c, NIST-COSMO-SAC; b, d: NIST-Modified UNIFAC.

Fig. 23. Comparison of the predicted and experimental pressures $P$ and first-component mole fractions $y_{1}$ in the gas phase at different first-component mole fractions in the liquid phase $x_{1}$ for the binaries of 2-methylphenol with alcohols: a, c, NIST-COSMO-SAC; b, d: NIST-Modified UNIFAC.

Fig. 24. Comparison of the predicted and experimental pressures $P$ and first-component mole fractions $y_{1}$ in the gas phase at different first-component mole fractions in the liquid phase $x_{1}$ for the binaries of 3-methylphenol with alcohols: a, c, NIST-COSMO-SAC; b, d: NIST-Modified UNIFAC.

Fig. 25. Comparison of the predicted and experimental pressures $P$ and first-component mole fractions $y_{1}$ in the gas phase at different first-component mole fractions in the liquid phase $x_{1}$ for the binaries of 4-methylphenol with alcohols: a, c, NIST-COSMO-SAC; b, d: NIST-Modified UNIFAC.....

Fig. 26. Comparison of the predicted and experimental pressures $P$ and first-component mole fractions $y_{1}$ in the gas phase at different first-component mole fractions in the liquid phase $x_{1}$ for the binaries of 1,3-benzenediol and 2-methoxyphenol with alcohols: a, c, NIST-COSMO-SAC; b, d: NIST-Modified UNIFAC. 


\section{Introduction}

Biomass constituents include oxygenated polymeric material such as cellulose, hemicellulose, and polyaromatic lignin with hydroxy and methoxy groups $[1,2]$. Fast pyrolysis is a process of thermal deconstruction of these materials at nearly $500^{\circ} \mathrm{C}$ with rapid heat transfer in a nonoxidative atmosphere, which produces solid char, non-condensable gases such as $\mathrm{CO}, \mathrm{CO}_{2}, \mathrm{CH}_{4}$, and vapors including $\mathrm{H}_{2} \mathrm{O}$ and numerous organic species [3]. Biomass reactions under these conditions are non-selective and the organic vapors include material of different molecular weights from the depolymerization process; additional reactions including the fragmentation of the monomeric constituents result in the formation of thousands of chemical species during fast pyrolysis. Condensation of fast pyrolysis vapors results in a liquid product known as bio-oil or pyrolysis-oil, which is unstable with regard to further chemical transformations because of its various oxygenated species including sugars, acids, and aldehydes [4]. Catalytic upgrading of the vapors prior to condensation, either within the fast pyrolysis reactor (in situ) or in a separate reactor following the fast pyrolysis reactor (ex situ) can help to improve the quality of the vapors by reducing the oxygen content and related reactivity [5]. Catalytic upgrading can also help funnel the numerous species from fast pyrolysis into a smaller subset of compounds suitable for production of valuable products, for example, Benzene-Toluene-Xylene (BTX) using zeolite catalysts $[6,7]$. However, even after the catalytic upgrading of vapors, hundreds of chemical species can still be present in the pyrolysis oil. The species and types of molecules and functional groups is a strong function of the type of catalyst used [8]. While zeolite catalysts produce aromatic compounds even from carbohydrates, other catalysts result in different chemistry. An efficient catalytic fast pyrolysis (CFP) should significantly eliminate the most reactive entities such as sugars and acids relative to its non-catalytic counterpart.

There is strong interest in the production of oxygenated compounds from biomass which allows the preservation and utilization of the high proportion of oxygen in biomass [9], instead of complete deoxygenation when the desired final products are only hydrocarbon fuels $[10,11,12]$. For the CFP process, increasing the selectivity towards specific oxygenated compounds via catalytic upgrading and effective separations are two prerequisites for the production of oxygenated chemicals. Separation of individual chemical compounds is challenging because of the often-small content of each of the species in a soup of numerous compounds [12, 13]. Phase behavior and related operations need to be strategically employed for the efficient separation of desired species. The significant quantity of water from CFP results in two or three liquid phases upon condensation, as discussed in the previous publication [14]. In addition to postcondensation liquid-liquid separation, vapor-liquid equilibrium (VLE) is also important for any distillation or fractional condensation for separating chemical species. It should be noted that although oxygen content and reactivity is reduced via catalytic upgrading of pyrolysis vapors, higher molecular weight species and remaining reactive functional groups can keep the pyrolysis-oil prone to repolymerization upon reheating. Thus, in addition to distillation, fractional condensation is another separation method considered in conceptual designs and experimental setups [10]. The available literature on multiphase equilibria for the fast pyrolysis bio-oils was partially considered recently [15]. The main idea of that paper was to extend the group-contribution associating equation of state to lignin derivatives. 
Various versions of the UNIFAC model [16] are widely used for VLE prediction. To calculate the liquid-phase activity coefficients with this model, a solution is presented as a mixture of functional groups. The group characteristics and binary interaction parameters are determined from the experimental data. This model is fast, performs well for multiple mixtures, but is limited to the systems for which the empirical parameters are available. A dielectric continuum model COSMO [17] or similar models [18] are used in quantum-chemical calculations to determine polarization charge density on the molecular surface. These results are coupled with statistical thermodynamic equations in the thermodynamic models like COSMO-RS [19] or COSMO-SAC [20]. The models of this type have a relatively small number of empirical parameters and wider applicability domain. Also, they are less sensitive to the training set quality than fully empirical models. The UNIFAC and COSMO-type thermodynamic models are based on different physical principles and are essentially uncorrelated. Therefore, it is reasonable to use these models as two independent sources of information for analysis of the available experimental data.

The models considered above are primarily used to predict liquid-phase activity coefficients. If VLE involves a supercritical component and/or high temperatures and pressures, it is reasonable to combine an equation of state with an activity-coefficient model. Examples of this approach include the group-contribution equations of state PSRK [21] and CGA-EOS [22]. The VLE pressures below $0.2 \mathrm{MPa}$ are considered in this paper and none of the components is supercritical. Therefore, the group-contribution equations of state are excessive for this work.

In this report, we explore the literature for VLE information on some of the known species from CFP and similar compounds towards the purpose of using the information for process modeling of the separation of oxygenated compounds, as well as segregation of potential fuel precursors into more optimal cuts. We analyze the effectiveness of two predictive methods, NIST-ModifiedUNIFAC and NIST-COSMO-SAC, in predicting VLE behavior using the available experimental data for binary mixtures and specify the mixtures for which additional experimental data are needed.

\section{Calculation}

\subsection{Compound selection}

The compounds relevant to CFP and other industrial processes as well as their isomers and homologs were considered. They were divided into principal and secondary components. The principal ones included furan derivatives and phenolic compounds because of the greater availability of experimental data for those groups. All possible binary mixtures were generated assuming that at least one principal component was present in a mixture, and the literature search was performed. The compounds listed in Table 1 have at least one binary VLE data point available in the literature. A list of the binary mixtures is presented in Table 2. 
Table 1. Principal and secondary components considered in this work.

\begin{tabular}{|c|c|c|c|c|c|}
\hline Chemical Name & CASRN & Formula & Chemical Name & CASRN & Formula \\
\hline \multicolumn{3}{|c|}{ Principal components } & \multicolumn{3}{|c|}{ Secondary components } \\
\hline \multicolumn{3}{|c|}{ Furan derivatives } & water & $7732-18-5$ & $\mathrm{H}_{2} \mathrm{O}$ \\
\hline furan & $110-00-9$ & $\mathrm{C}_{4} \mathrm{H}_{4} \mathrm{O}$ & methanol & $67-56-1$ & $\mathrm{CH}_{4} \mathrm{O}$ \\
\hline 2-furaldehyde & $98-01-1$ & $\mathrm{C}_{5} \mathrm{H}_{4} \mathrm{O}_{2}$ & acetic acid & $64-19-7$ & $\mathrm{C}_{2} \mathrm{H}_{4} \mathrm{O}_{2}$ \\
\hline 2-methylfuran & $534-22-5$ & $\mathrm{C}_{5} \mathrm{H}_{6} \mathrm{O}$ & ethanol & $64-17-5$ & $\mathrm{C}_{2} \mathrm{H}_{6} \mathrm{O}$ \\
\hline furfuryl alcohol & $98-00-0$ & $\mathrm{C}_{5} \mathrm{H}_{6} \mathrm{O}_{2}$ & 1,2-ethanediol & $107-21-1$ & $\mathrm{C}_{2} \mathrm{H}_{6} \mathrm{O}_{2}$ \\
\hline$\gamma$-valerolactone & $108-29-2$ & $\mathrm{C}_{5} \mathrm{H}_{8} \mathrm{O}_{2}$ & acetone & $67-64-1$ & $\mathrm{C}_{3} \mathrm{H}_{6} \mathrm{O}$ \\
\hline 2-acetylfuran & $1192-62-7$ & $\mathrm{C}_{6} \mathrm{H}_{6} \mathrm{O}_{2}$ & 1-propanol & $71-23-8$ & $\mathrm{C}_{3} \mathrm{H}_{8} \mathrm{O}$ \\
\hline 2,5-dimethylfuran & $625-86-5$ & $\mathrm{C}_{6} \mathrm{H}_{8} \mathrm{O}$ & 2-propanol & $67-63-0$ & $\mathrm{C}_{3} \mathrm{H}_{8} \mathrm{O}$ \\
\hline \multicolumn{3}{|c|}{ Phenolic compounds } & butanone & $78-93-3$ & $\mathrm{C}_{4} \mathrm{H}_{8} \mathrm{O}$ \\
\hline phenol & $108-95-2$ & $\mathrm{C}_{6} \mathrm{H}_{6} \mathrm{O}$ & 1-butanol & $71-36-3$ & $\mathrm{C}_{4} \mathrm{H}_{10} \mathrm{O}$ \\
\hline 1,2-benzenediol & $120-80-9$ & $\mathrm{C}_{6} \mathrm{H}_{6} \mathrm{O}_{2}$ & 2-butanol & $78-92-2$ & $\mathrm{C}_{4} \mathrm{H}_{10} \mathrm{O}$ \\
\hline 1,3-benzenediol & $108-46-3$ & $\mathrm{C}_{6} \mathrm{H}_{6} \mathrm{O}_{2}$ & 2-methyl-1-propanol & $78-83-1$ & $\mathrm{C}_{4} \mathrm{H}_{10} \mathrm{O}$ \\
\hline 1,4-benzenediol & $123-31-9$ & $\mathrm{C}_{6} \mathrm{H}_{6} \mathrm{O}_{2}$ & benzene & $71-43-2$ & $\mathrm{C}_{6} \mathrm{H}_{6}$ \\
\hline 2-methylphenol & $95-48-7$ & $\mathrm{C}_{7} \mathrm{H}_{8} \mathrm{O}$ & 4-methylpentan-2-one & $108-10-1$ & $\mathrm{C}_{6} \mathrm{H}_{12} \mathrm{O}$ \\
\hline 3-methylphenol & $108-39-4$ & $\mathrm{C}_{7} \mathrm{H}_{8} \mathrm{O}$ & toluene & $108-88-3$ & $\mathrm{C}_{7} \mathrm{H}_{8}$ \\
\hline 4-methylphenol & $106-44-5$ & $\mathrm{C}_{7} \mathrm{H}_{8} \mathrm{O}$ & methoxybenzene & $100-66-3$ & $\mathrm{C}_{7} \mathrm{H}_{8} \mathrm{O}$ \\
\hline 2-methoxyphenol & $90-05-1$ & $\mathrm{C}_{7} \mathrm{H}_{8} \mathrm{O}_{2}$ & 1,2-dimethylbenzene & $95-47-6$ & $\mathrm{C}_{8} \mathrm{H}_{10}$ \\
\hline 4-methoxyphenol & $150-76-5$ & $\mathrm{C}_{7} \mathrm{H}_{8} \mathrm{O}_{2}$ & 1,3-dimethylbenzene & $108-38-3$ & $\mathrm{C}_{8} \mathrm{H}_{10}$ \\
\hline 2,4-dimethylphenol & $105-67-9$ & $\mathrm{C}_{8} \mathrm{H}_{10} \mathrm{O}$ & 1,4-dimethylbenzene & $106-42-3$ & $\mathrm{C}_{8} \mathrm{H}_{10}$ \\
\hline 2,5-dimethylphenol & $95-87-4$ & $\mathrm{C}_{8} \mathrm{H}_{10} \mathrm{O}$ & ethylbenzene & $100-41-4$ & $\mathrm{C}_{8} \mathrm{H}_{10}$ \\
\hline 2,6-dimethylphenol & $576-26-1$ & $\mathrm{C}_{8} \mathrm{H}_{10} \mathrm{O}$ & acetophenone & $98-86-2$ & $\mathrm{C}_{8} \mathrm{H}_{8} \mathrm{O}$ \\
\hline 3,4-dimethylphenol & $95-65-8$ & $\mathrm{C}_{8} \mathrm{H}_{10} \mathrm{O}$ & 2-octanone & $111-13-7$ & $\mathrm{C}_{8} \mathrm{H}_{16} \mathrm{O}$ \\
\hline
\end{tabular}




\begin{tabular}{cccccc}
\hline Chemical Name & CASRN & Formula & Chemical Name & CASRN & Formula \\
\hline 3,5-dimethylphenol & $108-68-9$ & $\mathrm{C}_{8} \mathrm{H}_{10} \mathrm{O}$ & 1-octanol & $111-87-5$ & $\mathrm{C}_{8} \mathrm{H}_{18} \mathrm{O}$ \\
2,4,6-trimethylphenol & $527-60-6$ & $\mathrm{C}_{9} \mathrm{H}_{12} \mathrm{O}$ & isopropylbenzene & $98-82-8$ & $\mathrm{C}_{9} \mathrm{H}_{12}$ \\
& & & 2-methylnaphthalene & $91-57-6$ & $\mathrm{C}_{11} \mathrm{H}_{10}$ \\
\hline
\end{tabular}


Table 2. Binary mixtures with VLE data evaluated in this work.

\begin{tabular}{|c|c|c|c|c|c|c|}
\hline Mixture & GPM $^{\mathbf{a}}$ & Reference & Status $^{b}$ & $\underset{\mathbf{K}}{T \text { range / }}$ & $\begin{array}{c}P \text { range / } \\
\mathbf{k P a}\end{array}$ & $\begin{array}{c}\text { Data } \\
\text { type }\end{array}$ \\
\hline \multicolumn{7}{|c|}{ Furan derivative + aromatic hydrocarbon } \\
\hline \multirow[t]{2}{*}{ furan + toluene } & IG & Nala et al. [30] & & 305 to 382 & $101^{\mathrm{d}}$ & PTxy \\
\hline & & Thévaneau et al. [31] & & 313 to 353 & 13 to $173^{c}$ & PTxy \\
\hline \multirow{4}{*}{ 2-furaldehyde + benzene } & IG & Thornton and Garner [33] & & 356 to 428 & 101 & PTxy \\
\hline & & Kenny [34] & & 298 & 0.21 to 13 & $P T x$ \\
\hline & & Stephenson and Van Winkle [35] & & 373 to 386 & 53 & PTxy \\
\hline & & Garner and Ellis [36] & $\mathrm{N}$ & 357,365 & $101^{\mathrm{d}}$ & $P T x$ \\
\hline \multirow[t]{4}{*}{ 2-furaldehyde + toluene } & $\mathrm{IG}$ & Garner and Ellis [36] & & 390 to 402 & 101 & $P T x$ \\
\hline & & Thornton and Garner [37] & $\mathrm{N}$ & 384 to 426 & 101 & PTxy \\
\hline & & Garner and Hall [38] & & 386 to 419 & 101 & PTxy \\
\hline & & Rivenq [39] & & 343 to 435 & 27 to 101 & PTxy \\
\hline 2-furaldehyde +1 ,4-dimethylbenzene & $\mathrm{IG}$ & Puri and Raju [40] & & 407 to 429 & 96 & PTxy \\
\hline 2-furaldehyde + ethylbenzene & IG & Puri and Raju [40] & & 405 to 428 & 96 & PTxy \\
\hline \multirow[t]{2}{*}{ 2-methylfuran + benzene } & IG & Krevor and Prausnitz [32] & & 324,339 & 37 to 109 & PTxy \\
\hline & & Two furan derivatives & & & & \\
\hline \multirow[t]{3}{*}{ furan +2 -furaldehyde } & $\mathrm{IG}$ & Tai et al. [41] & A & 353 to 408 & 45 to $195^{\mathrm{c}}$ & PTxy \\
\hline & & Auger et al. [42] & A & 305 to 434 & $101^{\mathrm{d}}$ & $P T x$ \\
\hline & & Chen et al. [43] & A & 304 to 435 & 101 & PTxy \\
\hline 2-methylfuran +2 -furaldehyde & $\mathrm{IG}$ & Holdren and Hixon [44] & & 293 to 403 & 0.4 to 98 & $\begin{array}{c}\text { PTxy, } \\
\text { PTx }\end{array}$ \\
\hline
\end{tabular}




\begin{tabular}{|c|c|c|c|c|c|c|}
\hline Mixture & GPM $^{\mathbf{a}}$ & Reference & Status $^{b}$ & $T \underset{\mathbf{K}}{T \text { range / }}$ & $\begin{array}{c}P \text { range / } \\
\mathbf{k P a}\end{array}$ & $\begin{array}{l}\text { Data } \\
\text { type }\end{array}$ \\
\hline \multirow[t]{2}{*}{ 2-furaldehyde + furfuryl alcohol } & $\mathrm{V}$ & Myles and Wingard [46] & & 342 to 358 & 3.3 & PTxy \\
\hline & & Tsirlin and Vasil'eva [47] & $\mathrm{N}$ & 348 to 370 & 6.7 & PTxy \\
\hline 2-furaldehyde $+\gamma$-valerolactone & IG & Pokki et al. [48] & & 395 to 434 & 30 & PTxy \\
\hline 2-furaldehyde +2 -acetylfuran & IG & Zheng et al. [49] & & 342 to 361 & $3.6,5.2$ & PTxy \\
\hline \multirow[t]{2}{*}{ 2-furaldehyde +5 -methylfurfural } & $\mathrm{IG}$ & Fele and Grilic [50] & & 343 to 371 & $3.5,5.0$ & PTxy \\
\hline & & Zheng et al. [49] & & 342 to 373 & $3.6,5.2$ & PTxy \\
\hline 2-methylfuran + furfuryl alcohol & $\mathrm{V}$ & Tai et al. [41] & & 353 to 408 & 19 to $198^{c}$ & PTxy \\
\hline 2-acetylfuran +5 -methylfurfural & IG & Zheng et al. [49] & & 353 to 373 & $3.6,5.2$ & PTxy \\
\hline 2,5-dimethylfuran + furfuryl alcohol & $\mathrm{V}$ & Negadi et al. [45] & & & 0.24 to 213 & $P T x$ \\
\hline \multicolumn{7}{|c|}{ Furan derivative + acid or ketone } \\
\hline 2-furaldehyde + acetic acid & $\mathrm{HOC}$ & Fele and Grilic [50] & & 368 to 430 & 49,89 & PTxy \\
\hline 2-furaldehyde + acetone & $\mathrm{IG}$ & Myles and Wingard [46] & & 329 to 435 & 101 & PTxy \\
\hline \multirow{3}{*}{ 2-furaldehyde +4 -methylpentan-2-one } & \multirow{3}{*}{ IG } & Ma et al. [51] & A & 330 to 435 & 101 & PTxy \\
\hline & & Hauschild et al. [52] & & 368,383 & 11 to 85 & PTxy \\
\hline & & Zaitseva et al. [53] & & 333 to 369 & 4.2 to 32 & $\begin{array}{c}P T x y, \\
T x y\end{array}$ \\
\hline 2-methylfuran + butanone & IG & Smith and Labonte [54] & & 338 to 351 & 101 & $\begin{array}{l}\text { PTxy, } \\
P x y\end{array}$ \\
\hline furfuryl alcohol + acetone & $\mathrm{V}$ & Dudutkina and Lutugina [55] & & 329 to 370 & 101 & $P T x$ \\
\hline furfuryl alcohol + butanone & $\mathrm{V}$ & Dudutkina and Lutugina [55] & & 353 to 388 & 101 & $P T x$ \\
\hline 2,5-dimethylfuran +4 -methylpentan-2-one & IG & Negadi et al. [45] & & 313 to 393 & 6 to 213 & $P T x$ \\
\hline
\end{tabular}




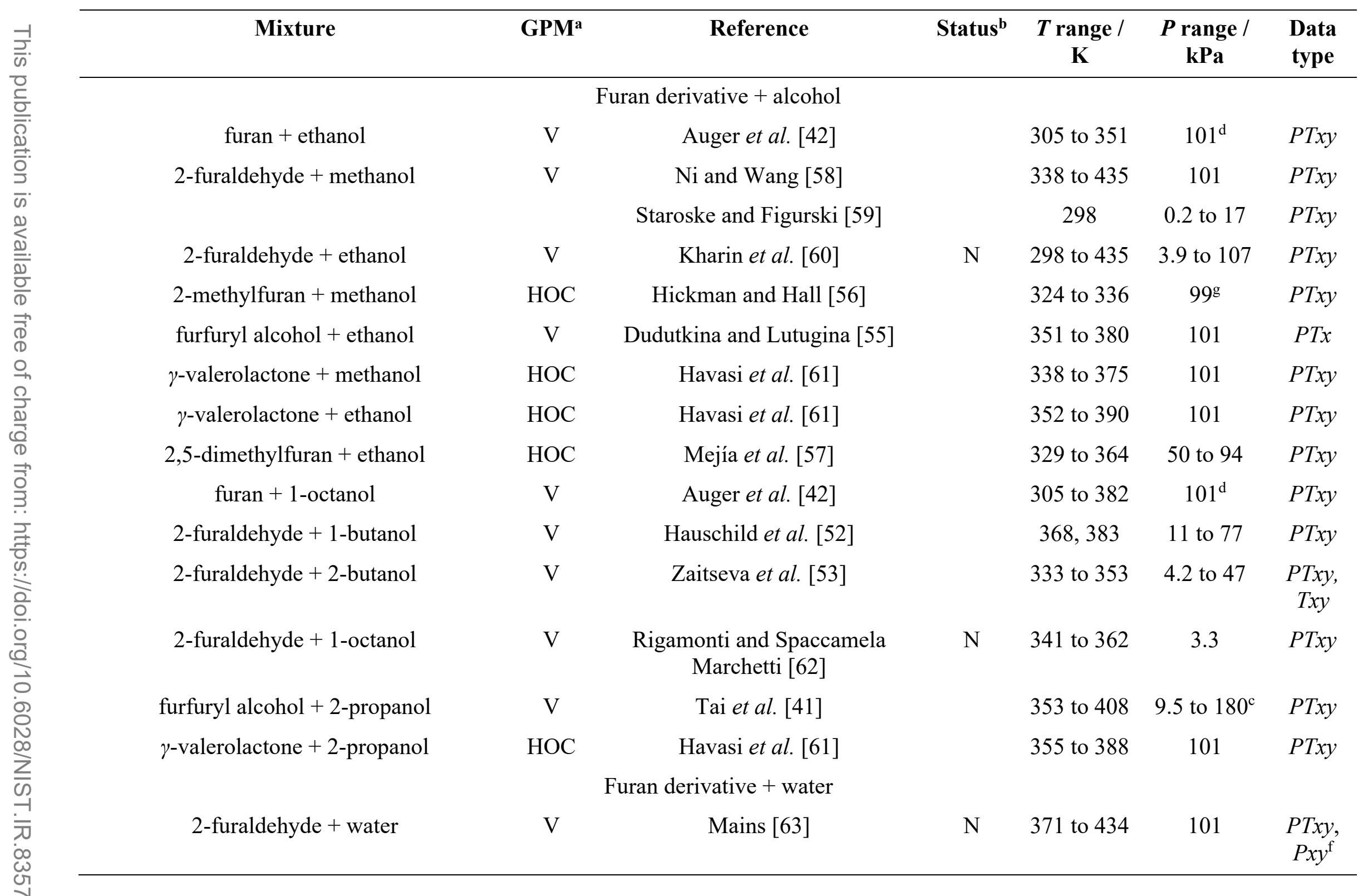




\begin{tabular}{|c|c|c|c|c|c|c|}
\hline Mixture & GPM $^{\mathbf{a}}$ & Reference & Status $^{b}$ & $\begin{array}{c}T \text { range / } \\
\mathbf{K}\end{array}$ & $\begin{array}{c}P \text { range / } \\
\mathbf{k P a}\end{array}$ & $\begin{array}{l}\text { Data } \\
\text { type }\end{array}$ \\
\hline & & Pearce and Gerster [64] & A & 311 to 366 & 2.0 to 85 & $P T x$ \\
\hline & & Tsirlin [65] & A & 313 to 426 & 7.3 to 101 & PTxy \\
\hline & & Kharin et al. [60] & $\mathrm{N}$ & 323 to 408 & 3.7 to 101 & PTxy \\
\hline & & $\mathrm{Ni}$ and Wang [58] & A & 371 to 435 & 101 & PTxy \\
\hline & & Staroske and Schuberth [66] & A & 298 & 0.21 to 3.3 & PTxy \\
\hline & & Sunder and Prasad [67] & $\mathrm{N}$ & 369 to 432 & 95 & $P T x$ \\
\hline \multirow[t]{2}{*}{ furfuryl alcohol + water } & V & Boldyrev et al. [68] & A & 313 to 366 & 7.3 & PTxy \\
\hline & & Dudutkina et al. [69] & $\mathrm{N}$ & 304 to 352 & 4.0 & $\begin{array}{l}P T x, \\
P x y^{\mathrm{e}}\end{array}$ \\
\hline \multirow[t]{3}{*}{$\gamma$-valerolactone + water } & $\mathrm{HOC}$ & Havasi et al. [70] & & 320 to 480 & 10 to 101 & PTxy \\
\hline & & Zaitseva et al. [71] & & 350 & 1.2 to 42 & PTxy \\
\hline & & Two phenolic compounds & & & & \\
\hline \multirow[t]{5}{*}{ phenol + 2-methylphenol } & V & Fox and Barker [72] & & 455 to 464 & 101 & $P T x$ \\
\hline & & Schneider and Oberkobusch [73] & & 455 to 464 & 101 & PTxy \\
\hline & & Vostrikova et al. [74] & & 359 to 362 & 2.7 & PTxy \\
\hline & & Clausse et al. [75] & & 399 to 405 & 16 & PTxy \\
\hline & & Selvam et al. [76] & & 412 to 462 & 27,96 & $P T x$ \\
\hline \multirow[t]{4}{*}{ phenol + 3-methylphenol } & V & Fox and Barker [72] & & 456 to 476 & 101 & $P T x$ \\
\hline & & Schneider and Oberkobusch [73] & & 455 to 475 & 101 & PTxy \\
\hline & & Vostrikova et al. [77] & & 394 to 411 & 13 & PTxy \\
\hline & & Cepeda et al. [78] & & 395 to 409 & 13 & PTxy \\
\hline
\end{tabular}




\begin{tabular}{|c|c|c|c|c|c|c|}
\hline Mixture & GPM $^{\mathbf{a}}$ & Reference & Status $^{b}$ & $T$ range / & $\begin{array}{l}P \text { range / } \\
\mathbf{k P a}\end{array}$ & $\begin{array}{l}\text { Data } \\
\text { type }\end{array}$ \\
\hline \multirow[t]{2}{*}{ phenol + 4-methylphenol } & \multirow[t]{2}{*}{$\mathrm{V}$} & Fox and Barker [72] & \multirow{7}{*}{$\mathrm{N}$} & 455 to 475 & 101 & $P T x$ \\
\hline & & Selvam et al. [76] & & 412 to 473 & 27,96 & $P T x$ \\
\hline 1,2-benzenediol + 4-methylphenol & $\mathrm{V}$ & Hwang et al. [79] & & 423 to 453 & 4.3 to 56 & $P T x$ \\
\hline 1,2-benzenediol $+1,4$-benzenediol & $\mathrm{V}$ & Shi et al. [80] & & 469 to 497 & 20 & PTxy \\
\hline 1,2-benzenediol + 4-methoxyphenol & $\mathrm{V}$ & Hwang et al. [79] & & 438,453 & 7.4 to 16 & PTxy \\
\hline \multirow[t]{2}{*}{ 2-methylphenol + 3-methylphenol } & \multirow[t]{2}{*}{$\mathrm{V}$} & Fox and Barker [72] & & 464 to 476 & 101 & $P T x$ \\
\hline & & Wang et al. [81] & & 411 to 422 & 20 & PTxy \\
\hline \multirow[t]{2}{*}{ 2-methylphenol + 4-methylphenol } & \multirow[t]{2}{*}{$\mathrm{V}$} & Vostrikova et al. [82] & & 401 to 409 & 13 & PTxy \\
\hline & & Selvam et al. [76] & & 420 to 473 & 27,96 & $P T x$ \\
\hline \multirow[t]{2}{*}{ 2-methylphenol + 2,6-dimethylphenol } & \multirow[t]{2}{*}{$\mathrm{V}$} & Ye et al. [83] & & 392 to 425 & 10,25 & PTxy \\
\hline & & Wang et al. [81] & & 411 to 418 & 20 & PTxy \\
\hline 2-methylphenol + 2,4,6-trimethylphenol & $\mathrm{V}$ & Ye et al. [83] & & 392 to 444 & 10,25 & PTxy \\
\hline 3-methylphenol + 2,6-dimethylphenol & $\mathrm{V}$ & Wang et al. [81] & & 418 to 422 & 20 & PTxy \\
\hline 4-methylphenol + 2,4-dimethylphenol & $\mathrm{V}$ & Selvam et al. [76] & & 430 to 482 & 27,96 & $P T x$ \\
\hline 4-methylphenol + 4-methoxyphenol & $\mathrm{V}$ & Hwang et al. [79] & & 423 to 453 & 4.3 to 56 & PTxy \\
\hline 2,5-dimethylphenol + 3,5-dimethylphenol & $\mathrm{V}$ & Schneider and Oberkobusch [73] & & 486 to 494 & 101 & PTxy \\
\hline 3,4-dimethylphenol + 3,5-dimethylphenol & $\mathrm{V}$ & Schneider and Oberkobusch [73] & & 398 to 444 & 10,25 & $P T x y$ \\
\hline $\begin{array}{l}\text { 2,6-dimethylphenol }+2,4,6- \\
\text { trimethylphenol }\end{array}$ & $\mathrm{V}$ & Ye et al. [83] & & 495 to 500 & 101 & PTxy \\
\hline \multicolumn{7}{|c|}{ Phenolic compound + alkylbenzene } \\
\hline phenol + benzene & $\mathrm{V}$ & Weissenberger et al. [84] & $\mathrm{A}$ & 288 & 5.7 to 7.3 & $P T x$ \\
\hline
\end{tabular}




\begin{tabular}{|c|c|c|c|c|c|c|}
\hline Mixture & GPM $^{\mathbf{a}}$ & Reference & Status $^{b}$ & $\begin{array}{c}T \text { range / } \\
\mathbf{K}\end{array}$ & $\begin{array}{c}P \text { range } / \\
\mathrm{kPa}\end{array}$ & $\begin{array}{l}\text { Data } \\
\text { type }\end{array}$ \\
\hline \multirow{9}{*}{ phenol + toluene } & \multirow{9}{*}{$\mathrm{V}$} & Martin and George [85] & & 343 & 1.1 to 71 & $P T x y$ \\
\hline & & Garner and Ellis [36] & & 366 & 101 & $P T x$ \\
\hline & & Gmehling [86] & & 353 & 2.1 to 101 & $P T x y$ \\
\hline & & Nienhaus et al. [87] & & 414 & 30 to $192^{c}$ & $P T x$ \\
\hline & & Weissenberger et al. [84] & A & 288 & 1.6 to 2.1 & $P T x$ \\
\hline & & Drickamer et al. [88] & & 384 to 446 & 101 & $P T x$ \\
\hline & & Garner and Ellis [36] & & 394 to 409 & 101 & $P T x$ \\
\hline & & Nienhaus et al. [87] & & 414 & 29 to $196^{\mathrm{c}}$ & $P T x$ \\
\hline & & Klauck et al. [89] & & 333,363 & 6.9 to 51 & PTxy \\
\hline phenol + ethylbenzene & $\mathrm{V}$ & Anderko [90] & & 393,403 & 13 to 85 & $P T x$ \\
\hline \multirow[t]{3}{*}{ phenol + isopropylbenzene } & $\mathrm{V}$ & Byk and Stroiteleva [91] & & 424 to 451 & 101 & $P T x y$ \\
\hline & & Anderko [90] & & 393,403 & 13 to 55 & $P T x$ \\
\hline & & Cepeda et al. [92] & & 361 to 455 & 13 to 101 & $P T x y$ \\
\hline 2-methylphenol + benzene & $\mathrm{V}$ & Weissenberger and Piatti [93] & A & 291 & 1.6 to 8.6 & $P T x$ \\
\hline \multirow[t]{2}{*}{ 2-methylphenol + toluene } & $\mathrm{V}$ & Weissenberger et al. [94] & & 288 & 1.2 to 2.0 & $P T x$ \\
\hline & & Klauck et al. [89] & & 333,363 & 4.2 to 48 & PTxy \\
\hline 2-methylphenol + 1,2-dimethylbenzene & $\mathrm{V}$ & Prasad et al. [95] & $\mathrm{N}$ & 416 to 462 & 96 & $P T x$ \\
\hline 2-methylphenol + 1,3-dimethylbenzene & $\mathrm{V}$ & Prasad et al. [95] & $\mathrm{N}$ & 410 to 462 & 96 & $P T x$ \\
\hline 2-methylphenol + 1,4-dimethylbenzene & $\mathrm{V}$ & Prasad et al. [95] & $\mathrm{N}$ & 409 to 462 & 96 & $P T x$ \\
\hline 2-methylphenol + ethylbenzene & $\mathrm{V}$ & Prasad et al. [96] & $\mathrm{N}$ & 407 to 462 & 95 & $P T x$ \\
\hline
\end{tabular}




\begin{tabular}{|c|c|c|c|c|c|c|}
\hline Mixture & GPM $^{\mathbf{a}}$ & Reference & Status $^{b}$ & $T \underset{\mathbf{K}}{T \text { range / }}$ & $\begin{array}{c}P \text { range / } \\
\mathbf{k P a}\end{array}$ & $\begin{array}{l}\text { Data } \\
\text { type }\end{array}$ \\
\hline \multirow[t]{2}{*}{ 3-methylphenol + benzene } & $\mathrm{V}$ & Weissenberger and Piatti [93] & $\mathrm{A}$ & 291 & 1.9 to 11 & $P T x$ \\
\hline & & Savitt and Othmer [97] & $\mathrm{N}$ & 353 to 476 & 101 & PTxy \\
\hline \multirow[t]{3}{*}{ 3-methylphenol + toluene } & $\mathrm{V}$ & Weissenberger et al. [94] & & 288 & 1.0 to 2.0 & $P T x$ \\
\hline & & Sartakova et al. [98] & & 391 to 455 & 101 & $P T x$ \\
\hline & & Klauck et al. [89] & & 333,363 & 4.8 to 53 & PTxy \\
\hline 3-methylphenol + 1,2-dimethylbenzene & $\mathrm{V}$ & Prasad et al. [99] & $\mathrm{N}$ & 415 to 474 & 96 & $P T x$ \\
\hline 3-methylphenol + 1,3-dimethylbenzene & $\mathrm{V}$ & Prasad et al. [99] & $\mathrm{N}$ & 429 to 474 & 96 & $P T x$ \\
\hline 3-methylphenol + 1,4-dimethylbenzene & $\mathrm{V}$ & Prasad et al. [99] & $\mathrm{N}$ & 409 to 474 & 96 & $P T x$ \\
\hline 3-methylphenol + isopropylbenzene & $\mathrm{V}$ & Cepeda et al. [78] & & 362 to 398 & 13 & PTxy \\
\hline \multirow[t]{2}{*}{ 3-methylphenol + 2-methylnaphthalene } & $\mathrm{V}$ & Othmer et al. [100] & A & 476 to 514 & 101 & PTxy \\
\hline & & Schmelzer et al. [101] & & 393 to 453 & 2.6 to 55 & $P T x y$ \\
\hline 4-methylphenol + benzene & $\mathrm{V}$ & Weissenberger and Piatti [93] & A & 291 & 2.0 to 9.1 & $P T x$ \\
\hline \multirow[t]{3}{*}{ 4-methylphenol + toluene } & $\mathrm{V}$ & Weissenberger et al. [94] & & 288 & 1.1 to 2.0 & $P T x$ \\
\hline & & Marks and Wingard [102] & & 384 to 475 & 101 & PTxy \\
\hline & & Klauck et al. [89] & & 333,363 & 8.7 to 50 & PTxy \\
\hline 4-methylphenol + 1,2-dimethylbenzene & $\mathrm{V}$ & Prasad et al. [103] & $\mathrm{N}$ & 415 to 473 & 95 & $P T x$ \\
\hline 4-methylphenol + 1,3-dimethylbenzene & $\mathrm{V}$ & Prasad et al. [103] & $\mathrm{N}$ & 410 to 473 & 95 & $P T x$ \\
\hline 4-methylphenol + 1,4-dimethylbenzene & $\mathrm{V}$ & Prasad et al. [103] & $\mathrm{N}$ & 409 to 473 & 95 & $P T x$ \\
\hline 4-methylphenol + ethylbenzene & $\mathrm{V}$ & Prasad et al. [96] & $\mathrm{N}$ & 407 to 473 & 95 & $P T x$ \\
\hline 4-methylphenol + 2-methylnaphthalene & $\mathrm{V}$ & Othmer et al. [100] & A & 475 to 514 & 101 & PTxy \\
\hline
\end{tabular}




\begin{tabular}{|c|c|c|c|c|c|c|}
\hline Mixture & GPM $^{\mathbf{a}}$ & Reference & Status $^{b}$ & $\begin{array}{c}T \text { range / } \\
\mathbf{K}\end{array}$ & $\begin{array}{c}P \text { range } / \\
\mathbf{k P a}\end{array}$ & $\begin{array}{l}\text { Data } \\
\text { type }\end{array}$ \\
\hline 2-methoxyphenol + benzene & $\mathrm{V}$ & Weissenberger et al. [104] & & 290 & 3.8 to 7.2 & $P T x$ \\
\hline \multicolumn{7}{|c|}{ Phenolic compound + methoxybenzene } \\
\hline phenol + methoxybenzene & V & Lebedeva et al. [105] & $\mathrm{N}$ & 370 to 398 & 13 & PTxy \\
\hline 2-methylphenol + methoxybenzene & $\mathrm{V}$ & Lebedeva et al. [105] & $\mathrm{N}$ & 370 to 397 & 13 & PTxy \\
\hline 2-methoxyphenol + methoxybenzene & $\mathrm{V}$ & Li et al. [106] & & 429 to 469 & 101 & PTxy \\
\hline \multicolumn{7}{|c|}{ Phenolic compound + water } \\
\hline \multirow[t]{13}{*}{ phenol + water } & V & Schreinemakers [107] & & 32 to 363 & 14 to 71 & PTxy \\
\hline & & Schükarew [108] & & 342 & 23 to 30 & $P T x$ \\
\hline & & Rhodes et al. [109] & & 313 & & Txy \\
\hline & & Ferguson [110] & & 348 & 39 & $P T x$ \\
\hline & & Campbell and Campbell [111] & $\mathrm{N}$ & 275 to 308 & 0.47 to 1.4 & $\begin{array}{c}P T x y, \\
P T x, \\
T x y\end{array}$ \\
\hline & & Brusset and Gaynès [112] & $\mathrm{N}$ & 373 to 455 & 101 & PTxy \\
\hline & & Markuzin [113] & & 288 & 0.02 to 1.7 & PTxy \\
\hline & & Weller et al. [114] & & 318 & 0.23 to 9.4 & PTxy \\
\hline & & Kliment et al. [115] & & 340 to 400 & 27 & PTxy \\
\hline & & Kiva et al. [116] & $\mathrm{N}$ & 328 to 397 & 15 & $P T x$ \\
\hline & & Kolyuchkina et al. [117] & & 361 to 440 & 67 & $P T x$ \\
\hline & & Hakuta $[118]^{\mathrm{e}}$ & & 354 to 394 & 48 to 203 & PTxy \\
\hline & & Karavaeva et al. [119] & & 332 to 381 & 20 & PTxy \\
\hline
\end{tabular}




\begin{tabular}{|c|c|c|c|c|c|c|}
\hline Mixture & GPM $^{\mathbf{a}}$ & Reference & Status $^{b}$ & $T$ range / & $\begin{array}{l}P \text { range / } \\
\mathbf{k P a}\end{array}$ & $\begin{array}{l}\text { Data } \\
\text { type }\end{array}$ \\
\hline & & Lyzlova and Susarev [120] & & 298 & 1.6 & PTxy \\
\hline & & Chou et al. [121] & & 373 to 455 & 101 & PTxy \\
\hline & & Tabai et al. [122] & & 313 to 363 & 7.4 to 71 & $P T x$ \\
\hline & & Shi et al. [80] & $\mathrm{N}$ & 334 to 396 & 20 & PTxy \\
\hline & & Klauck et al. [89] & & 333 to 363 & 11 to 69 & $P T x$ \\
\hline 1,3-benzenediol + water & $\mathrm{V}$ & $\begin{array}{l}\text { Shakhparonov and Martynova } \\
\text { [123] }\end{array}$ & & 273 to 298 & 0.57 to 3.2 & $P T x$ \\
\hline 2-methylphenol + water & $\mathrm{V}$ & Brusset and Gaynès [112] & $\mathrm{N}$ & 372 to 464 & 101 & PTxy \\
\hline 3-methylphenol + water & $\mathrm{V}$ & Klauck et al. [89] & & 333 to 363 & 11 to 70 & PTxy \\
\hline \multicolumn{7}{|c|}{ Phenolic compound + ketone } \\
\hline phenol + acetone & $\mathrm{V}$ & Weissenberger et al. [84] & $\mathrm{A}$ & 288 & 1.1 to 11 & $P T x$ \\
\hline & & Weissenberger et al. [124] & $\mathrm{N}$ & 293 & 0.81 to 14 & $P T x$ \\
\hline & & Chalov et al. [125] & A & 329 to 454 & 101 & PTxy \\
\hline & & Gölles [126] & A & 323 to 348 & 0.40 to 97 & $P T x$ \\
\hline & & Motina et al. [127] & $\mathrm{N}$ & 330 to 425 & $101^{\mathrm{d}}$ & PTxy \\
\hline & & Vasil'eva et al. [128] & $\mathrm{A}$ & 323 to 420 & 9.5 to 101 & PTxy \\
\hline \multirow[t]{2}{*}{ phenol + butanone } & $\mathrm{V}$ & Byk and Shcherbak [129] & $\mathrm{N}$ & 325 to 450 & 27 to 101 & PTxy \\
\hline & & Oscarson et al. [130] & & 393 to 453 & 19 to $182^{\mathrm{c}}$ & PTxy \\
\hline \multirow[t]{3}{*}{ phenol + acetophenone } & $\mathrm{V}$ & Fried and Pick [131] & & 394 to 442 & 13,40 & PTxy \\
\hline & & Aarna and Kaps [132] & & 455 to 476 & 101 & PTxy \\
\hline & & Giles and Wilson [133] & & 373,433 & 3.1 to 53 & $P T x$ \\
\hline
\end{tabular}




\begin{tabular}{|c|c|c|c|c|c|c|}
\hline Mixture & GPM $^{\mathbf{a}}$ & Reference & Status $^{b}$ & $T$ range / & $\begin{array}{l}P \text { range / } \\
\mathbf{k P a}\end{array}$ & $\begin{array}{l}\text { Data } \\
\text { type }\end{array}$ \\
\hline \multirow[t]{4}{*}{ 2-methylphenol + acetone } & $\mathrm{V}$ & $\begin{array}{l}\text { Weissenberger and Schuster } \\
{[134]}\end{array}$ & & 291 & 0.32 to 16 & $P T x$ \\
\hline & & Weissenberger and Piatti [135] & & 291 & 0.20 to 15 & $P T x$ \\
\hline & & Piatti [136] & & 329 to 464 & 101 & $P T x$ \\
\hline & & Chalov et al. [125] & A & 329 to 455 & 101 & PTxy \\
\hline 2-methylphenol +2 -octanone & $\mathrm{V}$ & Aarna and Kaps [132] & & 446 to 465 & 101 & PTxy \\
\hline 2-methylphenol + acetophenone & $\mathrm{V}$ & Aarna and Kaps [132] & & 464 to 478 & 101 & PTxy \\
\hline \multirow[t]{3}{*}{ 3-methylphenol + acetone } & $\mathrm{V}$ & $\begin{array}{l}\text { Weissenberger and Schuster } \\
{[134]}\end{array}$ & & 291 & 0.39 to 15 & $P T x$ \\
\hline & & Weissenberger and Piatti [135] & & 291 & 0.35 to 16 & $P T x$ \\
\hline & & Piatti [136] & & 329 to 475 & 101 & $P T x$ \\
\hline \multirow[t]{3}{*}{ 4-methylphenol + acetone } & $\mathrm{V}$ & $\begin{array}{l}\text { Weissenberger and Schuster } \\
{[134]}\end{array}$ & & 291 & 0.24 to 16 & $P T x$ \\
\hline & & Weissenberger and Piatti [135] & & 291 & 0.33 to 17 & $P T x$ \\
\hline & & Piatti [136] & & 329 to 475 & 101 & $P T x$ \\
\hline \multirow[t]{2}{*}{ 1,3-benzenediol + acetone } & $\mathrm{V}$ & Weissenberger et al. [104] & & 293 & 2.6 to 16 & \\
\hline & & $\begin{array}{c}\text { Shakhparonov and Martynova } \\
\qquad[123]\end{array}$ & & 273,278 & 5.5 to 11 & \\
\hline \multirow[t]{2}{*}{ 2-methoxyphenol + acetone } & $\mathrm{V}$ & Weissenberger et al. [104] & & 290 & 1.9 to 13 & $P T x$ \\
\hline & & Chalov et al. [125] & & 329 to 468 & 101 & PTxy \\
\hline \multicolumn{7}{|c|}{ Phenolic compound + alcohol } \\
\hline phenol + methanol & $\mathrm{V}$ & Weissenberger et al. [84] & & 288 & 1.1 to 6.5 & $P T x$ \\
\hline
\end{tabular}




\begin{tabular}{|c|c|c|c|c|c|c|}
\hline Mixture & GPM $^{\mathbf{a}}$ & Reference & Status $^{\mathrm{b}}$ & $\begin{array}{c}T \text { range / } \\
\mathbf{K}\end{array}$ & $\begin{array}{l}P \text { range / } \\
\mathbf{k P a}\end{array}$ & $\begin{array}{l}\text { Data } \\
\text { type }\end{array}$ \\
\hline \multirow{8}{*}{ phenol + ethanol } & \multirow{8}{*}{$\mathrm{V}$} & Weissenberger et al. [124] & & 293 & 1.5 to 8.5 & $P T x$ \\
\hline & & Chalov et al. [125] & A & 338 to 455 & 101 & PTxy \\
\hline & & Hu et al. [138] & A & 338 to 455 & 101 & PTxy \\
\hline & & Weissenberger et al. [84] & & 288 & 0.81 to 3.2 & $P T x$ \\
\hline & & Weissenberger et al. [124] & & 293 & 0.59 to 4.0 & $P T x$ \\
\hline & & Garner and Ellis [36] & & 374 & 101 & $P T x$ \\
\hline & & Chou et al. [121] & & 352 to 451 & 101 & PTxy \\
\hline & & Cesari et al. [139] & & 303 to 390 & 9 to 99 & $P T x$ \\
\hline phenol + 1-propanol & $\mathrm{V}$ & Ravikumar et al. [140] & & 341 to 439 & 27,95 & $P T x$ \\
\hline \multirow[t]{2}{*}{ phenol + 2-propanol } & $\mathrm{V}$ & Weissenberger et al. [124] & & 293 & 0.24 to 3.5 & $P T x$ \\
\hline & & Veeranna et al. [141] & & 327 to 435 & 28 to 95 & $P T x$ \\
\hline phenol + 1,2-ethanediol & $\mathrm{V}$ & Brusset et al. [142] & & 455 to 468 & 100 & PTxy \\
\hline 2-methylphenol + methanol & $\mathrm{V}$ & $\begin{array}{l}\text { Weissenberger and Schuster } \\
\qquad[134]\end{array}$ & & 288 & 2.0 to 7.6 & $P T x$ \\
\hline \multirow{5}{*}{ 2-methylphenol + ethanol } & \multirow{5}{*}{$\mathrm{V}$} & Chalov et al. [125] & A & 338 to 464 & 101 & PTxy \\
\hline & & Prasad et al. [143] & $\mathrm{N}$ & 336 to 462 & 96 & $P T x$ \\
\hline & & Weissenberger and Piatti [135] & & 291 & 0.37 to 4.1 & $P T x$ \\
\hline & & Prasad et al. [143] & $\mathrm{N}$ & 350 to 462 & 96 & $P T x$ \\
\hline & & Cesari et al. [139] & & 302 to 394 & 9.0 to 100 & $P T x$ \\
\hline 2-methylphenol + 1-propanol & $\mathrm{V}$ & Prasad et al. [143] & $\mathrm{N}$ & 369 to 62 & 96 & $P T x$ \\
\hline 2-methylphenol + 2-propanol & $\mathrm{V}$ & Prasad et al. [143] & $\mathrm{N}$ & 354 to 462 & 96 & $P T x$ \\
\hline
\end{tabular}




\begin{tabular}{|c|c|c|c|c|c|c|}
\hline Mixture & GPM $^{\mathbf{a}}$ & Reference & Status $^{b}$ & $\begin{array}{c}T \text { range / } \\
\mathbf{K}\end{array}$ & $\begin{array}{c}P \text { range / } \\
\mathbf{k P a}\end{array}$ & $\begin{array}{l}\text { Data } \\
\text { type }\end{array}$ \\
\hline 2-methylphenol + 1-butanol & $\mathrm{V}$ & Prasad et al. [143] & $\mathrm{N}$ & 389 to 462 & 96 & $P T x$ \\
\hline 2-methylphenol + 2-butanol & $\mathrm{V}$ & Prasad et al. [143] & $\mathrm{N}$ & 371 to 462 & 96 & $P T x$ \\
\hline 2-methylphenol + 2-methyl-1-propanol & $\mathrm{V}$ & Prasad et al. [143] & $\mathrm{N}$ & 380 to 462 & 96 & $P T x$ \\
\hline 2-methylphenol + 1,2-ethanediol & $\mathrm{V}$ & Kurtyka [144] & & 463 & 101 & $P T x$ \\
\hline 3-methylphenol + methanol & $\mathrm{V}$ & Weissenberger et al. [94] & & 288 & 2.1 to 7.6 & $P T x$ \\
\hline \multirow{4}{*}{ 3-methylphenol + ethanol } & \multirow{4}{*}{$\mathrm{V}$} & Prasad et al. [145] & $\mathrm{N}$ & 336 to 474 & 96 & $P T x$ \\
\hline & & Weissenberger and Piatti [135] & & 291 & 0.80 to 3.9 & $P T x$ \\
\hline & & Piatti [146] & & 351 to 475 & 101 & $P T x$ \\
\hline & & Prasad et al. [145] & $\mathrm{N}$ & 350 to 474 & 96 & $P T x$ \\
\hline 3-methylphenol + 1-propanol & $\mathrm{V}$ & Prasad et al. [145] & $\mathrm{N}$ & 369 to 474 & 96 & $P T x$ \\
\hline 3-methylphenol + 2-propanol & $\mathrm{V}$ & Prasad et al. [145] & $\mathrm{N}$ & 355 to 474 & 96 & $P T x$ \\
\hline 3-methylphenol + 1-butanol & $\mathrm{V}$ & Prasad et al. [145] & $\mathrm{N}$ & 389 to 474 & 96 & $P T x$ \\
\hline 3-methylphenol + 2-butanol & $\mathrm{V}$ & Prasad et al. [145] & $\mathrm{N}$ & 371 to 474 & 96 & $P T x$ \\
\hline 3-methylphenol + 2-methyl-1-propanol & $\mathrm{V}$ & Prasad et al. [145] & $\mathrm{N}$ & 380 to 474 & 96 & $P T x$ \\
\hline \multirow[t]{2}{*}{ 3-methylphenol + 1,2-ethanediol } & \multirow[t]{2}{*}{$\mathrm{V}$} & Othmer et al. [100] & & 468 to 476 & 101 & PTxy \\
\hline & & Brusset et al. [142] & & 468 to 473 & 100 & PTxy \\
\hline \multirow[t]{2}{*}{ 4-methylphenol + methanol } & \multirow[t]{2}{*}{$\mathrm{V}$} & Weissenberger et al. [94] & & 288 & 2.2 to 7.5 & $P T x$ \\
\hline & & Prasad et al. [143] & $\mathrm{N}$ & 336 to 473 & 95 & $P T x$ \\
\hline \multirow[t]{2}{*}{ 4-methylphenol + ethanol } & \multirow[t]{2}{*}{$\mathrm{V}$} & Weissenberger and Piatti [135] & & 291 & 0.53 to 4.0 & $P T x$ \\
\hline & & Prasad et al. [143] & $\mathrm{N}$ & 350 to 473 & 95 & $P T x$ \\
\hline
\end{tabular}




\begin{tabular}{|c|c|c|c|c|c|c|}
\hline Mixture & GPM $^{\mathbf{a}}$ & Reference & Status $^{b}$ & $T$ range / & $\begin{array}{l}P \text { range / } \\
\mathbf{k P a}\end{array}$ & $\begin{array}{l}\text { Data } \\
\text { type }\end{array}$ \\
\hline 4-methylphenol + 1-propanol & $\mathrm{V}$ & Prasad et al. [143] & $\mathrm{N}$ & 369 to 473 & 95 & $P T x$ \\
\hline 4-methylphenol + 2-propanol & $\mathrm{V}$ & Prasad et al. [143] & $\mathrm{N}$ & 354 to 473 & 95 & $P T x$ \\
\hline 4-methylphenol + 1-butanol & $\mathrm{V}$ & Prasad et al. [143] & $\mathrm{N}$ & 392 to 473 & 95 & $P T x$ \\
\hline 4-methylphenol + 2-butanol & $\mathrm{V}$ & Prasad et al. [143] & $\mathrm{N}$ & 372 to 473 & 95 & $P T x$ \\
\hline 4-methylphenol + 2-methyl-1-propanol & $\mathrm{V}$ & Prasad et al. [143] & $\mathrm{N}$ & 380 to 473 & 95 & $P T x$ \\
\hline 4-methylphenol + 1,2-ethanediol & $\mathrm{V}$ & Othmer et al. [100] & & 468 to 475 & 101 & $P T x y$ \\
\hline & & Brusset et al. [142] & & 464 to 473 & 100 & PTxy \\
\hline 1,3-benzenediol + methanol & $\mathrm{V}$ & $\begin{array}{l}\text { Shakhparonov and Martynova } \\
\text { [123] }\end{array}$ & & 273 to 298 & 2.5 to 17 & $P T x$ \\
\hline 1,3-benzenediol + ethanol & $\mathrm{V}$ & Weissenberger et al. [104] & & 290 & 1.7 to 3.9 & $P T x$ \\
\hline & & $\begin{array}{l}\text { Shakhparonov and Martynova } \\
\text { [123] }\end{array}$ & & 273 to 298 & 0.67 to 7.9 & $P T x$ \\
\hline 1,3-benzenediol +1 -butanol & $\mathrm{V}$ & $\begin{array}{l}\text { Shakhparonov and Martynova } \\
\text { [123] }\end{array}$ & & 293,298 & $\begin{array}{l}0.38 \text { to } \\
0.93\end{array}$ & $P T x$ \\
\hline 1,4-benzenediol + methanol & $\mathrm{V}$ & Kodama et al. $[137]^{\mathrm{e}}$ & & 337 & 98 to 100 & $P T x y$ \\
\hline 1,4-benzenediol + ethanol & $\mathrm{V}$ & Kodama et al. [137] ${ }^{\mathrm{e}}$ & & 351 & 99 & PTxy \\
\hline 2-methoxyphenol + methanol & $\mathrm{V}$ & Chalov et al. [125] & & 338 to 478 & 101 & PTxy \\
\hline 2-methoxyphenol + ethanol & $\mathrm{V}$ & Weissenberger et al. [104] & & 290 & 1.0 to 3.6 & $P T x$ \\
\hline & & Cesari et al. [139] & & 300 to 409 & 9.0 to 100 & $P T x$ \\
\hline
\end{tabular}

${ }^{a}$ Gas-phase model: IG, ideal gas; V, virial; HOC, Hayden-O'Connell. ${ }^{b} \mathrm{~A}$, new experimental data are required to identify the reason of inconsistency either between the available experimental data or between the experimental and predicted values; $\mathrm{N}$, not recommended. More details about each case are provided in

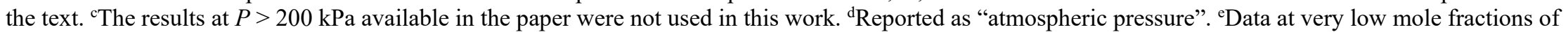
the first component; ${ }^{\mathrm{f}} \mathrm{P} x \mathrm{~d}$ data are not considered; ' estimated experimental pressure based on the reported boiling temperatures of pure liquids. 


\subsection{Models}

$p T x$ or $p T x y$ experimental data were considered for this analysis. For a given $(x, T)$ pair, the pressure over the solution and the gas-phase composition were calculated using the component activity coefficients predicted with the NIST-COSMO-SAC [23] and NISTmodified UNIFAC [24] models. The $\sigma$ profiles were generated at the B3LYP/6-311G(d,p) theory level using Gaussian 09 [25]. ${ }^{1}$ The detailed procedure has been described earlier [23]. All thermodynamic calculations were carried out with the NIST ThermoData Engine (TDE) v. 10.4 [26]. The vapor pressures of pure compounds critically evaluated by TDE were used. The evaluation procedures $[27,28]$ did not involve either of the models. The real-gas model was automatically selected by the software and specified in Table 2 . Predictions were not reported if (a) the pure-compound vapor pressure could not be evaluated; (b) a model predicted the liquid-liquid equilibrium for an experimental point; or (c) the UNIFAC parameters were missing.

The NIST-COSMO-SAC parameters were determined using the experimental data in the temperature range $T=(15$ to 457$) \mathrm{K}$ [23]. NIST-modified UNIFAC [24] uses the temperature-dependent formulation similar to that in the modified UNIFAC [29]. For this model, the upper temperature of experimental data in the training set for different parameters varied from (293 to 644$) \mathrm{K}$, and the average value was close to $T=400 \mathrm{~K}$. $67 \%$ of the VLE points considered in this work were reported at $T<404 \mathrm{~K}$ and $95 \%$ of the data were at $T<$ 468 K. NIST-COSMO-SAC was parameterized using the experimental VLE data at $P \leq 127$ $\mathrm{K}$ assuming the ideal-gas behavior for the vapor phase [23]. In this work, the considered pressure range was extended to $P<200 \mathrm{kPa}$ and the gas-phase non-ideality was taken into account. Thus, we do not a priori expect problems caused by the use of the model parameters beyond their applicability domain.

\subsection{Uncertainties}

Uncertainties and differences between the calculated and experimental values will further be considered in terms of the relative values of pressures and absolute values of mole fractions in the gas phase. The uncertainties are converted to combined uncertainties accounting for the contribution propagated from the uncertainties in the state variables. The combined uncertainties of pressures are partially caused by uncertainty of the pressure measurements. The latter can be the major contribution, however, the contributions due to uncertainties for the temperature and liquid-phase composition are often also significant.

If the gas phase is ideal, the pressure $P$ over a binary solution equals

$$
P=P_{01} x_{1} \gamma_{1}+P_{02}\left(1-x_{1}\right) \gamma_{2}
$$

where $x_{1}$ is the mole fraction of the first component in the liquid phase; $p_{0 i}$ and $\gamma_{i}$ are the vapor pressure and liquid-phase activity coefficient of the $i$ th component, respectively. In an ideal solution, $\gamma_{i}=1$ and the uncertainty in temperature propagates to VLE pressure as

${ }^{1}$ Trade names are provided only to specify procedures adequately and do not imply endorsement by the National Institute of Standards and Technology or the National Renewable Energy Laboratory. Similar products by other manufacturers may be found to work as well or better. 


$$
\frac{u_{\mathrm{r}}(P)}{u(T)} \approx \frac{d \log P}{d T}=\frac{1}{P}\left(P_{01} x_{1} \frac{\Delta_{\mathrm{vap}} H_{1}}{R T^{2}}+P_{02}\left(1-x_{1}\right) \frac{\Delta_{\mathrm{vap}} H_{2}}{R T^{2}}\right)
$$

here $\Delta_{\mathrm{vap}} H_{i}$ is the enthalpy of vaporization of the $i$ th component; $R$ is the molar gas constant; $T$ is the experimental temperature; $u(T)$ is the standard uncertainty of temperature; and $u_{\mathrm{r}}(P)$ is the relative standard uncertainty of pressure. Typically, a temperature change of $1 \mathrm{~K}$ corresponds to a pressure change of several per cent. For example, if the partial pressure of the first component dominates in the total VLE pressure and its enthalpy of vaporization is $\Delta_{\text {vap }} H_{1}=50 \mathrm{~kJ} \cdot \mathrm{mol}^{-1}$ at $T=350 \mathrm{~K}, u_{\mathrm{r}}(P) \approx 0.049 u(T)$. Eq. (2) can also be used to estimate deviations between the predicted and experimental VLE temperatures, if the pressure deviations are known and vice versa.

Uncertainties for the pressure and mole fraction for the ideal solution are related by the equation

$$
\frac{u_{\mathrm{r}}(P)}{u(x)} \approx \frac{d|\ln P|}{d x}=\frac{\left|P_{01}-P_{02}\right|}{P}
$$

The effect will be minimal at $P_{01} \approx P_{02}$. If $P_{01}>>P_{02}$ or $P_{01}<<P_{02}, u_{\mathrm{r}}(P) \approx u\left(x_{1}\right)$. For nonideal solutions, the dependence of the activity coefficients on the liquid-phase composition should be considered.

An effect of the sample purity on the uncertainty should also be considered. To quantify this contribution, the nature of the impurity must be known. This information is typically not available in the literature.

\subsection{Criteria for analysis of the experimental and predicted data}

A universal rigorous criterion to evaluate the quality of VLE data does not exist. All methods evaluate the mutual consistency with other data or models. Previously, we demonstrated that the relative standard uncertainty close to $u_{\mathrm{r}}(P)=0.15$ can be expected for both NISTCOSMO-SAC and NIST-modified-UNIFAC models [23]. Thus, any difference between the predicted and experimental pressure significantly exceeding this value would require special attention. A similar limit for the gas-phase mole fractions has been estimated to be close to $0.05[14]$ and is supported by the statistical analysis below.

Two scenarios are possible. First, all available experimental data for a mixture are mutually consistent and are also consistent with the predicted values. This includes the cases where a single dataset is available. In this case, no action is required. Second, inconsistency of some kind is detected. This may include inconsistent experimental data sets, predicted and experimental values, or results from two models. In this scenario, the inconsistencies are further analyzed using the following criteria: (i) consistency of results for the same mixture obtained in different laboratories; (ii) consistency of the data for chemically similar systems (for example, those with isomers or homologs); (iii) model performance for chemically similar systems; (iv) overall data quality originating from a laboratory. If a model is found to give unsatisfactory results for a mixture, it is specified in the text. The experimental data found to be problematic are marked with the $\mathrm{N}$ letter in the last column of Table 2 . If the 
available information is not conclusive, the data are marked with the letter A meaning new VLE measurements are suggested for this mixture. The flags for the experimental data are independent of evaluation of the predicted values. For example, new experimental data can be needed, and the predictions can be not satisfactory for the same mixture.

\section{Results}

\subsection{VLE for furan derivatives}

We considered 1630 data points for 39 binaries with furan derivatives. For 1295 points, the gas-phase composition was reported. The results are presented in Figs. 1-8.

\subsubsection{VLE with aromatic compounds}

These results include the data for (furan + toluene), (2-methylfuran + benzene), and four binaries with 2-furaldehyde (Fig. 1). The predicted values are generally in good agreement with the experimental data. Krevor and Prausnitz [32] reported that the component activity coefficients for (2-methylfuran + benzene) are within (1 to 1.06). This behavior is very well reproduced by both considered models. A similar behavior with $\gamma$ within (1.0 to 1.12) is predicted for (furan + toluene) by NIST-COSMO-SAC, the only model available for this mixture. The reported experimental pressures $[30,31]$ are generally lower than corresponding pressures over an ideal solution. However, consistency of the predicted and experimental values is still acceptable.

The experimental data for the 2-furaldehyde mixtures with benzene and toluene have been reported in multiple works, primarily by Garner et al. (Table 2). The gas-phase compositions for (2-furaldehyde + toluene) reported in Ref. [37] deviate by up to 0.1 mole fraction from the other data for this mixture, including those from the same laboratory. The same problem exists for the pressures of (2-furaldehyde + benzene) reported by Garner and Ellis [36]. These results will not be further used.

The vapor pressure of 2-furaldehyde in Ref. [34] is inconsistent with multiple data available in the literature. However, its partial pressure is relatively small at most compositions. Thus, this problem should not affect most of the VLE data. This is a typical problem also found in the results by Staroske et al. for (2-furaldehyde + methanol) [59] and (2-furaldehyde + water) [66] and by Holdren and Hixon for (2-methylfuran +2 -furaldehyde) [44]. 


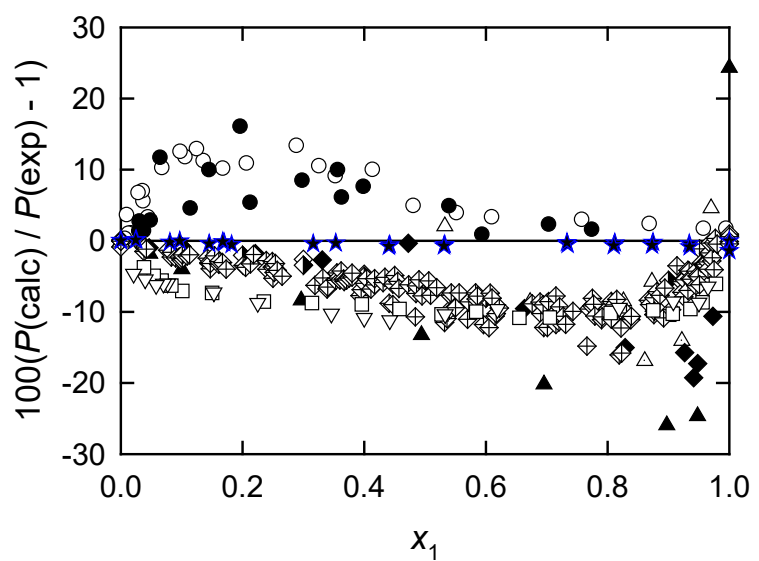

$a$

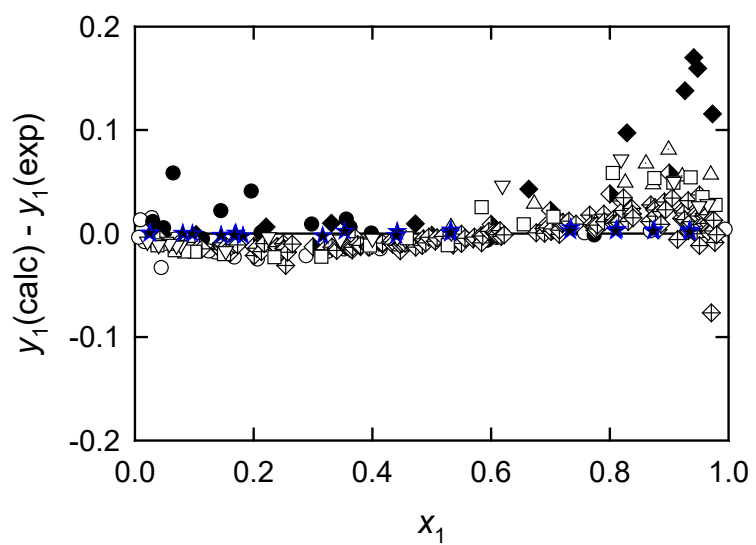

$c$

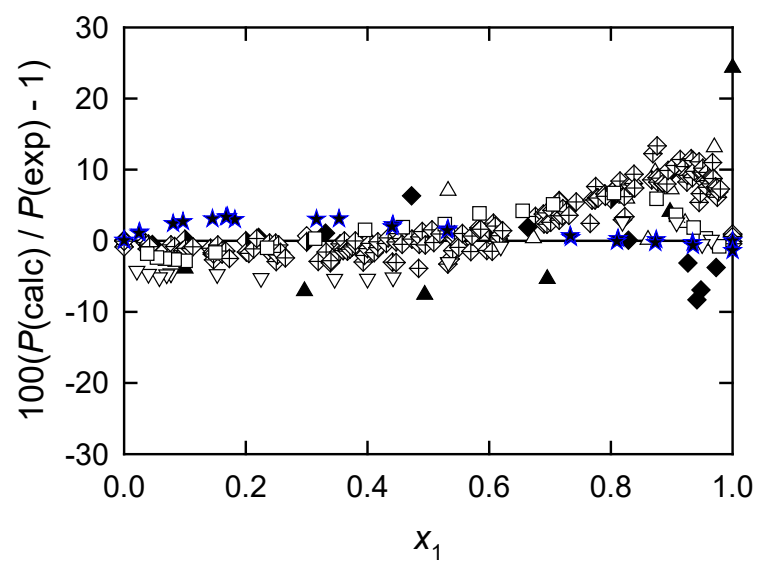

$b$

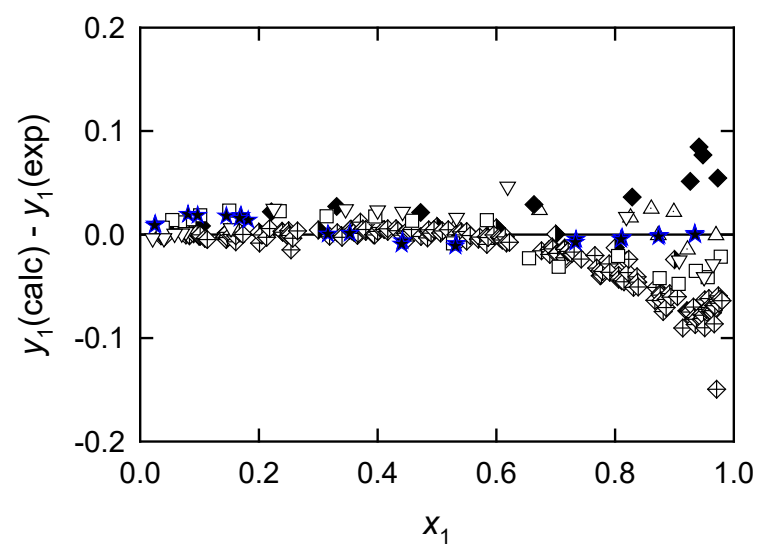

$d$

Fig. 1. Comparison of the predicted and experimental pressures $P$ and first-component mole fractions $y_{1}$ in the gas phase at different first-component mole fractions in the liquid phase $x_{1}$ for the binaries of furan derivatives with aromatic compounds: $a, c$, NIST-COSMO-SAC; $b$, d: NIST-Modified UNIFAC.

Circles are for furan + toluene: $O$, Nala et al. [30]; •, Thévaneau et al. [31].

Stars $(\star)$ are for 2-methylfuran + benzene, Krevor and Prausnitz [32].

Triangles are for 2-furaldehyde + benzene: $\triangle$, Thornton and Garner [33]; $\boldsymbol{\Delta}$, Kenny [34]; $\triangle$, Stephenson and

Van Winkle [35]. The results of Garner and Ellis [36] obtained in the same laboratory as Ref. [33] are not shown because of a large deviation.

Diamonds are for 2-furaldehyde + toluene: $\diamond$, Garner and Ellis [36]; $\diamond$, Thornton and Garner [37]; $\triangleleft$, Garner and Hall [38]; $\oplus$, Rivenq [39].

Squares $(\square)$ are for 2-furaldehyde + 1,4-dimethylbenzene, Puri and Raju [40].

Triangles down $(\nabla)$ are for 2-furaldehyde + ethylbenzene, Puri and Raju [40]. 


\subsubsection{VLE of two furan derivatives}

The experimental data are available for the mixtures with furan, 2-methyl-, and 2,5dimethylfurans (Fig. 2) and five mixtures containing two furan derivatives with polar substituents (Fig. 3). For the first group, significant inconsistencies exist for both the experimental and computed results. VLE for (furan +2 -furaldehyde) have been reported in three publications $[41,42,43]$. Despite the pressures predicted with the two models differ significantly (Fig. 2), it is seen that these experimental results are inconsistent. The gas-phase compositions from both models agree with ones reported by Tai et al. [41] and disagree by up to 0.2 mole fraction with the data of Chen et al. [43]. The pressure deviations [42] are supported by those for (2-methylfuran +2 -furaldehyde) [44] and (2,5-dimethylfuran + furfuryl alcohol) [45] and those of Ref. [43] are consistent with the data for (2-methylfuran + furfuryl alcohol) [41]. While the analysis above gives a certain preference to the PTx data by Auger et al. [42], the results are inconclusive. New experimental data are required for (furan +2 -furaldehyde). Also, efforts should be made to resolve the existing inconsistencies between the VLE pressures predicted with NIST-COSMO-CAS and NIST-modified UNIFAC.

The pressures and gas-phase compositions predicted with NIST-COSMO-SAC for the polar binaries are generally in good agreement with the experimental data (Figs. 3a and 3c). The (2-furaldehyde + furfuryl alcohol) VLE data at low pressures have been published in two papers $[46,47]$. Only NIST-COSMO-SAC predictions are available for this system due to lack of the UNIFAC parameters. The predicted pressures are about $30 \%$ lower than those in Ref. [47] for all but three points, and this problem does not exist for the results from Ref. [46]. Both works reported isobars at reduced pressure (6.7 and $3.3 \mathrm{kPa}$, respectively). Thus, a similar correlation between the predicted and experimental values is expected. Considering good performance of the NIST-COSMO-SAC model for this group of mixtures, the data of Myles and Wingard [46] should be preferred. A reasonable explanation could be that the real pressure in most experiments from Ref. [47] was $4.7 \mathrm{kPa}$ instead of $6.7 \mathrm{kPa}$ stated by the authors.

The (2-furaldehyde +5 -methylfurfural) binary was studied in two works [49,50]. These results are mutually consistent though the values predicted with NIST-modified UNIFAC deviate from them (Figs. 3b and 3d). We believe the predictions are inadequate for this binary. This problem does not occur in the NIST-COSMO-SAC predictions (Figs. 3a and $3 \mathrm{c})$. 


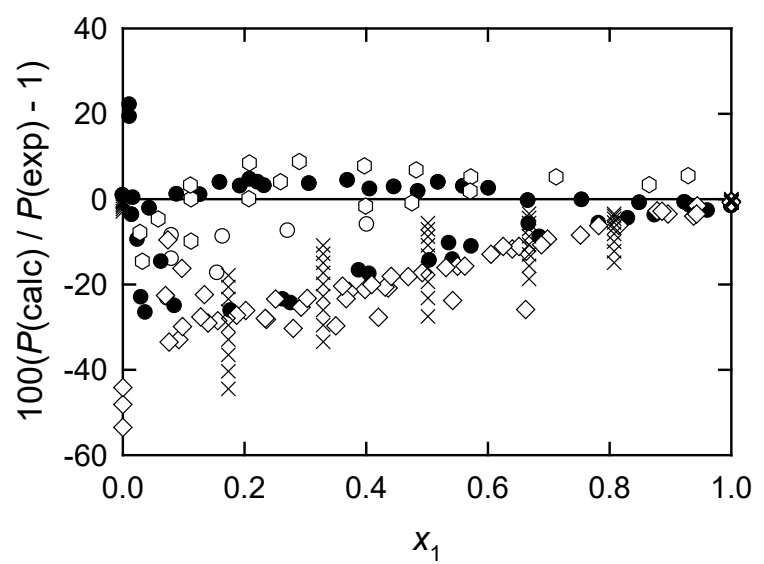

$a$

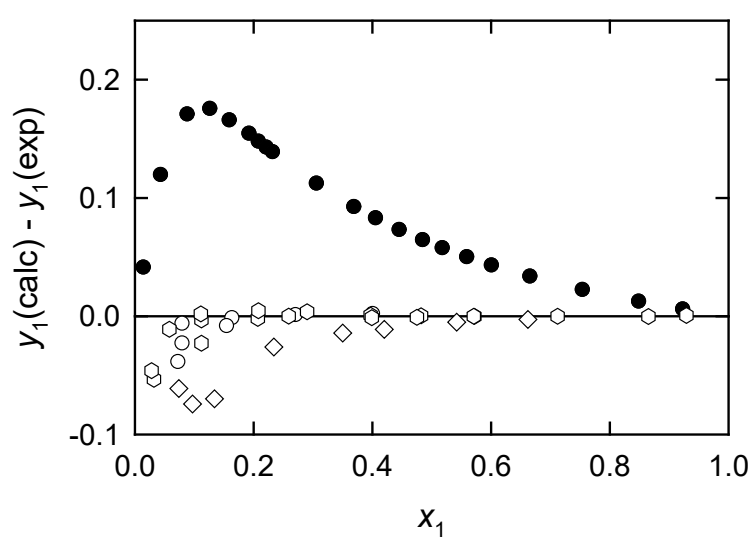

$c$

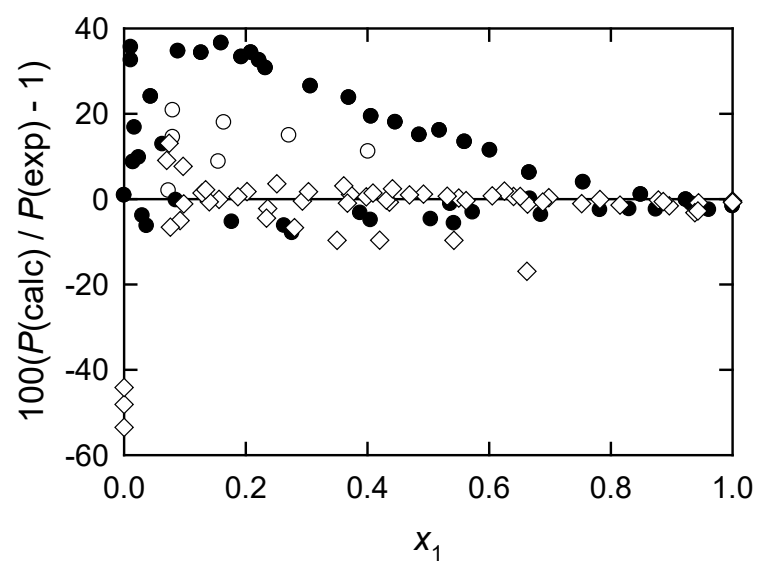

$b$

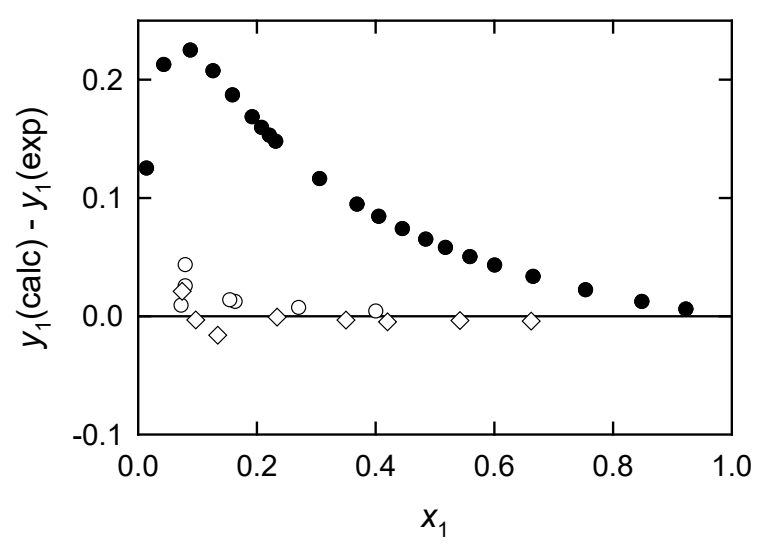

$d$

Fig. 2. Comparison of the predicted and experimental pressures $P$ and first-component mole fractions $y_{1}$ in the gas phase at different first-component mole fractions in the liquid phase $x_{1}$ for the binaries of furan derivatives one of which is furan or methylfuranes: a, c, NISTCOSMO-SAC; b, d: NIST-Modified UNIFAC.

Circles are for furan + 2-furaldehyde: O, Tai et al. [41]; $\bullet$, Auger et al. [42]; $\mathbf{O}$, Chen et al. [43].

Diamonds $(\diamond)$ are for 2-methylfuran +2 -furaldehyde, Holdren and Hixon [44].

Hexagons $(\bigcirc)$ are for 2-methylfuran + furfuryl alcohol, Tai et al. [41].

Crosses $(\times)$ are for 2,5-dimethylfuran + furfuryl alcohol, Negadi et al. [45]. 


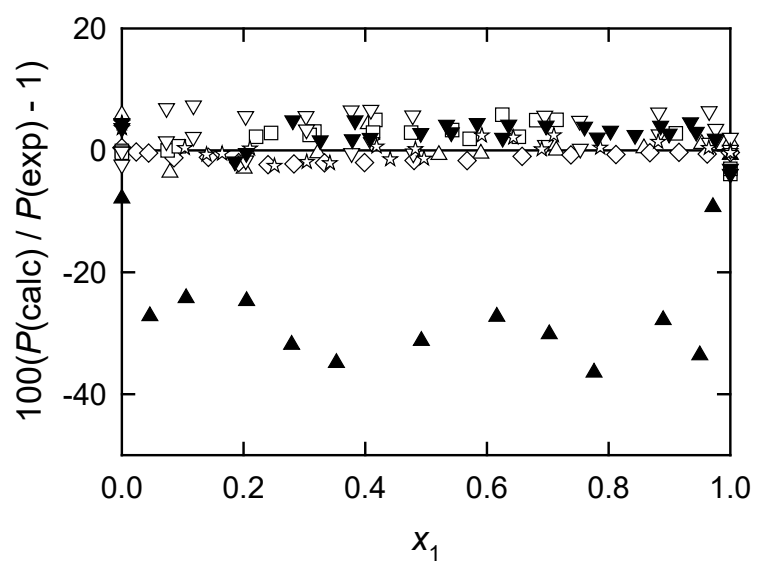

$a$

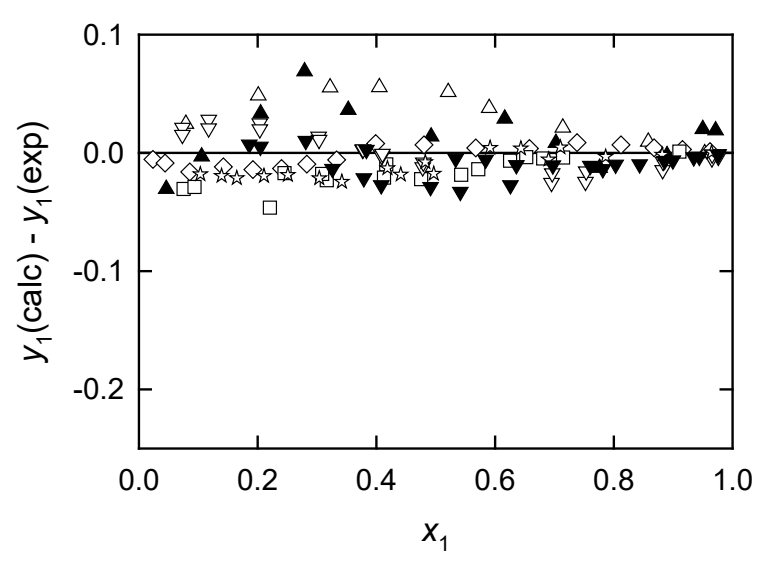

$c$

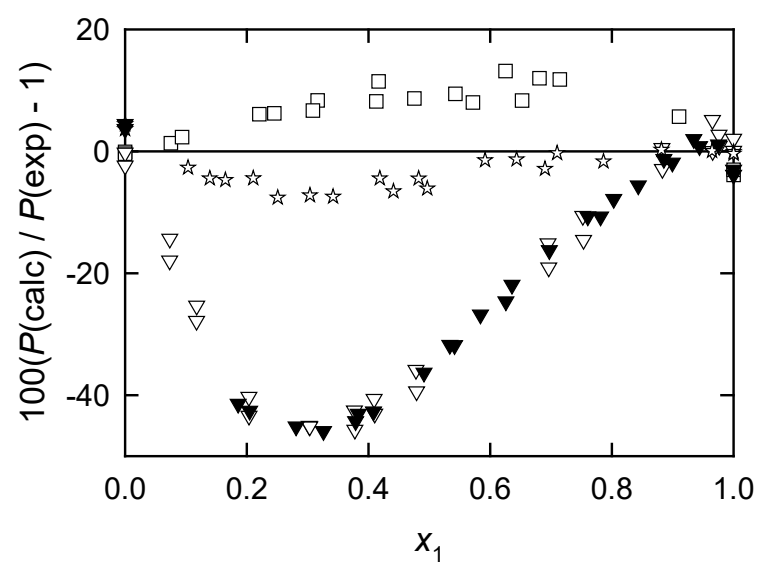

$b$

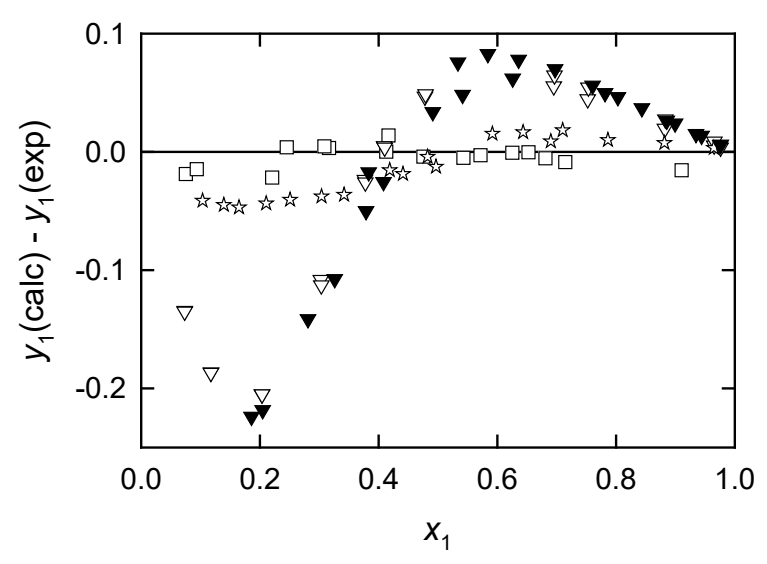

$d$

Fig. 3. Comparison of the predicted and experimental pressures $P$ and first-component mole fractions $y_{1}$ in the gas phase at different first-component mole fractions in the liquid phase $x_{1}$ for the binaries of furan derivatives: a, c, NIST-COSMO-SAC; $b$, d: NIST-Modified UNIFAC.

Triangles are for 2-furaldehyde + furfuryl alcohol: $\triangle$, Myles and Wingard [46]; $\boldsymbol{\Delta}$, Tsirlin and Vasil'eva [47]. Diamonds $(\diamond)$ are for 2-furaldehyde $+\gamma$-valerolactone, Pokki et al. [48].

Squares $(\square)$ are for 2-furaldehyde +2 -acetylfuran, Zheng et al. [49].

Triangles down are for 2-furaldehyde + 5-methylfurfural: $\nabla$, Fele and Grilic [50]; $\nabla$, Zheng et al. [49]. The data obtained with NIST-modified UNIFAC seem to be incorrect.

Stars ( $\left.\aleph^{2}\right)$ are for 2-acetylfuran + 5-methylfurfural, Zheng et al. [49]. 


\subsubsection{VLE with ketones and acetic acid}

For this group (Fig. 4), the experimental and predicted results are generally in good agreement. NIST-COSMO-SAC describes the experimental data somewhat better at $x_{1}>0.8$ than NIST-modified UNIFAC though the consistency trends are similar. The predicted pressures and gas-phase compositions are in good agreement with the experimental data for (2-methylfuran + butanone) [54]. The deviations close to - $20 \%$ are observed for (2,5dimethylfuran + 4-methylpentan-2-one) [45] at the pressures close to $10 \mathrm{kPa}$. At the higher pressures, the deviations decrease becoming comparable to those for other mixtures for NIST-COSMO-SAC (Fig. 4a).

A few points at high mole fractions of 2-furaldehyde in its mixtures with acetone reported by Ma et al. [51] have anomalous deviations of the predicted $P$ and $y$ for both considered models. This behavior is not observed for any other mixture of this group. Additional experimental data are required to support these experimental results.

The gas-phase compositions of (2-furaldehyde + 4-methylpentan-2-one) predicted with NIST-modified UNIFAC significantly deviate from the values reported by Hauschild et al. [52] and Zaitseva et al. [53]. This deviation is specific to this model is probably not related to the quality of the experimental data.

\subsubsection{VLE with alcohols}

For most furan and alkylfuran mixtures with alcohols, NIST-COSMO-SAC is the only available model (Fig. 5) due to the lack of NIST-modified UNIFAC parameters. The predicted pressures are typically (10 to 25 ) \% lower than the experimental ones. For these mixtures, the model incorrectly predicts gas-phase mole fractions unless one of the components is predominant in the gas phase $(y>0.95)$. The deviations are consistent, which indicates that the experimental data do not have significant problems.

The predicted pressures and gas-phase compositions for the other binaries with alcohols agree with the experimental data (Figs. 6 and 7) except two datasets. The pressures and gasphase compositions of (2-furaldehyde + ethanol) at $x_{1}>0.9$ [60] notable deviate from the values predicted with both models (Fig. 6). Since this problem does not occur for 2furaldehyde binaries with other alcohols, these data should be discarded. The gas-phase compositions for (2-furaldehyde + 1-octanol) [62] are inconsistent with both models. 1octanol used in Ref. [62] is actually a mixture of alcohols with 0.85 mass fraction of 1octanol. Therefore, the results obtained in this work should not be used. 


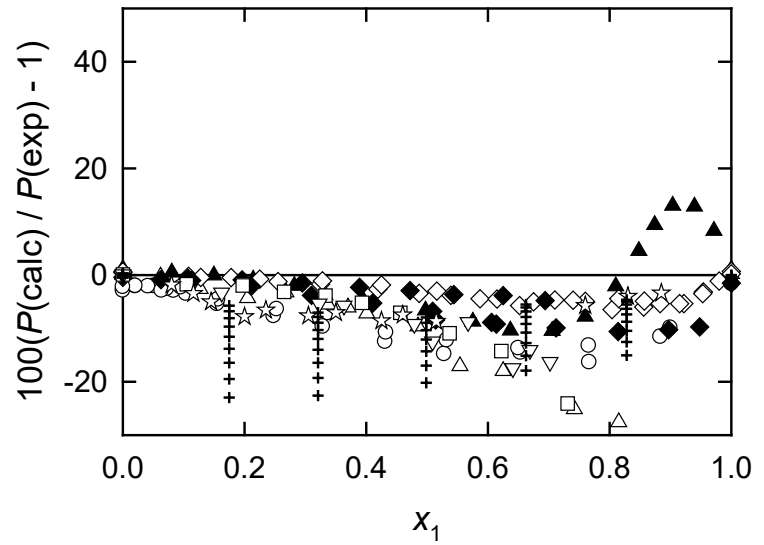

$a$

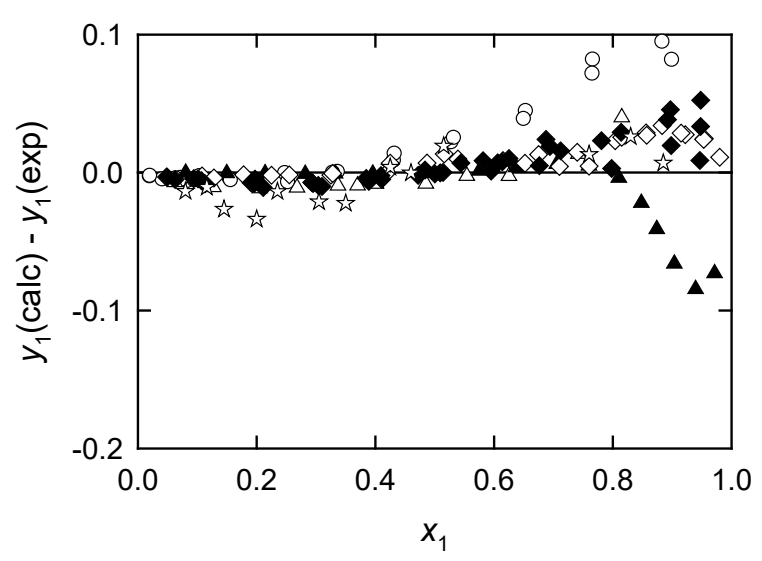

c

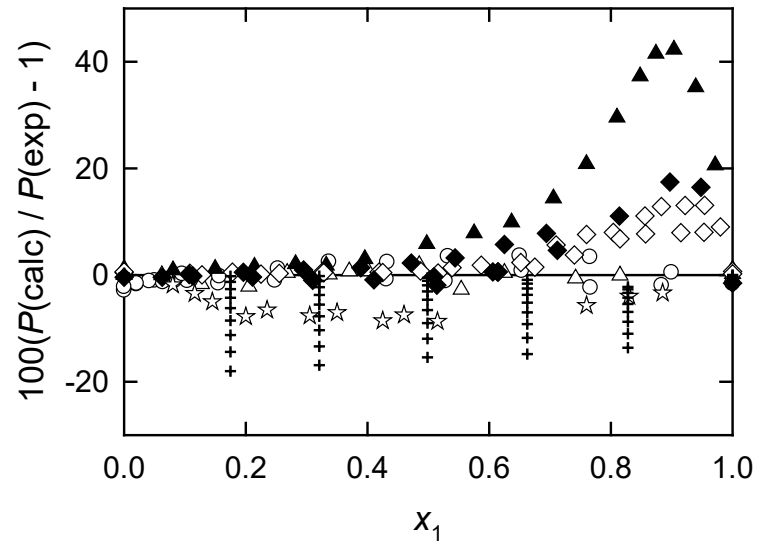

$b$

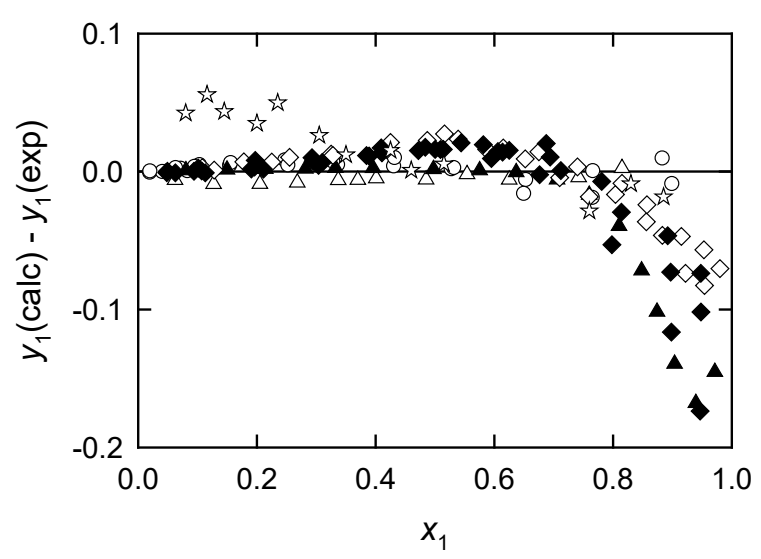

$d$

Fig. 4. Comparison of the predicted and experimental pressures $P$ and first-component mole fractions $y_{1}$ in the gas phase at different first-component mole fractions in the liquid phase $x_{1}$ for the binaries of furan derivatives with ketones and acetic acid: a, c, NIST-COSMO-SAC; b, d: NIST-Modified UNIFAC.

Circles $(\mathrm{O})$ are for 2-furaldehyde + acetic acid, Fele and Grilic [50].

Triangles are for 2-furaldehyde + acetone: $\triangle$, Myles and Wingard [46]; $\boldsymbol{\Delta}$, Ma et al. [51].

Diamonds are for 2-furaldehyde + 4-methylpentan-2-one: $\diamond$, Hauschild et al. [52]; $\diamond$, Zaitseva et al. [53].

Stars ( $(2)$ ) are for 2-methylfuran + butanone, Smith and Labonte [54].

Pluses $(+)$ are for 2,5-dimethylfuran +4 -methylpentan-2-one, Negadi et al. [45].

Squares $(\square)$ are for furfuryl alcohol + acetone, Dudutkina and Lutugina [55].

Triangles down $(\nabla)$ are for furfuryl alcohol + butanone, Dudutkina and Lutugina [55]. 


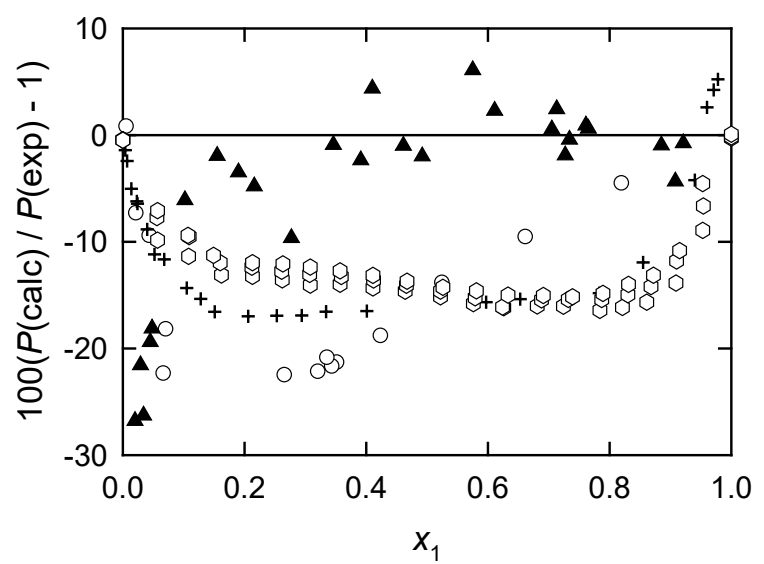

$a$

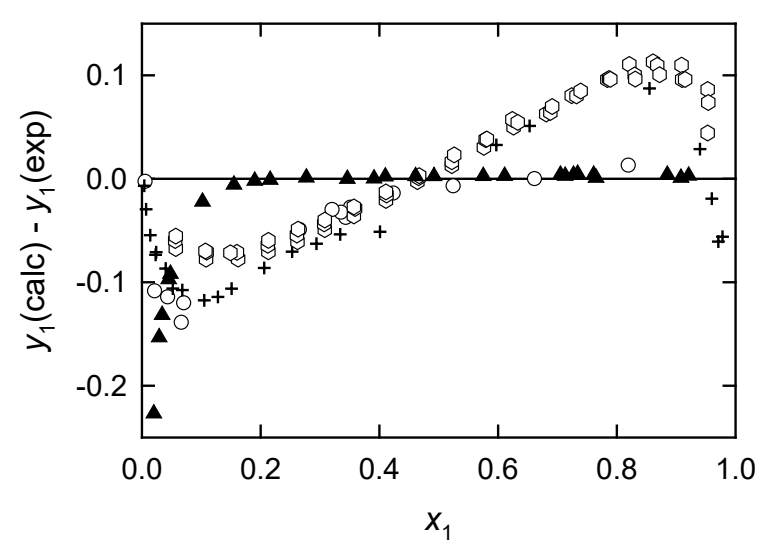

c

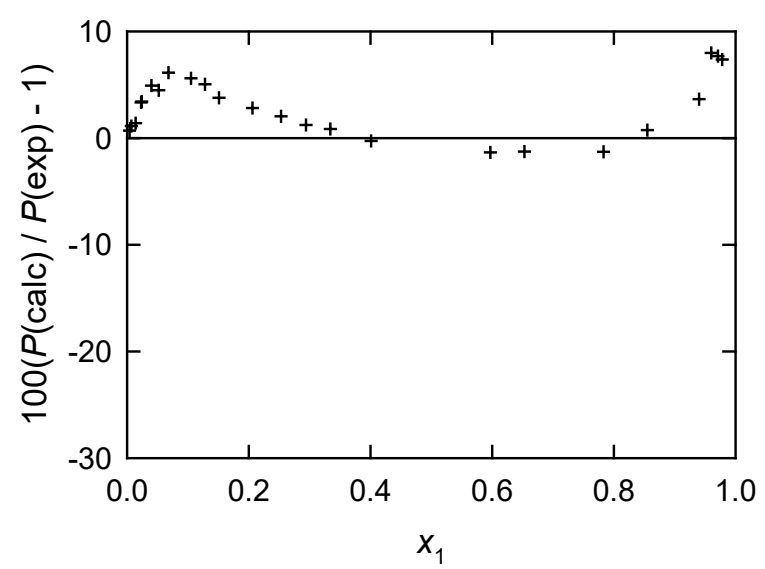

$b$

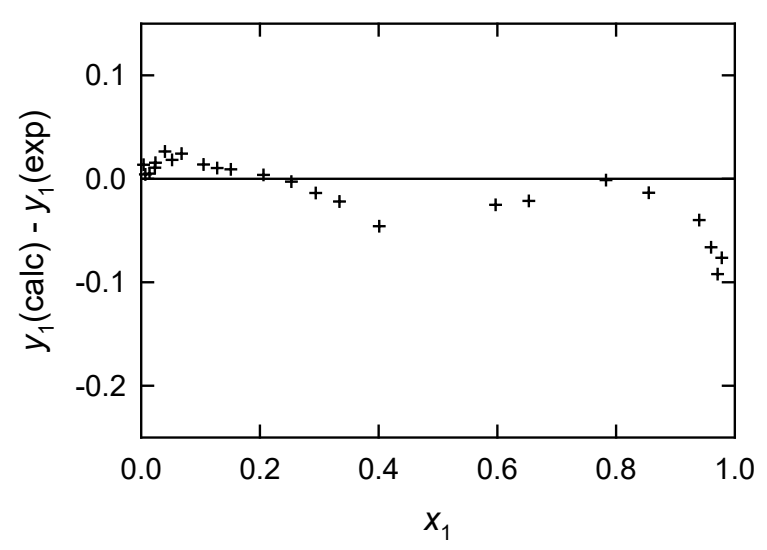

$d$

Fig. 5. Comparison of the predicted and experimental pressures $P$ and first-component mole fractions $y_{1}$ in the gas phase at different first-component mole fractions in the liquid phase $x_{1}$ for the binaries of furan and methylfuranes with methanol and ethanol: a, c, NIST-COSMO-

SAC; b, d: NIST-Modified UNIFAC.

Circles (O) are for furan + ethanol, Auger et al. [42].

Triangles $(\boldsymbol{\Delta})$ are for furan + 1-octanol, Auger et al. [42].

Pluses (+) are for 2-methylfuran + methanol, Hickman and Hall [56].

Hexagons $(\bigcirc)$ are for 2,5-dimethylfuran + ethanol, Mejía et al. [57]. 


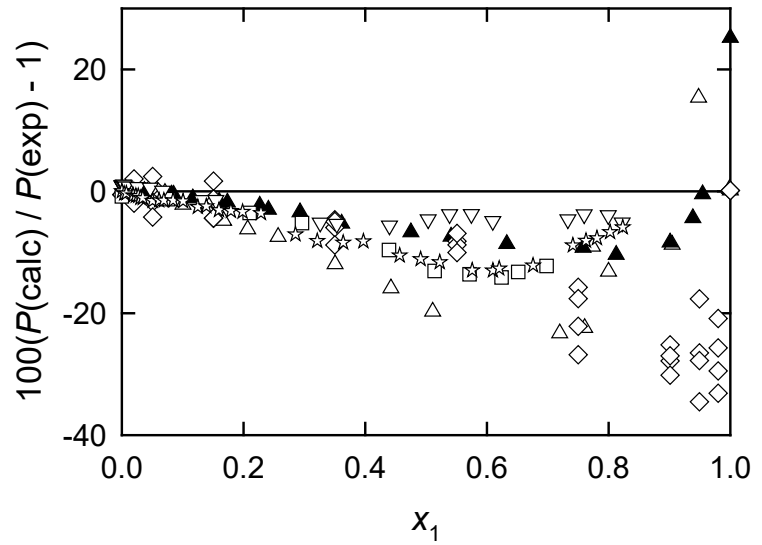

$a$

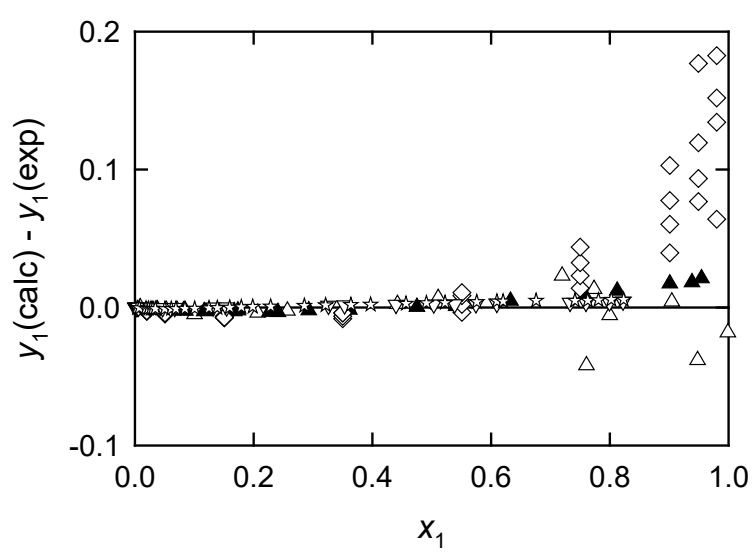

$c$

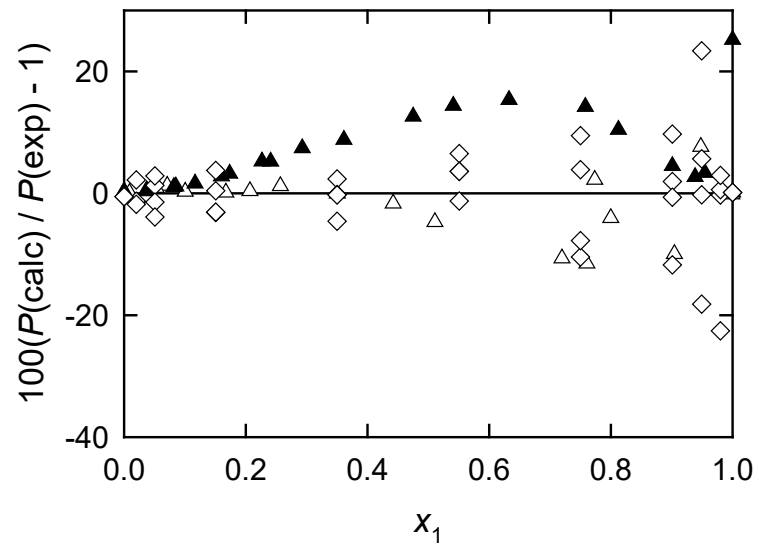

$b$

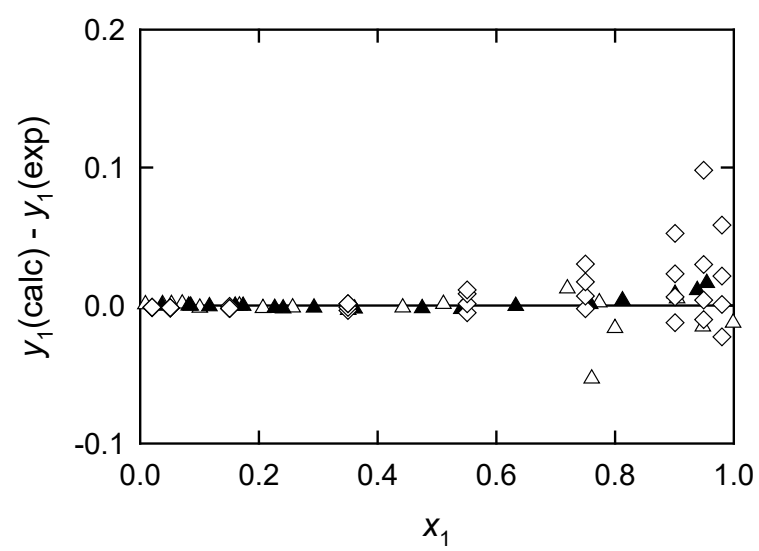

$d$

Fig. 6. Comparison of the predicted and experimental pressures $P$ and first-component mole fractions $y_{1}$ in the gas phase at different first-component mole fractions in the liquid phase $x_{1}$ for the binaries of furan derivatives with methanol and ethanol: a, c, NIST-COSMO-SAC; b, d: NIST-Modified UNIFAC.

Triangles are for 2-furaldehyde + methanol: $\triangle$, Ni and Wang [58]; $\boldsymbol{\Delta}$, Staroske and Figurski [59].

Diamonds $(\diamond)$ are for 2-furaldehyde + ethanol, Kharin et al. [60].

Squares $(\square)$ are for furfuryl alcohol + ethanol, Dudutkina and Lutugina [55].

Triangles down $(\nabla)$ are for $\gamma$-valerolactone + methanol, Havasi et al. [61].

Stars (하) are for $\gamma$-valerolactone + ethanol, Havasi et al. [61]. 


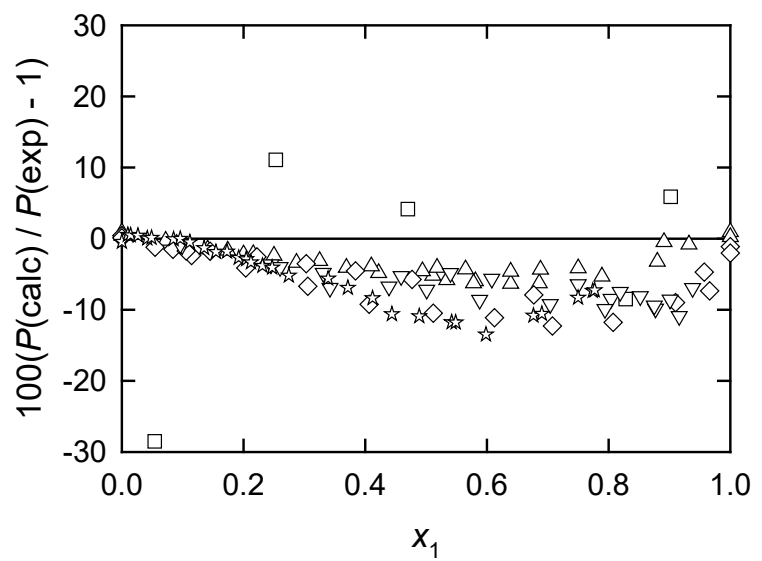

$a$

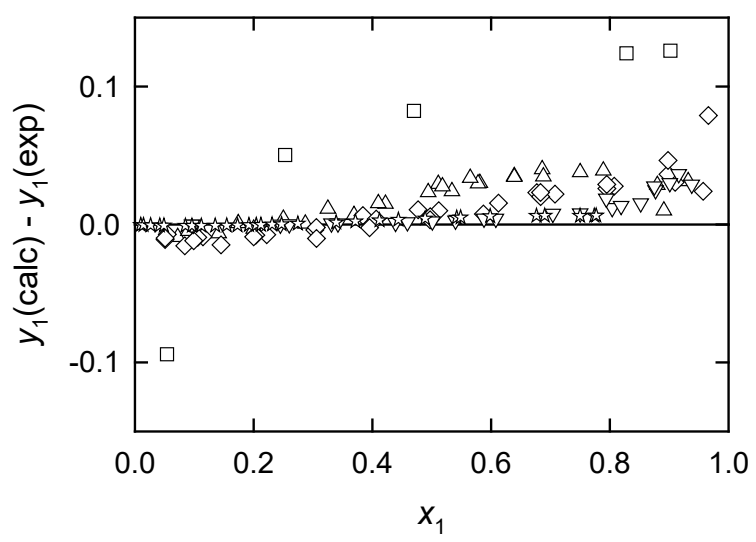

c

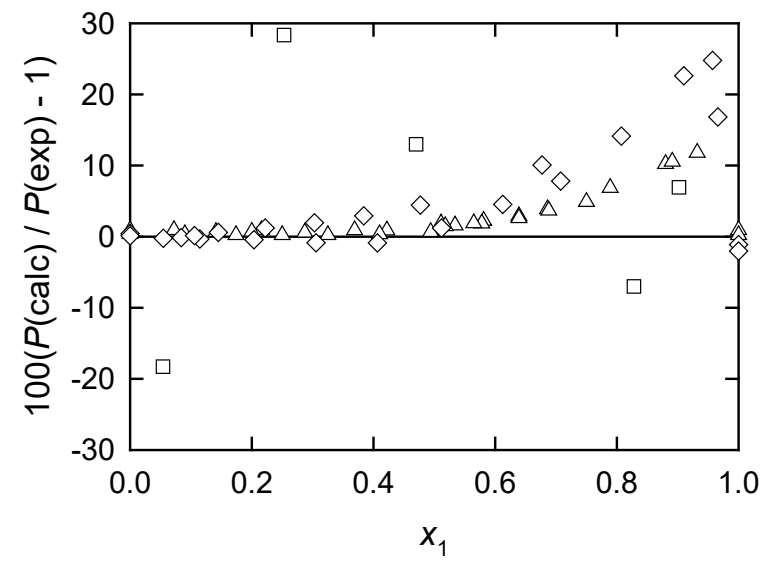

$b$

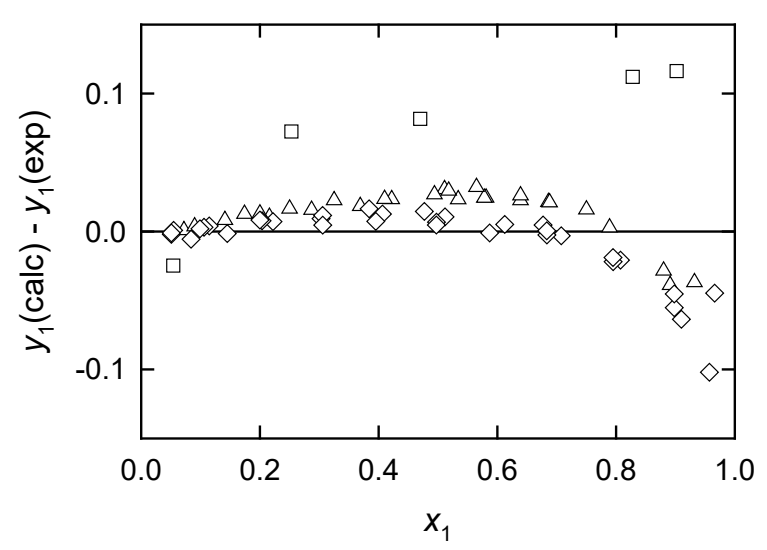

$d$

Fig. 7. Comparison of the predicted and experimental pressures $P$ and first-component mole fractions $y_{1}$ in the gas phase at different first-component mole fractions in the liquid phase $x_{1}$ for the binaries of furan derivatives with longer-chain alcohols: $a, c$, NIST-COSMO-SAC; $b$, $\mathrm{d}$ : NIST-Modified UNIFAC.

Triangles $(\triangle)$ are for 2-furaldehyde + 1-butanol, Hauschild et al. [52].

Diamonds $(\diamond)$ are for 2-furaldehyde + 2-butanol, Zaitseva et al. [53].

Squares $(\square)$ are for 2-furaldehyde + 1-octanol, Rigamonti and Spaccamela Marchetti [62].

Triangles down $(\nabla)$ are for furfuryl alcohol + 2-propanol, Tai et al. [41].

Stars (光) are for $\gamma$-valerolactone + 2-propanol, Havasi et al. [61]. 


\subsubsection{VLE with water}

(2-furaldehyde + water) is the most studied mixture in this group (Fig. 8). The results for the binaries with furfuryl alcohol and $\gamma$-valerolactone are also available. The vapor pressure of water significantly exceeds that of the organic components. At low water content, the consistency between the experimental and predicted pressures and gas-phase compositions will be sensitive to the correctness of the experimental liquid-phase compositions. At $x$ (water) $>0.2\left(x_{1}<0.8\right)$, a good agreement is observed in Fig. 8. However, at $x$ (water) $<0.2$, the deviations and agreement between the experimental data are not satisfactory. As demonstrated below, this problem is caused by both systematic errors in determination of the liquid compositions and limitations of the models. A similar problem for (phenol + water) discussed later exists in a significantly shorter mole fraction range $(x($ water $)<0.05)$. In Figs. $8 \mathrm{~b}$ and $8 \mathrm{~d}$, there are no data points from $x_{1}=(0.05$ to 0.45$)$. This happens because of the predicted (2-furaldehyde + water) LLE and the lack of the NIST-modified UNIFAC parameters for the other two binaries.

The differences between the computed and experimental pressures of (2-furaldehyde + water) at $x_{1}>0.8$ vary from (-18 to 138$) \%$ for NIST-COSMO-SAC and (-18 to 58$) \%$ for NIST-modified UNIFAC. Similar deviations in the gas-phase mole fractions are (0.04 to 0.47 ) and (0.06 to -0.27$)$, respectively. Generally, the deviation increases with pressure/temperature. A scatter of the experimental data is large and additional efforts are required to identify all problematic datasets. Several comments can be made though.

The results of Mains [63] have the largest deviation at $x_{1}$ close to unity. The author claimed that the uncertainty of the temperature measurements at $x_{1}>0.78$ was at least $1 \mathrm{~K}$. Also, the gas-phase composition had a significant uncertainty due to fractionation in a flask. Therefore, the PTxy dataset from Ref. [63] should not be used. Also, the author provided an improved Pxy dataset for water-rich compositions, which does not cover the questionable range.

At $T=338.1 \mathrm{~K}$ and $x_{1}=0.949$, the NIST-COSMO-SAC prediction is $104 \%$ higher than the experimental pressure $P=6.8 \mathrm{kPa}$ reported by Kharin et al. [60]. Such a large deviation is not supported by other experimental data $[64,65]$ at similar pressures and compositions. An identical problem with the results (2-furaldehyde + ethanol) reported in Ref. [60] was discussed in Sec. 3.1.4. Therefore, this dataset should also be excluded.

Sunder and Prasad [67] reported VLE for the entire composition range including the LLE region. The liquid-liquid phase separation was not discussed in that paper. A large uncertainty is expected for these results, as discussed below.

Two isobars at reduced pressure have been reported $[68,69]$ for (furfuryl alcohol + water). The PTxy results of Boldyrev et al. [68] at $P=7.3 \mathrm{kPa}$ are within the expected deviations from the predicted values. The NIST-COSMO-SAC pressures are systematically higher than the data of Dudutkina et al. [55] $(P=4.0 \mathrm{kPa})$ over the entire composition range, even for very low water content. This is the only dataset demonstrating this behavior. For most points, the predicted pressures are close to $P=4.4 \mathrm{kPa}$, and the difference may be caused by the incorrect pressure determination. Two experimental points at $x_{1}>0.8$ have very large $(>100$ $\%$ ) differences with the predicted values. This is inconsistent with the deviation trend for the other work [68]. The latter results seem to be preferable, however, new measurements are required to clarify the behavior of this system at $x_{1}>0.8$. 
For $(\gamma$-valerolactone + water $)$, two consistent datasets are available [70,71]. At $x_{1}>0.8$, the predicted pressures are up to $56 \%$ higher than the experimental counterparts (Fig. 8a), which seems to be caused by the model limitations. The predicted and experimental gas-phase compositions are still in good agreement (Fig. 8b).

Overall, the models demonstrated similar deviations from the experimental VLE pressures and gas-phase compositions (Table 3 ). The relative standard deviations for the pressures were comparable to those reported previously [23]. For the considered dataset with furan derivatives, the reported vapor pressures of pure liquids have a relative standard deviation of about $2 \%$ from the TDE recommendations, which indicates that the temperature and pressure measurements have a relatively small contribution to the inconsistencies between the predicted and experimental pressures. The NIST-COSMO-SAC model demonstrated significantly lower standard deviations for the binaries with organic components only. Consistency with experimental data was further improved when the problematic data considered above (code N in Table 2) were excluded. Surprisingly, the performance of the NIST-modified UNIFAC model remained virtually the same upon removal of the doubtful data. This limitation seems to be caused by the quality of the training set used to derive the empirical parameters of this model. 

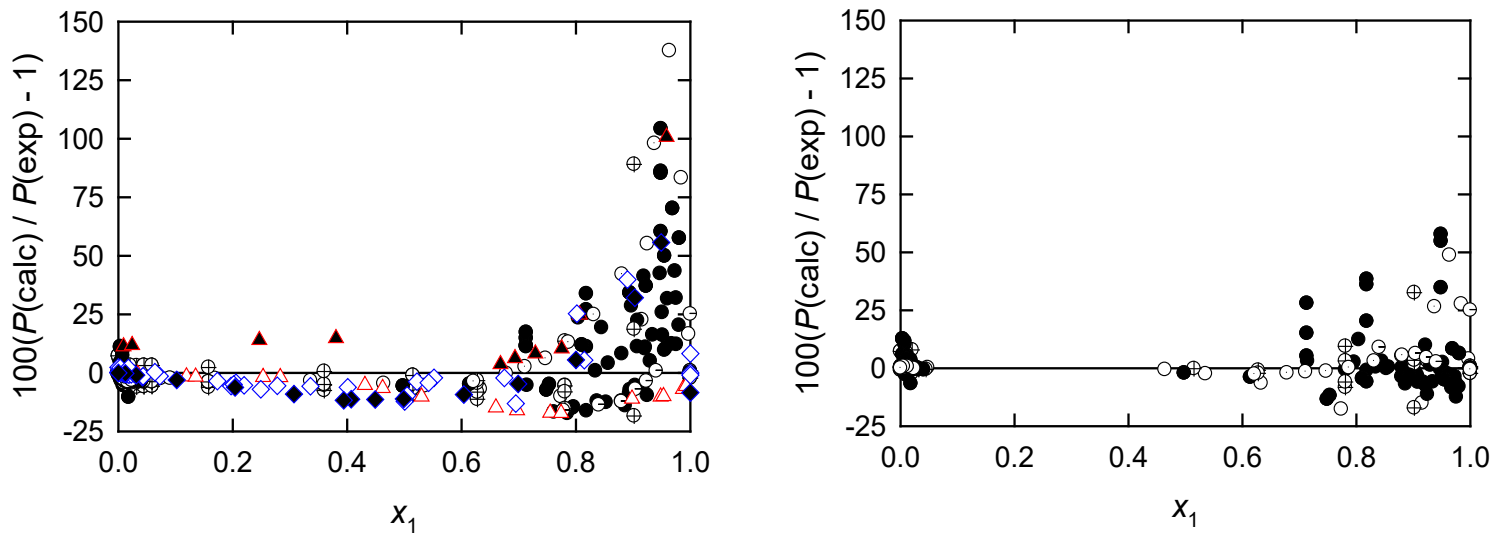

$a$

$b$
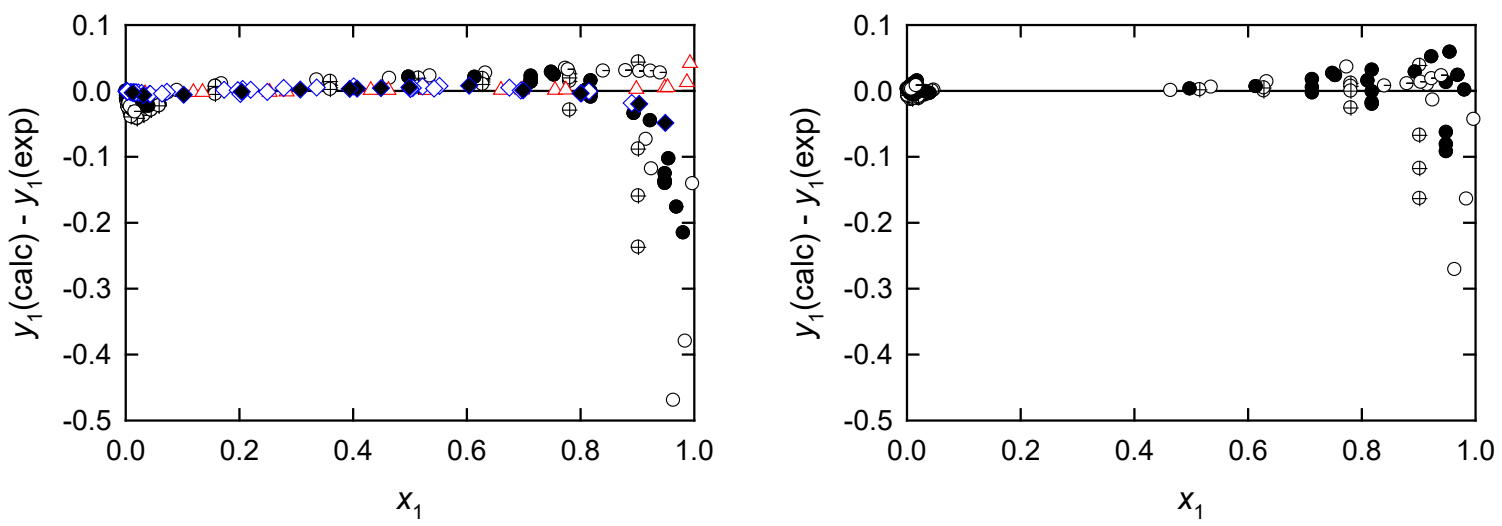

C

$d$

Fig. 8. Comparison of the predicted and experimental pressures $P$ and first-component mole fractions $y_{1}$ in the gas phase at different first-component mole fractions in the liquid phase $x_{1}$ for the binaries of furan derivatives with water: a, c, NIST-COSMO-SAC; b, d: NISTModified UNIFAC.

Circles are for 2-furaldehyde + water: $\bigcirc$, Mains [63]; $\bullet$, Pearce and Gerster [64]; $\oplus$, Tsirlin [65]; $\mathbf{O}$, Kharin et al. [60]; $\boldsymbol{\odot , ~ N i ~ a n d ~ W a n g ~ [ 5 8 ] ; ~} \boldsymbol{\oplus}$, Staroske and Schuberth [66]; $\odot$, Sunder and Prasad [67].

Red triangles are for furfuryl alcohol + water: $\triangle$, Boldyrev et al. [68]; $\boldsymbol{\Delta}$, Dudutkina et al. [69].

Blue diamonds are for $\gamma$-valerolactone + water: $\diamond$, Havasi et al. [70]; $\diamond$, Zaitseva et al. [71]. 
Table 3. Statistical analysis of the reported data.

\begin{tabular}{|c|c|c|c|c|}
\hline \multirow[t]{2}{*}{ Subset } & \multicolumn{2}{|c|}{ NIST-COSMO-SAC } & \multicolumn{2}{|c|}{ NIST-mod. UNIFAC } \\
\hline & $($ Rel. std. dev. for $p) \cdot 100$ & Std. dev. for $y$ & $($ Rel. std. dev. for $p) \cdot 100$ & Std. dev. for $y$ \\
\hline \multicolumn{5}{|c|}{ Furan derivatives } \\
\hline All data & 12.8 & 0.042 & 10.6 & 0.045 \\
\hline Organics only & 8.8 & 0.038 & 10.7 & 0.045 \\
\hline Cleaned dataset w/o water ${ }^{a}$ & 8.2 & 0.034 & 10.6 & 0.045 \\
\hline \multicolumn{5}{|c|}{ Phenolic compounds } \\
\hline All data & 20.5 & 0.055 & 19.5 & 0.069 \\
\hline Organics only & 20.9 & 0.053 & 19.7 & 0.068 \\
\hline Cleaned dataset $w / o$ water ${ }^{a}$ & 12.3 & 0.052 & 15.2 & 0.067 \\
\hline
\end{tabular}




\subsection{VLE for phenolic compounds}

The considered main components are listed in Table 1 . Out of 2838 points, 1238 were reported for the phenol binaries; 1511 points are available for monomethylphenols. The points for (phenol + methylphenol) are included in both scores. The high availability of the methylphenol data is explained by the activity of Prasad et al. who reported the results for 32 binaries of phenols with alcohols, dimethylbenzenes, and ethylbenzene $[95,96,99,103,143,145]$. A significant contribution to the VLE studies for phenolic compounds was also made by Weissenberger et al. [84,93,94,104,124,134,135,136,146]. The gas-phase compositions were only reported for $36 \%$ of the data points. In many cases, the component volatilities differed significantly, and the more volatile component predominated in the gas phase.

\subsubsection{VLE with two phenolic compounds}

The phenol mixtures with methylphenols are close to the ideal ones. The pressures predicted with both models are in very good agreement with the experimental results (Fig. 9). The predictions for (1,2-benzenediol + 4-methylphenol) and (1,2-benzenediol + 4methoxyphenol) (Fig. 10) are also consistent with the experimental data [79]. The only exception is the pressure over pure 1,2-benzenediol at $T=423.15 \mathrm{~K}$, which is inconsistent with multiple data available in the literature, per the data analysis performed with NIST ThermoData Engine. For (1,2-benzenediol + 1,4-benzenediol), however, both models consistently predict the experimental pressure of about $25 \mathrm{kPa}$ instead of $20 \mathrm{kPa}$ reported in the original publication [80] despite this mixture is expected to behave as an ideal solution. We believe the results from that work may be incorrect and should not be used. For methylphenols, the agreement between the experimental and predicted values is generally very good (Figs. 11 and 12).

The experimental and predicted gas-phase compositions typically agree within \pm 0.04 mole fraction. However, differences up to 0.1 mole fraction are observed for some systems (Figs. $10 \mathrm{c}, 10 \mathrm{~d}, 12 \mathrm{~d})$. 


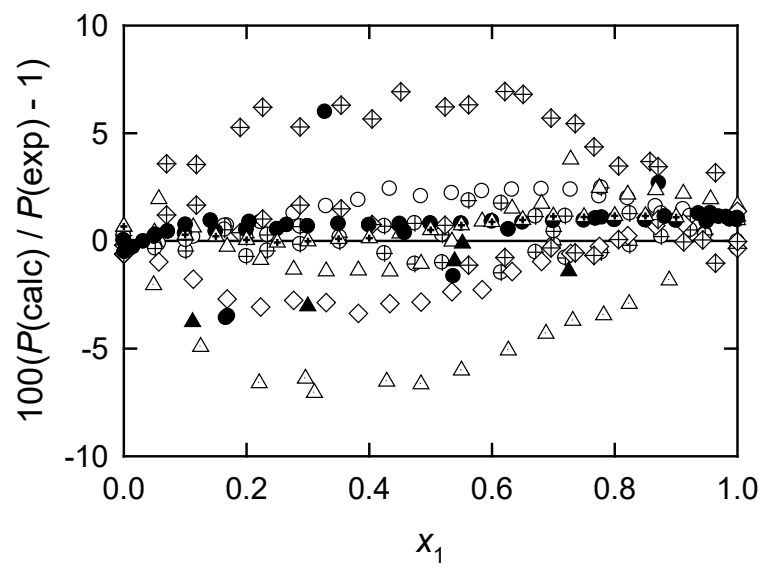

$a$

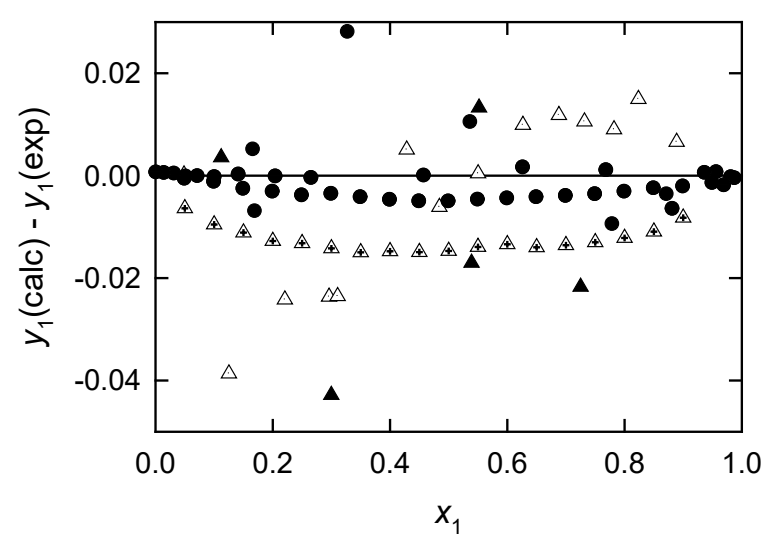

c

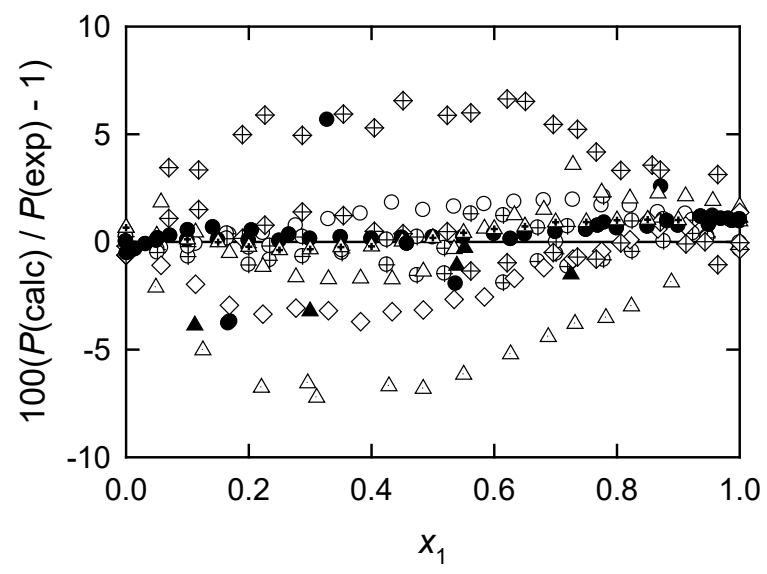

$b$

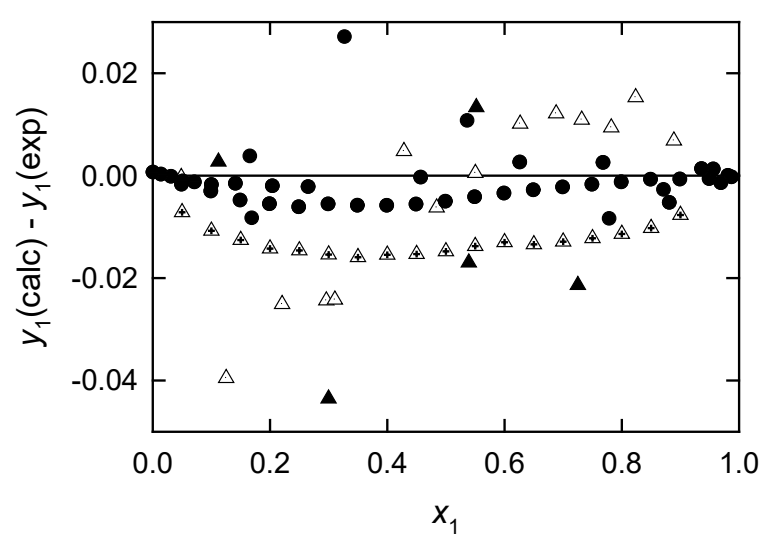

$d$

Fig. 9. Comparison of the predicted and experimental pressures $P$ and first-component mole fractions $y_{1}$ in the gas phase at different first-component mole fractions in the liquid phase $x_{1}$ for the binaries of phenol with methylphenols: a, c, NIST-COSMO-SAC; b, d: NISTModified UNIFAC.

Circles are for phenol + 2-methylphenol: O, Fox and Barker [72]; $\mathbf{O}$, Schneider and Oberkobusch [73]; $\bullet$, Vostrikova et al. [74]; $\bullet$, Clausse et al. [75]; $\oplus$, Selvam et al. [76].

Triangles are for phenol + 3-methylphenol: $\triangle$, Fox and Barker [72]; $A$, Schneider and Oberkobusch [73]; Vostrikova et al. [77]; $\triangle$, Cepeda et al. [78].

Diamonds are for phenol + 4-methylphenol: $\diamond$, Fox and Barker [72]; $\diamond$, Selvam et al. [76]. 


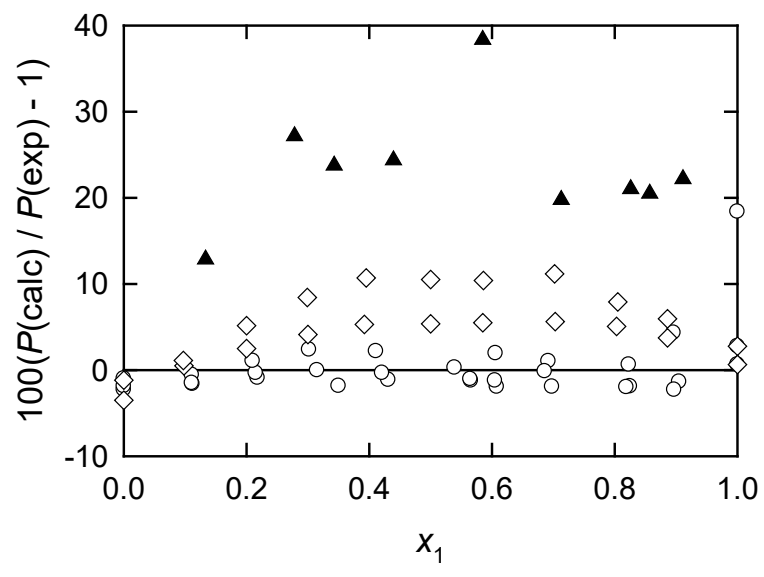

$a$

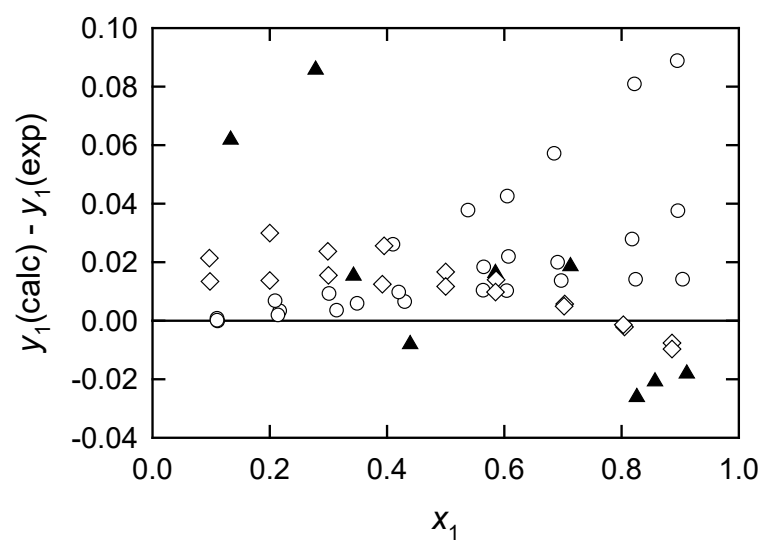

c

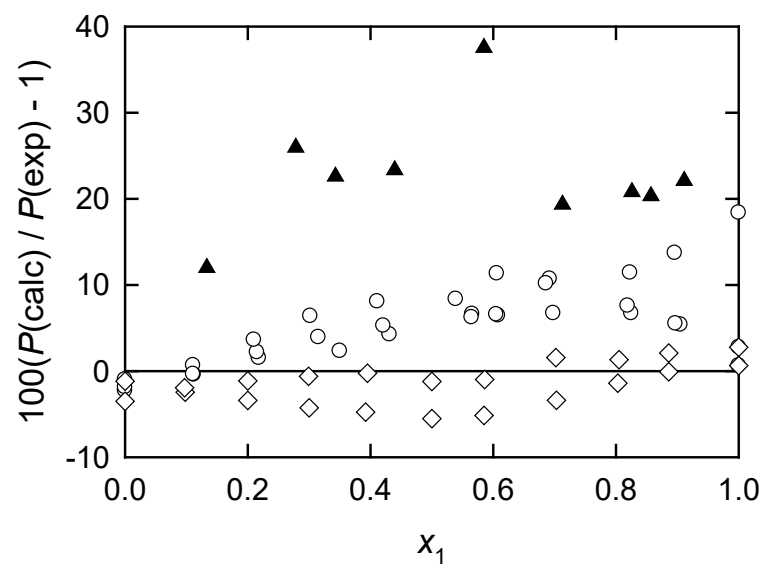

$b$

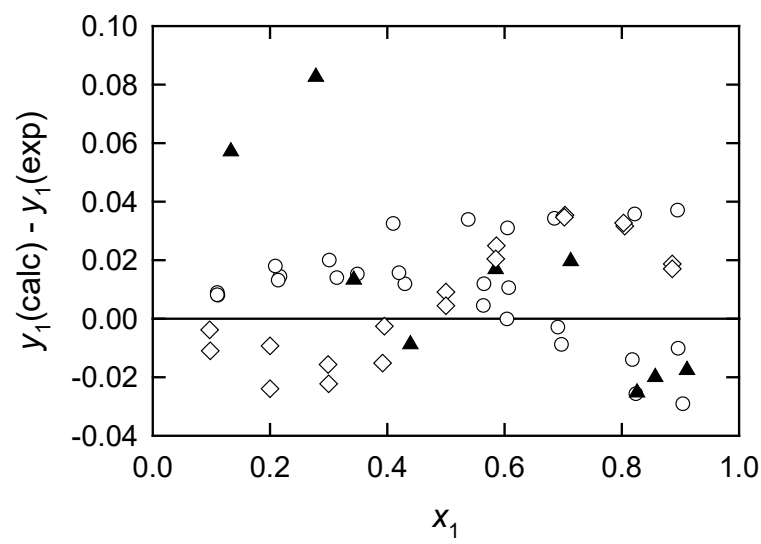

$d$

Fig. 10. Comparison of the predicted and experimental pressures $P$ and first-component mole fractions $y_{1}$ in the gas phase at different first-component mole fractions in the liquid phase $x_{1}$ for the 1,2-benzenediol binaries: a, c, NIST-COSMO-SAC; b, d: NIST-Modified UNIFAC.

Circles $(O)$ are for 1,2-benzenediol + 4-methylphenol, Hwang et al. [79].

Triangles $(\mathbf{\Delta})$ are for 1,2-benzenediol + 1,4-benzenediol, Shi et al. [80].

Diamonds $(\diamond)$ are for 1,2-benzenediol +4 -methoxyphenol, Hwang et al. [79]. 


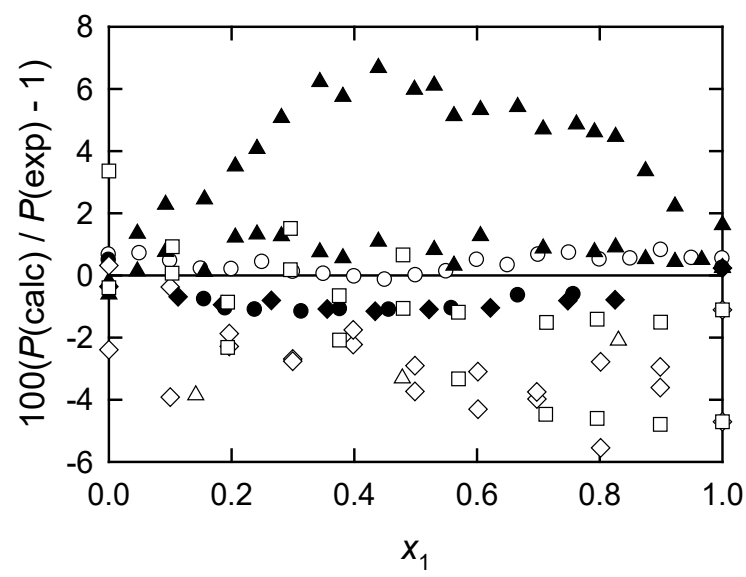

$a$

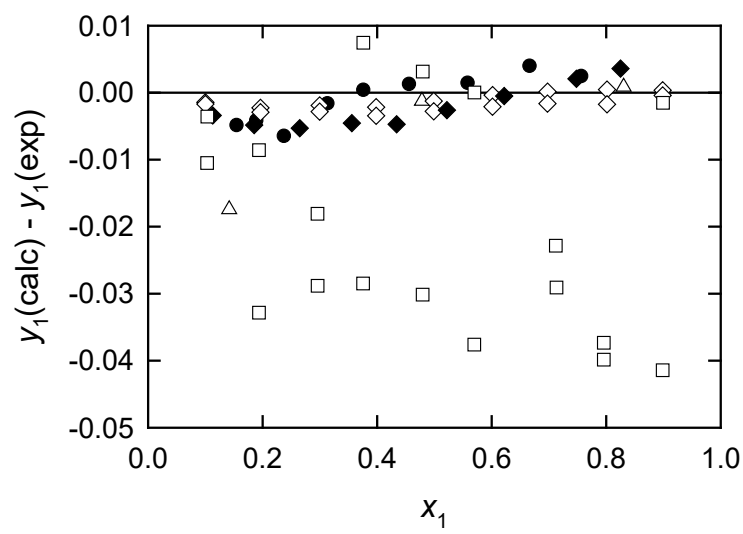

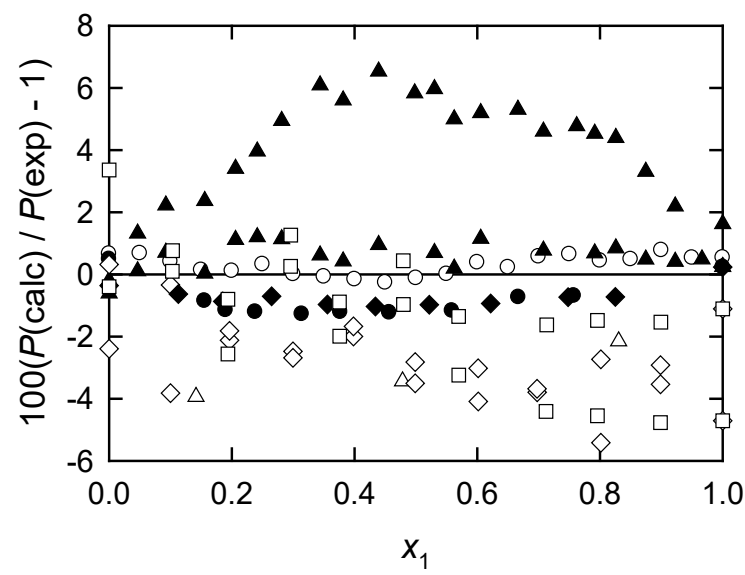

$b$

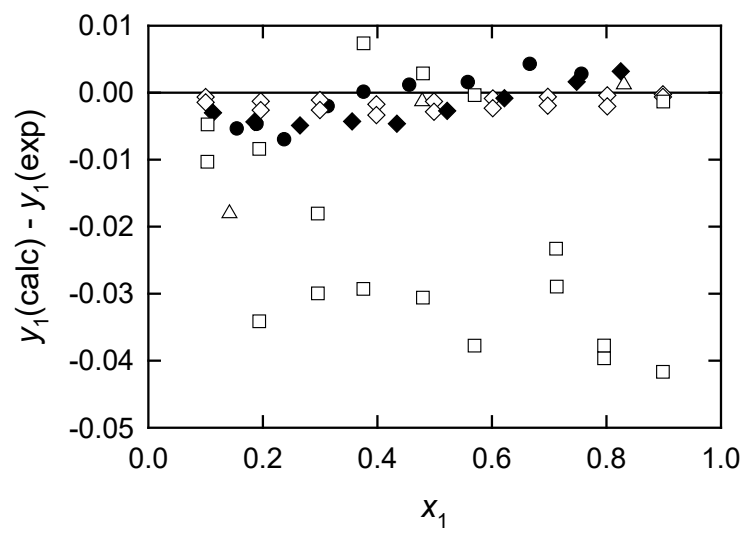

$d$

Fig. 11. Comparison of the predicted and experimental pressures $P$ and first-component mole fractions $y_{1}$ in the gas phase at different first-component mole fractions in the liquid phase $x_{1}$ for the 2-methylphenol binaries: a, c, NIST-COSMO-SAC; $b$, d: NIST-Modified UNIFAC.

Circles are for 2-methylphenol + 3-methylphenol: O, Fox and Barker [72]; $\bullet$, Wang et al. [81].

Triangles are for 2-methylphenol + 4-methylphenol: $\triangle$, Vostrikova et al. [82]; $\boldsymbol{\Delta}$, Selvam et al. [76].

Diamonds are for 2-methylphenol + 2,6-dimethylphenol: $\diamond$, Ye et al. [83]; $\diamond$, Wang et al. [81]. Squares $(\square)$ are for 2-methylphenol +2,4,6-trimethylphenol, Ye et al. [83]. 


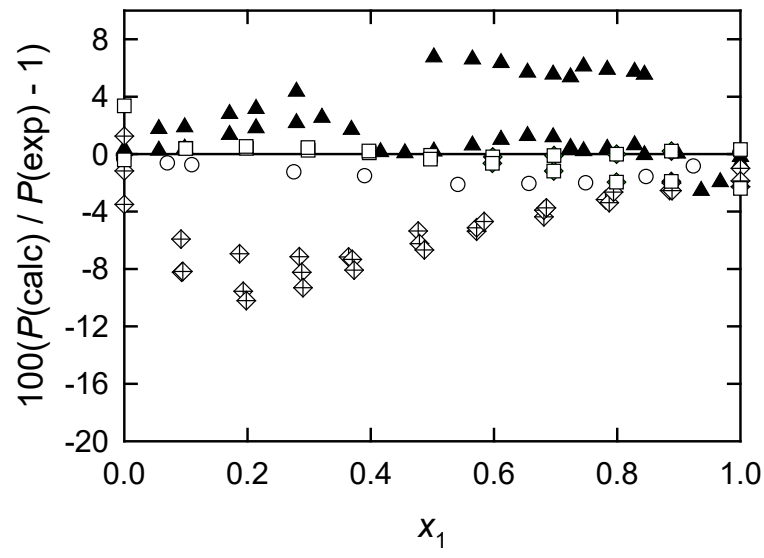

$a$

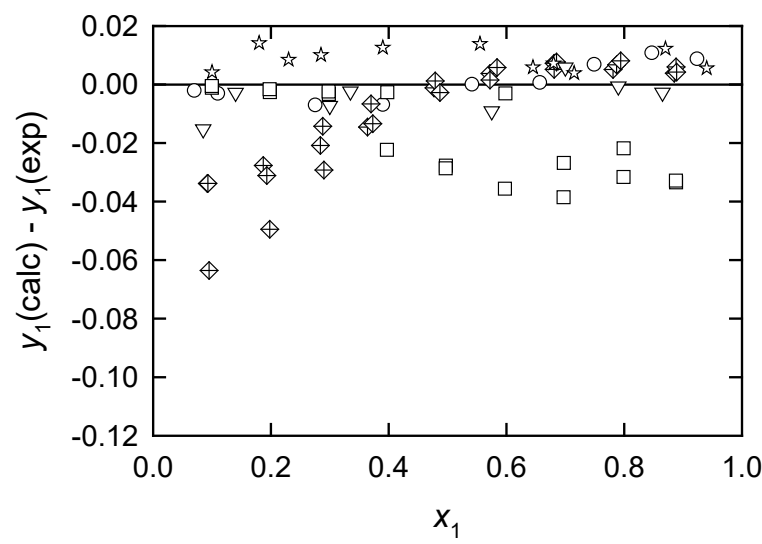

$c$

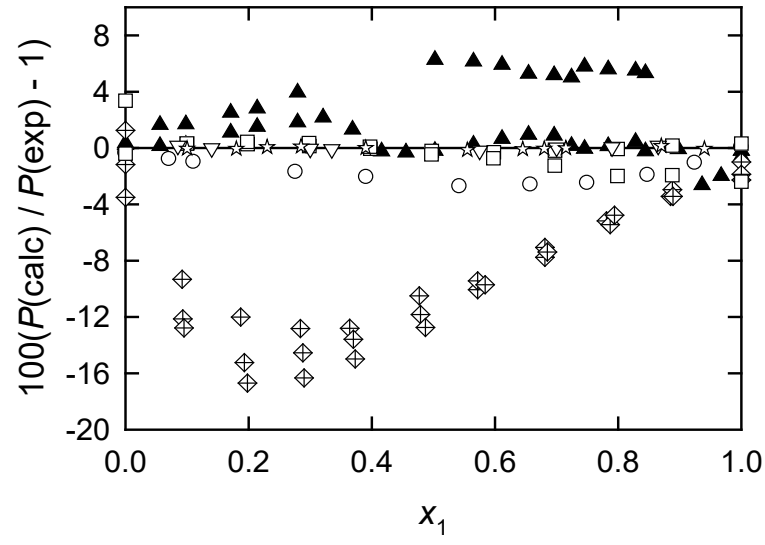

$b$

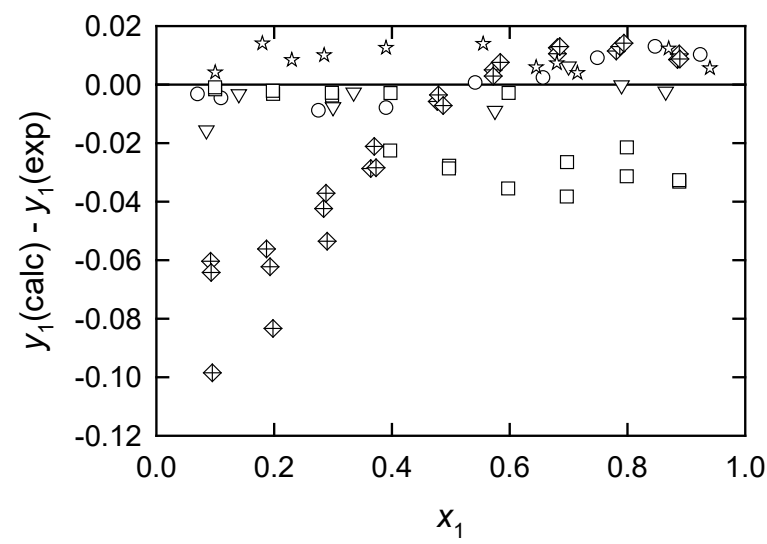

$d$

Fig. 12. Comparison of the predicted and experimental pressures $P$ and first-component mole fractions $y_{1}$ in the gas phase at different first-component mole fractions in the liquid phase $x_{1}$ for the binaries with methylphenols: a, c, NIST-COSMO-SAC; b, d: NIST-Modified UNIFAC.

Circles $(O)$ are for 3-methylphenol + 2,6-dimethylphenol, Wang et al. [81].

Triangles $(\mathbf{\Delta})$ are for 4-methylphenol + 2,4-dimethylphenol, Selvam et al. [76].

Diamonds $(\oplus)$ are for 4-methylphenol + 4-methoxyphenol, Hwang et al. [79].

Triangles down $(\nabla)$ are for 2,5-dimethylphenol + 3,5-dimethylphenol, Schneider and Oberkobusch [73]. The equilibrium temperature for the point at $x_{1}=0.200$ is inconsistent with the other results and not shown here.

Stars (访) are for 3,4-dimethylphenol + 3,5-dimethylphenol, Schneider and Oberkobusch [73].

Squares $(\square)$ are for 2,6-dimethylphenol + 2,4,6-trimethylphenol, Ye et al. [83]. 


\subsubsection{VLE with benzene and alkylbenzenes}

Agreement between the experimental and predicted values for the binaries with phenol is very good at the low content of phenol and satisfactory when its mole fraction is high (Fig. 13). For the other phenols, the results of Prasad et al. $[95,96,99,103]$ predominate. Significant data scatter and the non-systematic nature of the deviations (empty symbols in Figs. 14-16) for chemically similar systems indicate that these results have a large uncertainty. For example, the maximum deviation of the vapor pressures predicted with NIST-COSMO-SAC from the experimental values are $40 \%, 30 \%, 19 \%$, and $7 \%$ for the 2-methylphenol binaries with 1,3-dimethyl-, 1,2-dimethyl-, ethyl-, and 1,4-dimethylbenzene, respectively. The trend remains for the predictions with NIST-modified UNIFAC though the magnitude of deviations change. Even larger (>150 \%) non-systematic deviations can be found in the data for alkylphenols with alcohols discussed below. For many binaries, the results by Prasad et $a l$. are the only available data. However, one should avoid using them because of their low reliability.

The NIST-COSMO-SAC predicted pressures for the isomeric methylphenol binaries with benzene and the phenol binaries with benzene and toluene systematically deviate from the values reported by Weissenberger et al. [84,93]. The deviation is lower for the predictions with the NIST-modified UNIFAC. All results from these works seem to have a large uncertainty though poor model performance cannot be fully excluded. More experimental data are necessary to resolve this inconsistency.

The (3-methylphenol + benzene) pressures reported by Savitt and Othmer [97] and the gasphase compositions of 2-methylnaphthalene binaries from the same laboratory [100] have anomalously high deviations from the values predicted by both models (Figs. 15 and 16). The pressures [97] have the largest deviations among all similar systems and seem to have a large uncertainty of the reported VLE temperatures. The gas-phase composition problem is not that obvious. These results are the only data for 2-methylnaphthalene mixtures at $P=101 \mathrm{kPa}$ and the equilibrium temperatures are high (close to $500 \mathrm{~K}$ ). Therefore, the available information is not conclusive and more experimental efforts are required to resolve this inconsistency.

The pressures of (2-methoxyphenol + benzene) [104] significantly deviate from the ones predicted with NIST-modified UNIFAC (Fig. 16b). This inconsistency is not observed for the NIST-COSMO-SAC predictions and is probably due to parameterization of the former model. 


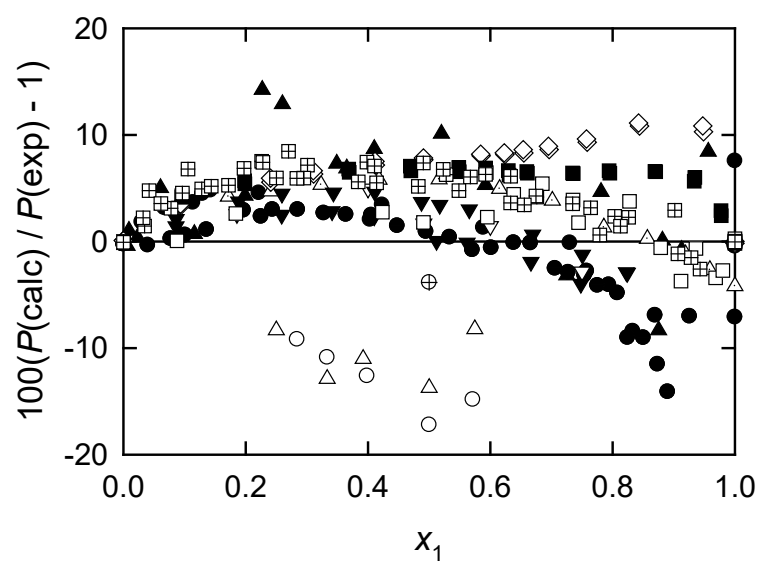

$a$

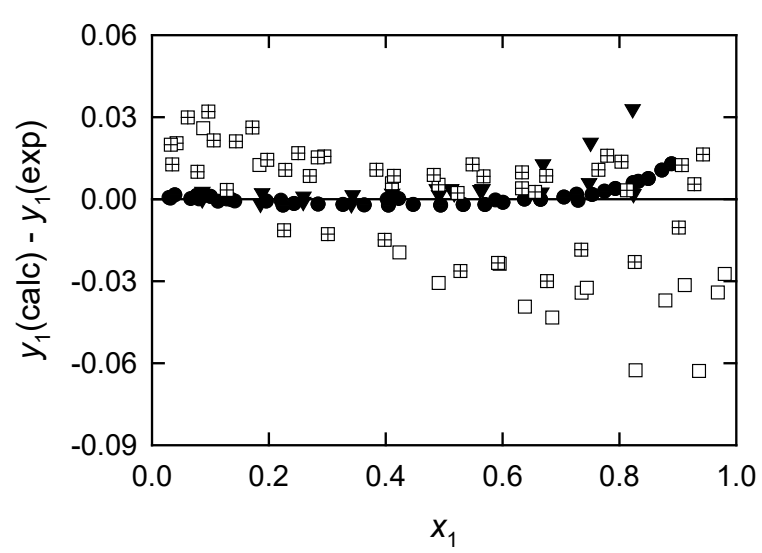

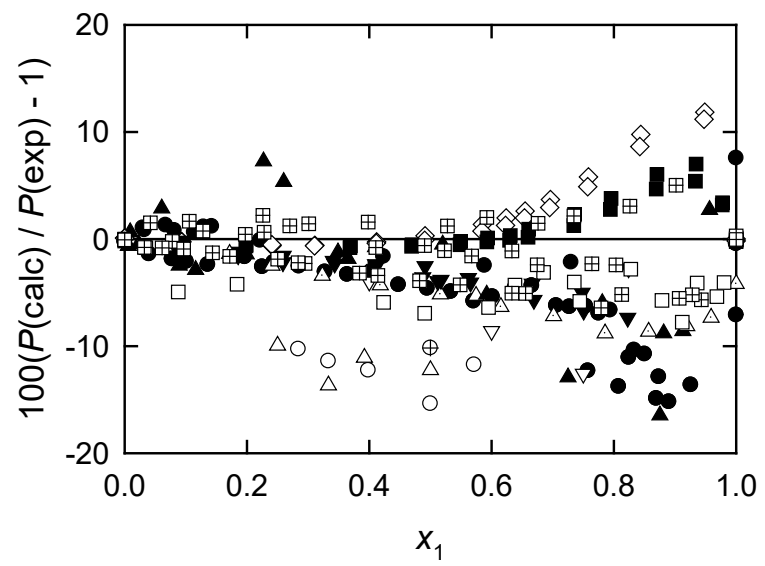

$b$

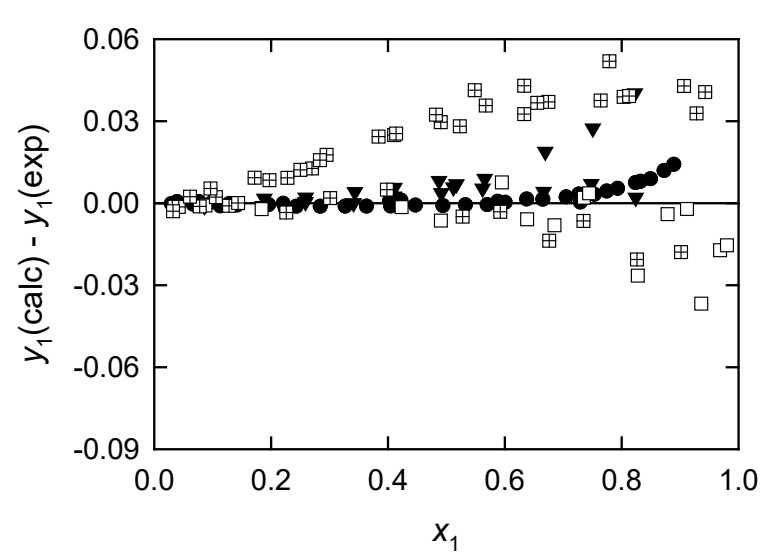

$c$

$d$

Fig. 13. Comparison of the predicted and experimental pressures $P$ and first-component mole fractions $y_{1}$ in the gas phase at different first-component mole fractions in the liquid phase $x_{1}$ for the binaries of phenol with alkylbenzenes: a, c, NIST-COSMO-SAC; b, d: NISTModified UNIFAC.

Circles are for phenol + benzene: $\bigcirc$, Weissenberger et al. [84]; $\bullet$, Martin and George [85]; $\oplus$, Garner and Ellis [36]; $\gg$, Gmehling [86]; $\boldsymbol{O}$, Nienhaus et al. [87].

Triangles are for phenol + toluene: $\triangle$, Weissenberger et al. [84]; $\mathbf{\Delta}$, Drickamer et al. [88]; $\nabla$, Garner and Ellis [36]; $\triangle$, Nienhaus et al. [87]; $\boldsymbol{\nabla}$, Klauck et al. [89].

Diamonds $(\diamond)$ are for phenol + ethylbenzene, Anderko [90].

Squares are for phenol + isopropylbenzene: $\square$, Byk and Stroiteleva [91]; $\mathbf{\square}$, Anderko [90]; $\boxplus$, Cepeda et al. [92]. 


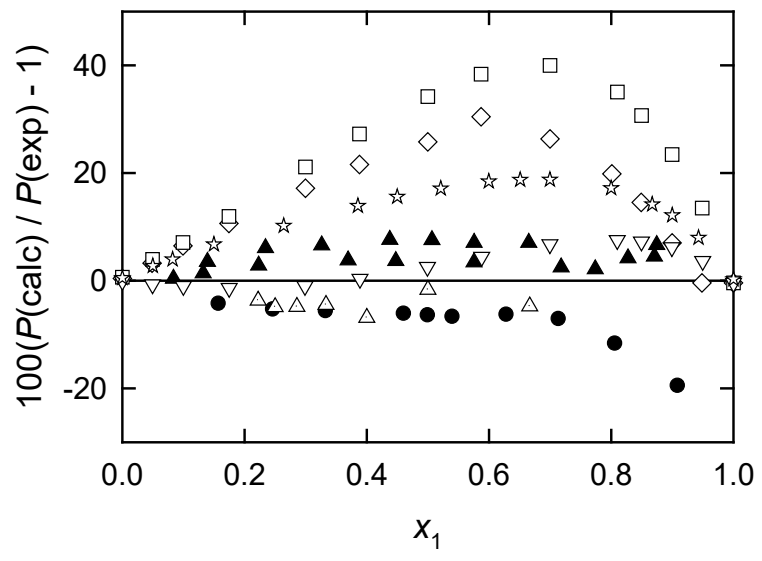

$a$

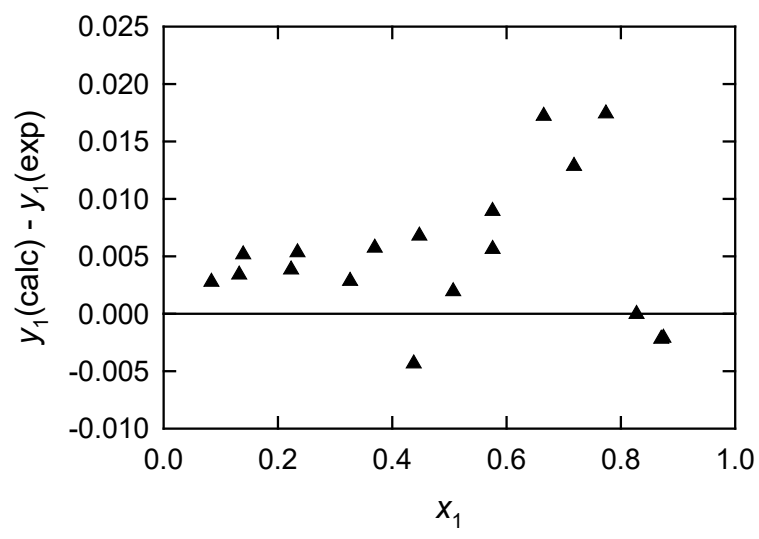

c

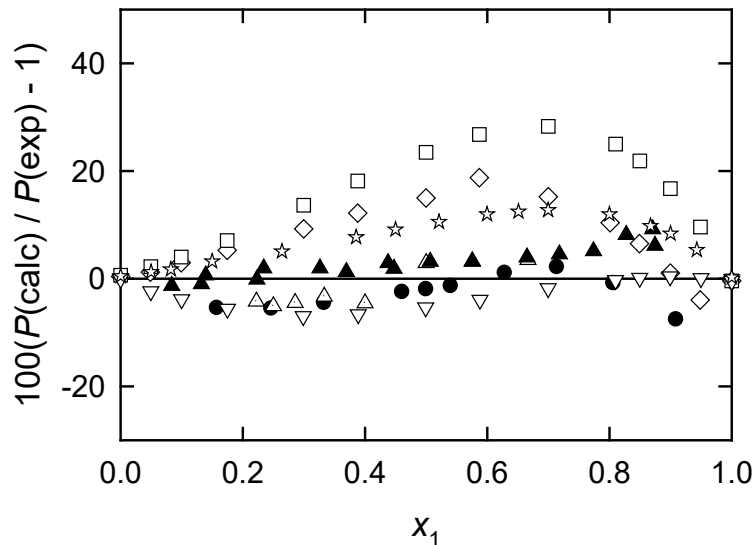

b

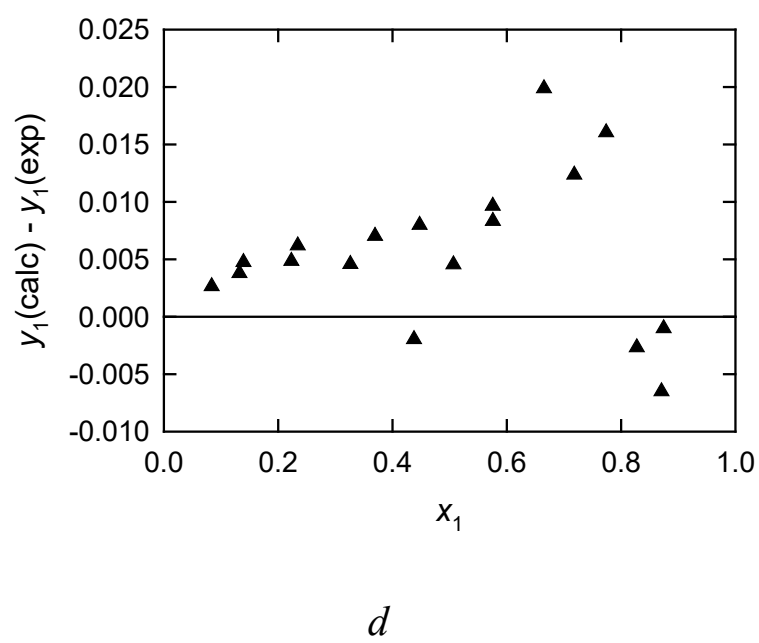

Fig. 14. Comparison of the predicted and experimental pressures $P$ and first-component mole fractions $y_{1}$ in the gas phase at different first-component mole fractions in the liquid phase $x_{1}$ for the binaries of 2-methylphenol with alkylbenzenes: a, c, NIST-COSMO-SAC; b, d: NIST-Modified UNIFAC.

Circles (•) are for 2-methylphenol + benzene, Weissenberger and Piatti [93].

Triangles are for 2-methylphenol + toluene: $\triangle$, Weissenberger et al. [94]; $\boldsymbol{\Delta}$, Klauck et al. [89].

Diamonds $(\diamond)$ are for 2-methylphenol + 1,2-dimethylbenzene, Prasad et al. [95].

Squares $(\square)$ are for 2-methylphenol + 1,3-dimethylbenzene, Prasad et al. [95]. Triangles down $(\nabla)$ are for 2-methylphenol + 1,4-dimethylbenzene, Prasad et al. [95]. Stars (it) are for 2-methylphenol + ethylbenzene, Prasad et al. [96]. 


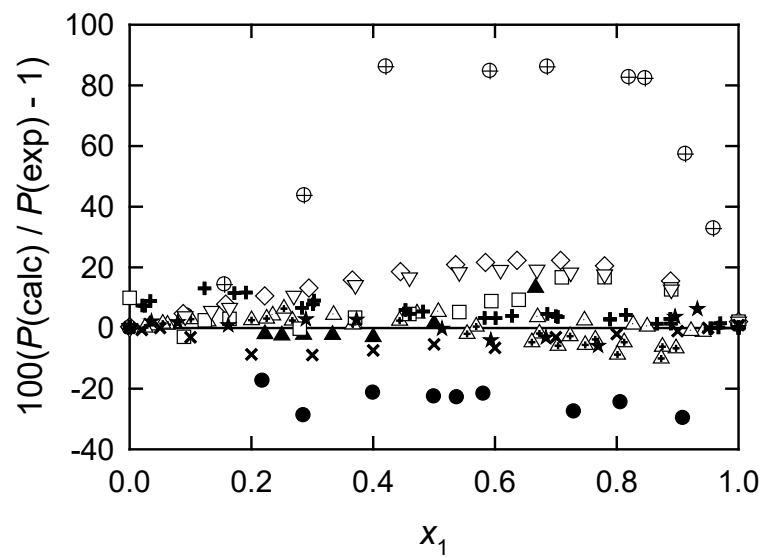

$a$

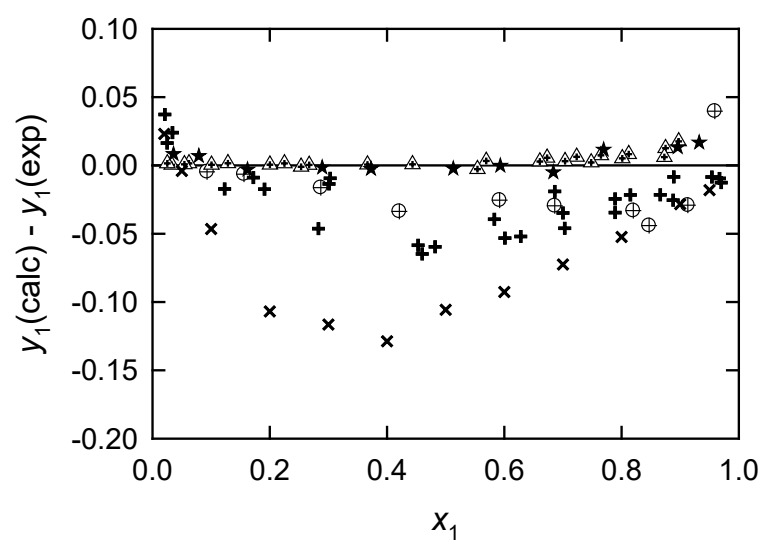

$c$

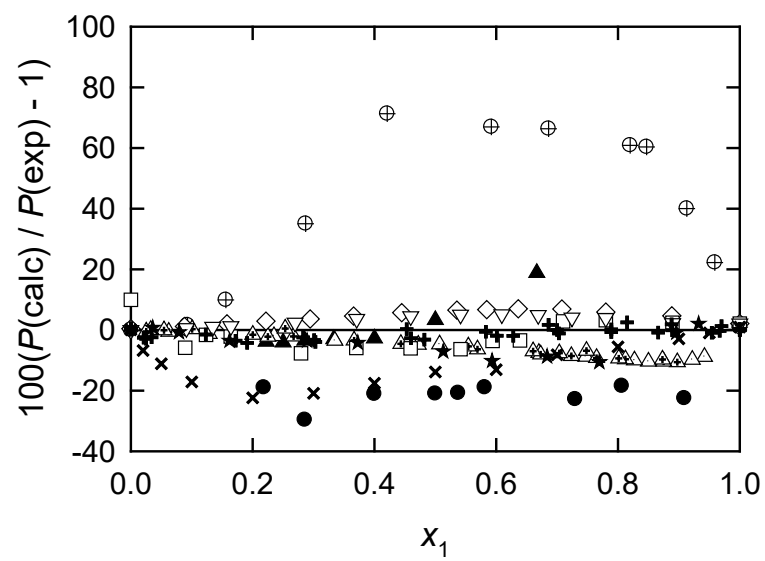

$b$

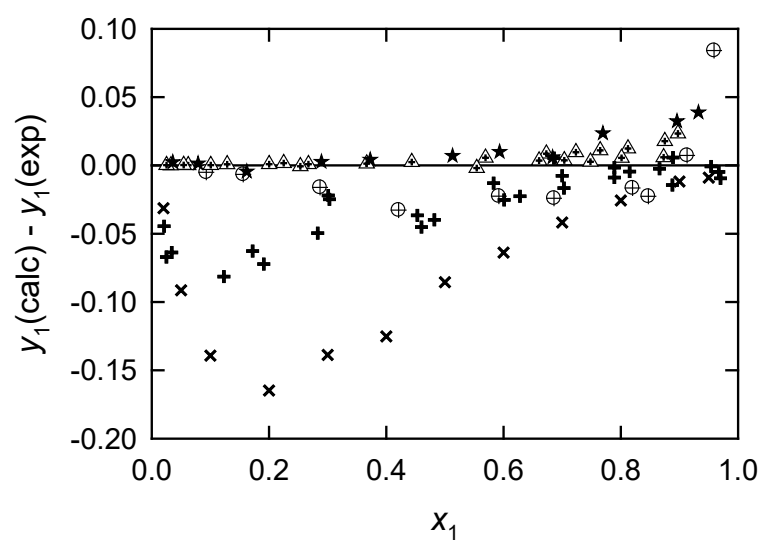

$d$

Fig. 15. Comparison of the predicted and experimental pressures $P$ and first-component mole fractions $y_{1}$ in the gas phase at different first-component mole fractions in the liquid phase $x_{1}$ for the binaries of 3-methylphenol with alkylbenzenes and 2-methylnaphthalene: a, c, NISTCOSMO-SAC; b, d: NIST-Modified UNIFAC.

Circles are for 3-methylphenol + benzene: $\bullet$, Weissenberger and Piatti [93]; $\oplus$, Savitt and Othmer [97]. Triangles are for 3-methylphenol + toluene: $\boldsymbol{\Delta}$, Weissenberger et al. [94]; $\triangle$, Sartakova et al. [98]; $\Delta$, Klauck et al. [89].

Diamonds $(\diamond)$ are for 3-methylphenol + 1,2-dimethylbenzene, Prasad et al. [99].

Squares $(\square)$ are for 3-methylphenol + 1,3-dimethylbenzene, Prasad et al. [99].

Triangles down $(\nabla)$ are for 3-methylphenol + 1,4-dimethylbenzene, Prasad et al. [99].

Stars $(\star)$ are for 3-methylphenol + isopropylbenzene, Cepeda et al. [78].

3-methylphenol + 2-methylnaphthalene: $\times$, Othmer et al. [100]; +, Schmelzer et al. [101]. 


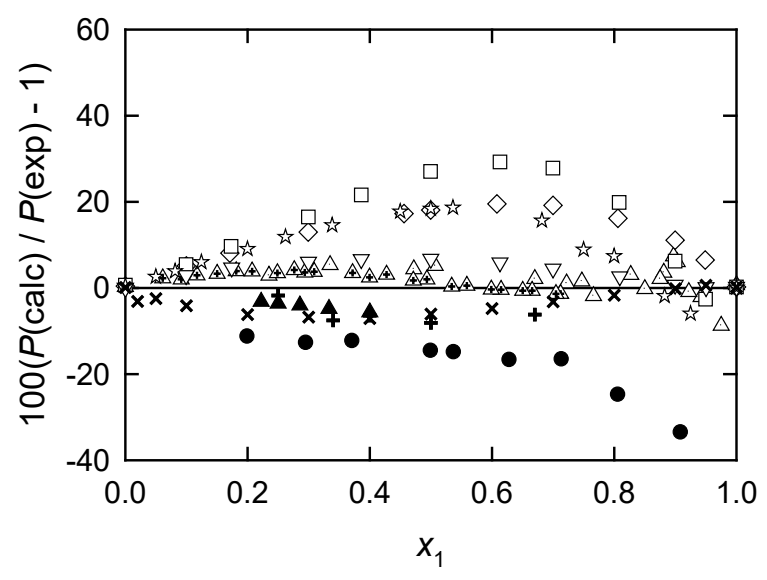

$a$

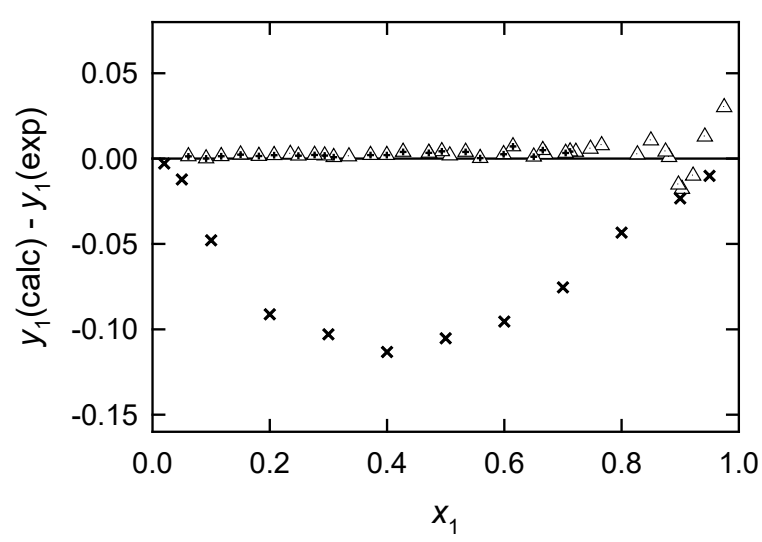

c

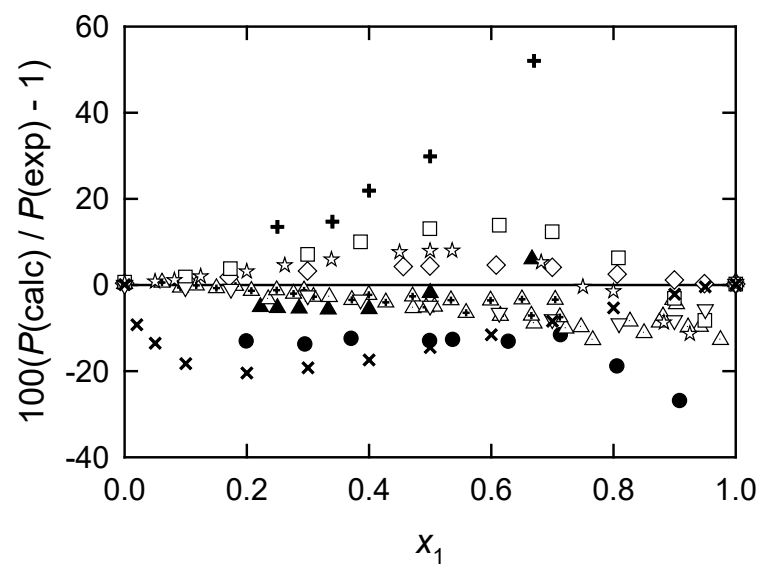

$b$

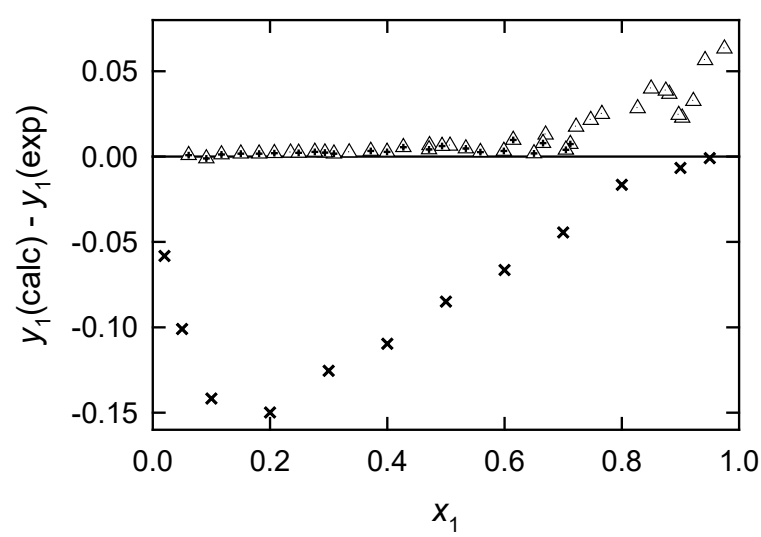

$d$

Fig. 16. Comparison of the predicted and experimental pressures $P$ and first-component mole fractions $y_{1}$ in the gas phase at different first-component mole fractions in the liquid phase $x_{1}$ for the binaries of 4-methylphenol and 2-methoxyphenol with alkylbenzenes: a, c, NIST-

COSMO-SAC; b, d: NIST-Modified UNIFAC.

Circles $(\bullet)$ are for 4-methylphenol + benzene, Weissenberger and Piatti [93].

Triangles are for 4-methylphenol + toluene: $\boldsymbol{\Delta}$, Weissenberger et al. [94]; $\triangle$, Marks and Wingard [102]; $\mathbb{A}$, Klauck et al. [89].

Diamonds $(\diamond)$ are for 4-methylphenol + 1,2-dimethylbenzene, Prasad et al. [103].

Squares $(\square)$ are for 4-methylphenol + 1,3-dimethylbenzene, Prasad et al. [103].

Triangles down $(\nabla)$ are for 4-methylphenol + 1,4-dimethylbenzene, Prasad et al. [103].

Stars ( 3 ) are for 4-methylphenol + ethylbenzene, Prasad et al. [96].

Crosses $(X)$ are for 4-methylphenol + 2-methylnaphthalene, Othmer et al. [100].

Pluses $(+)$ are for 2-methoxyphenol + benzene, Weissenberger et al. [104]. 


\subsubsection{VLE with methoxybenzene}

VLE phenol derivatives with methoxybenzene has been studied in two works [105, 106]

(Fig. 17). Lebedeva et al. [105] reported VLE of phenol and 2-methylphenol with methoxybenzene at $P=13.3 \mathrm{kPa}$. NIST-COSMO-SAC predicts pressures of (15 to 17$) \mathrm{kPa}$ for most points. NIST-Modified UNIFAC has better agreement with the experimental values for $($ phenol + methoxybenzene $)$ at $x($ phenol $)=(0.3$ to 0.9$)$. Unlike the gas-phase compositions obtained with the NIST-modified UNIFAC, the ones predicted with the NISTCOSMO-SAC for (phenol + methoxybenzene) were consistent with the experimental values. The models are consistent for $P$ and $y$ of (2-methylphenol + methoxybenzene), but inconsistent with experimental results.

Both pressures and gas-phase compositions for (2-methoxyphenol + methoxybenzene) [106] agree with the model predictions very well. All considered systems have similar intermolecular interactions. Thus, in the former work, the experimental problems seem to occur.

\subsubsection{VLE with water}

In this group (Figs. 18 and 19), (phenol + water) is the most studied binary. The volatility of water is significantly higher than that of the phenols, and their mole fraction in the gas phase remains small over a wide range of liquid compositions. The differences between the predicted and experimental gas-phase mole fractions are expectedly small up to $x$ (phenols) $=$ 0.95 .

Good agreement between the experimental and predicted pressures for (phenol + water) holds at $x$ (phenol) $<0.4$. At higher $x$ (phenol), the deviations increase reaching $\pm 80 \%$ at the right-hand side of the graphs. Typically, the predicted values are higher than the experimental ones. At least, four problematic sources can be identified. The pressures reported by Campbell and Campbell for SVLE [111] are about $40 \%$ lower than the predicted values over the considered concentration range $\left(x_{1}=(0.38\right.$ to 0.87$\left.)\right)$ and significantly deviate from most other experimental data at $x_{1}<0.6$. The gas-phase compositions from this work are reasonable. Thus, one can conclude that the problem is due to incorrect pressure measurements.

The pressures reported by Kiva et al. [116] originate from the same laboratory as the problematic data [105] discussed above. Their reliability is questionable as well. The scatter of the data of Shi et al. [80] is very large. The irregular deviations from the pressures predicted with NIST-COSMO-SAC vary from (1 to 86$) \%$, which is highly unexpected. Brusset and Gaynès [112] reported VLE for (phenol + water) and (2-methylphenol + water). For these systems, large deviations from the pressures and mole fractions predicted with both models are observed at the large content of the phenols. For (phenol + water), these deviations are not supported by other experimental data at high $x_{1}$ including those of Chou et al. [121] at the same pressure. The reliability of these results is questionable.

All (phenol + water) pressures reported by Schükarew [108] are in very good agreement with the predictions except the one at $x_{1}=0.8511$. The vapor pressure of phenol at $T=288.2 \mathrm{~K}$ [113] is too low for the liquid phase and should be assigned to the crystal. 
After exclusion of the problematic data, the data scatter for the pressure over (phenol + water) becomes comparable with that for the other binaries. We believe that the large scatter for (water + furan derivatives) discussed above (Fig. 8) is partially caused by issues in the experimental data as well, although no compelling reason to exclude these data could be identified. More efforts are needed to further clarify this.
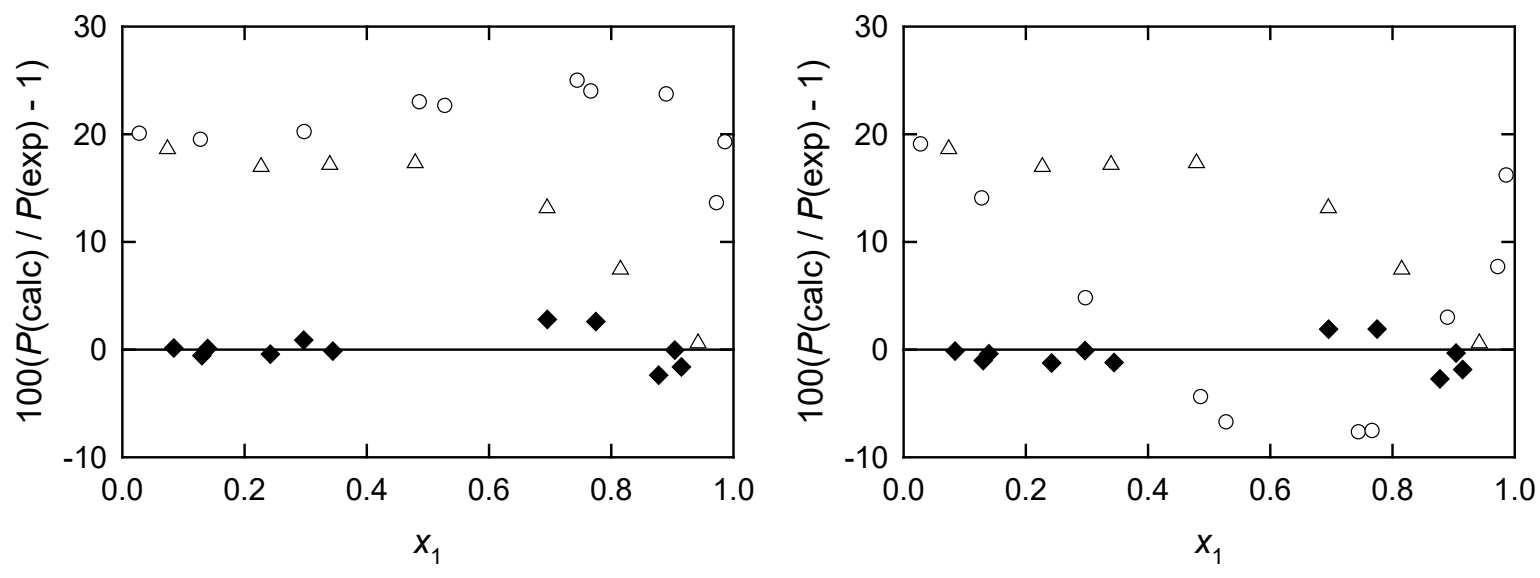

$a$
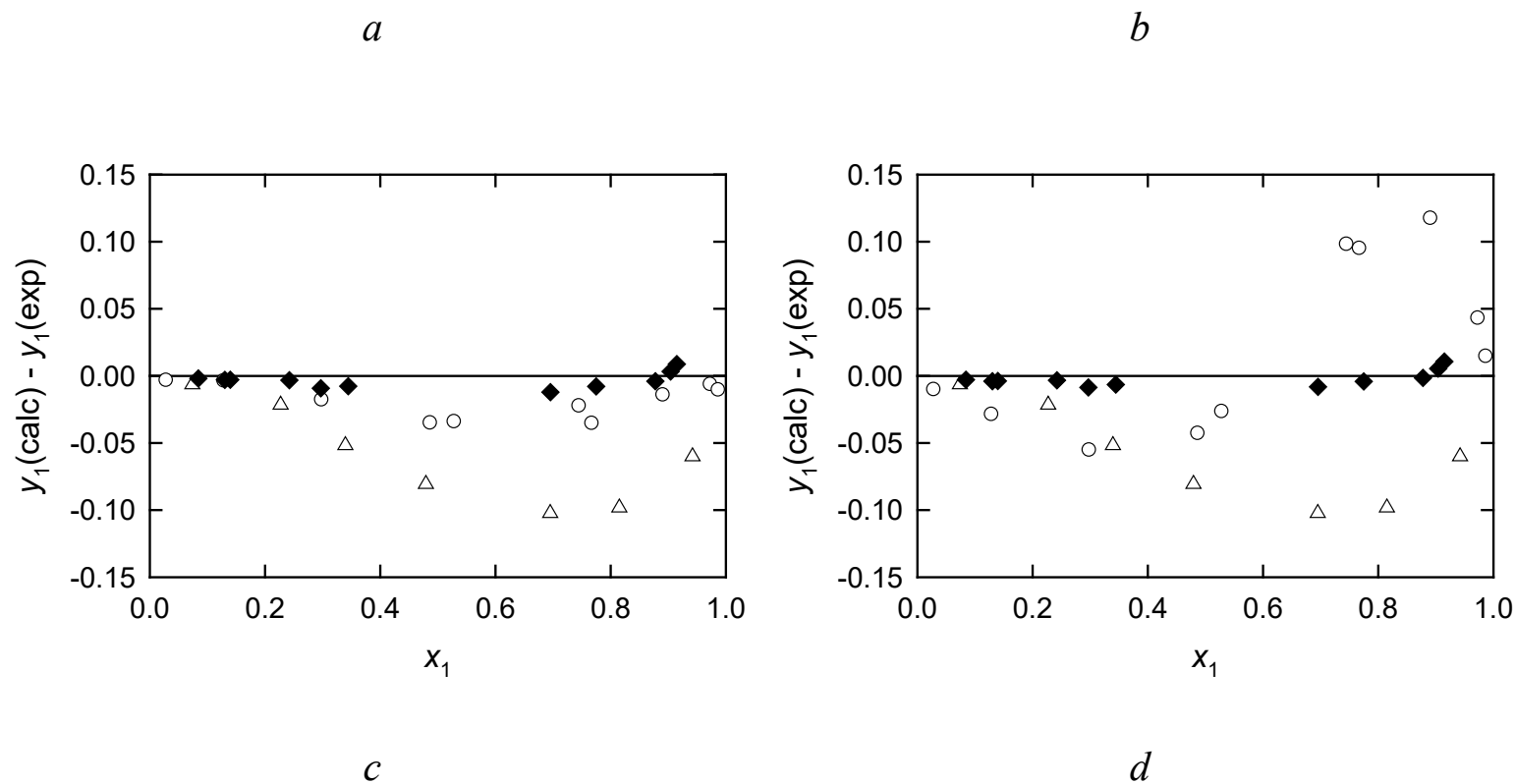

Fig. 17. Comparison of the predicted and experimental pressures $P$ and first-component mole fractions $y_{1}$ in the gas phase at different first-component mole fractions in the liquid phase $x_{1}$ for the binaries with methoxybenzene: a, c, NIST-COSMO-SAC; b, d: NIST-Modified UNIFAC.

Circles (O) are for phenol + methoxybenzene, Lebedeva et al. [105].

Triangles $(\triangle)$ are for 2-methylphenol + methoxybenzene, Lebedeva et al. [105].

Diamonds $(\diamond)$ are for 2-methoxyphenol + methoxybenzene, Li et al. [106]. 


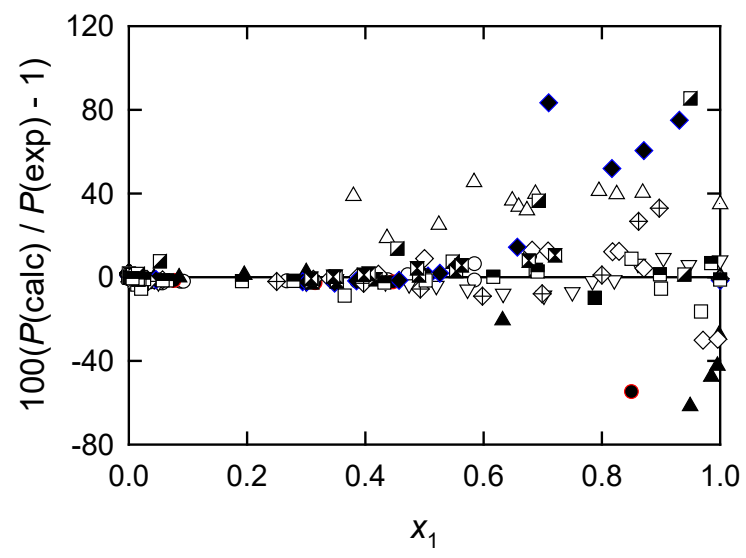

$a$

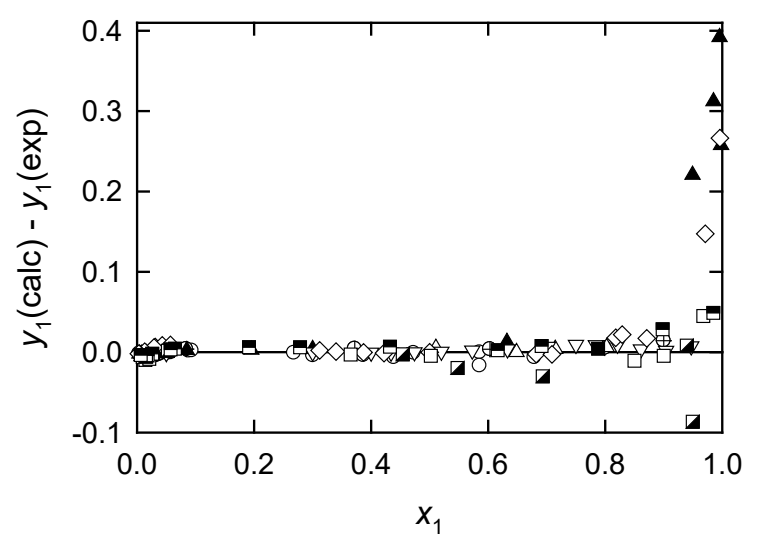

$c$

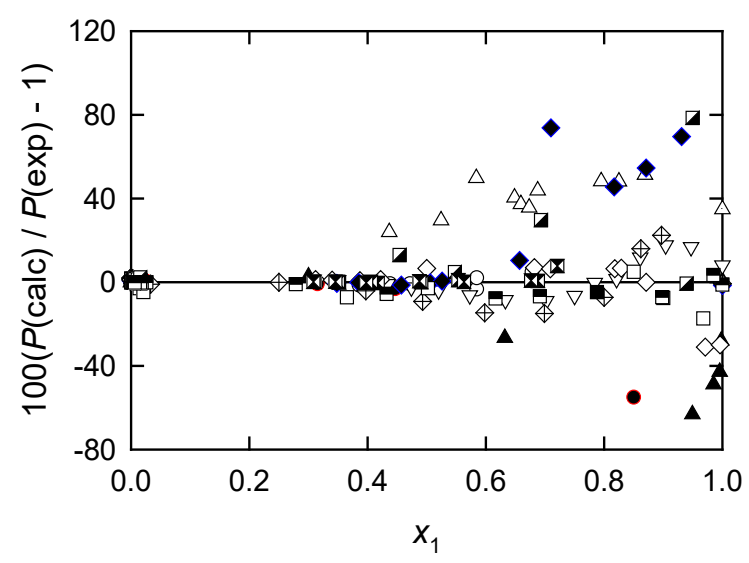

$b$

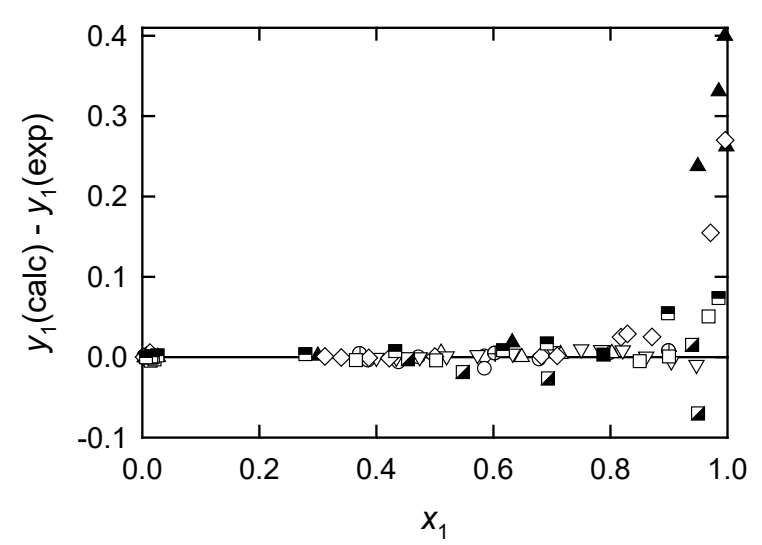

$d$

Fig. 18. Comparison of the predicted and experimental pressures $P$ and first-component mole fractions $y_{1}$ in the gas phase at different first-component mole fractions in the liquid phase $x_{1}$ for (phenol + water): a, c, NIST-COSMO-SAC; b, d: NIST-Modified UNIFAC.

Circles: O, Schreinemakers [107]; •, Schükarew [108]; $\oplus$, Rhodes et al. [109] (pressure not available); Ferguson [110].

Triangles: $\triangle$, Campbell and Campbell [111]; $\mathbf{\Delta}$, Brusset and Gaynès [112]; $\triangle$, Markuzin [113]; $\nabla$, Weller $e t$ al. [114].

Diamonds: $\diamond$, Kliment et al. [115]; $\diamond$, Kiva et al. [116]; $\diamond$, Kolyuchkina et al. [117]; $\triangleleft$, Hakuta [118].

Squares: $\square$, Karavaeva et al. [119]; $\mathbf{\square}$, Lyzlova and Susarev [120]; $\square$, Chou et al. [121]; 田, Tabai et al. [122];

$\boldsymbol{\nabla}$, Shi et al. [80]; $\mathbf{X}$, Klauck et al. [89]. 

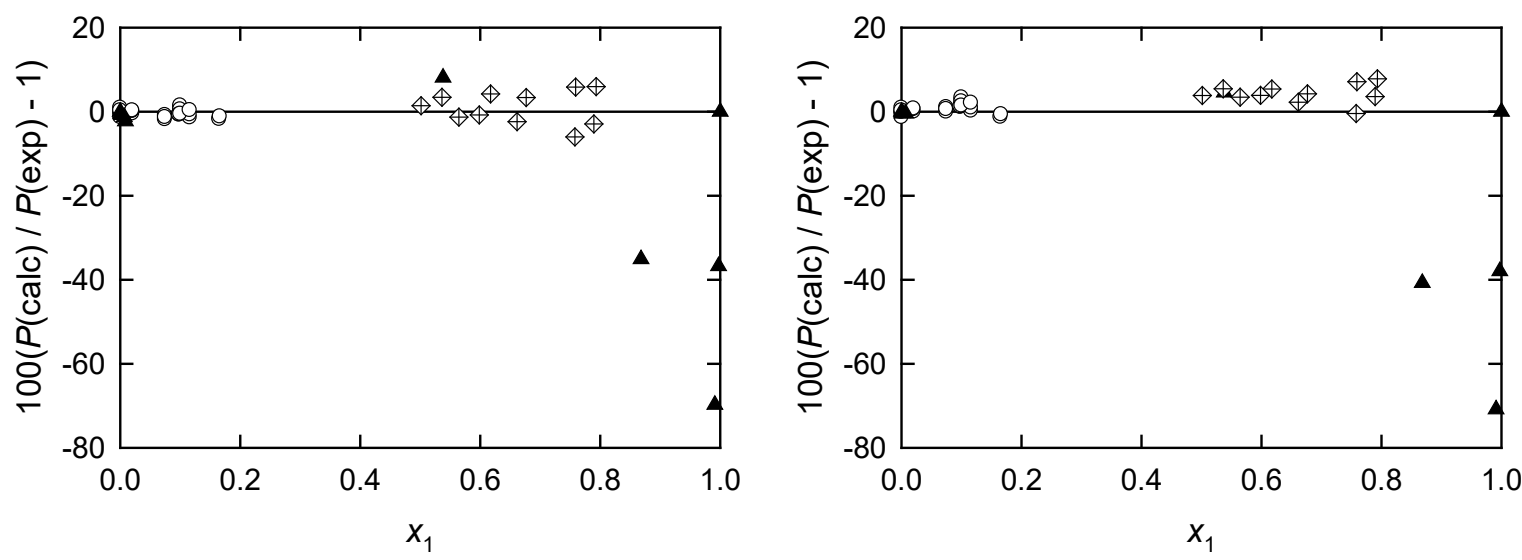

$a$
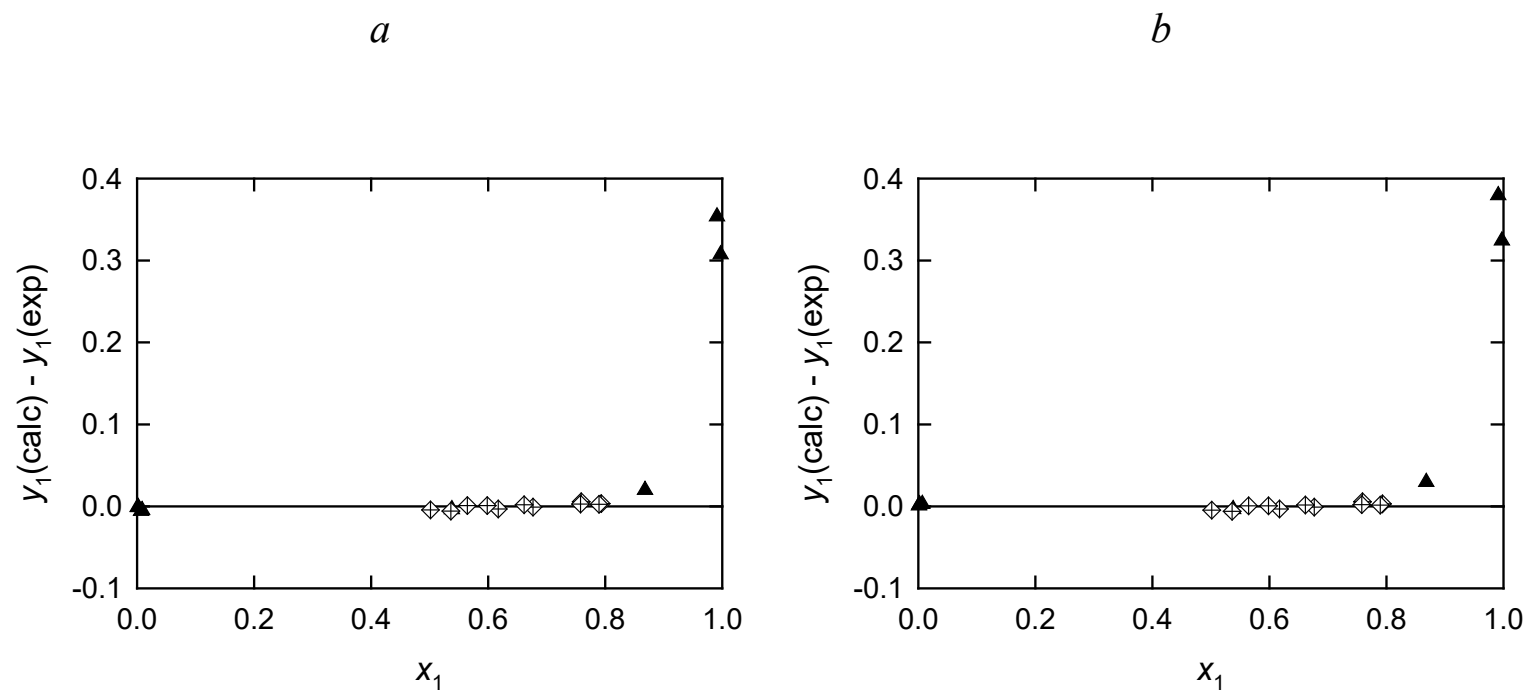

\section{$c$}

$d$

Fig. 19. Comparison of the predicted and experimental pressures $P$ and first-component mole fractions $y_{1}$ in the gas phase at different first-component mole fractions in the liquid phase $x_{1}$ for the binaries with water: a, c, NIST-COSMO-SAC; b, d: NIST-Modified UNIFAC.

Circles $(O)$ are for 1,3-benzenediol + water, Shakhparonov and Martynova [123].

Triangles $(\mathbf{\Lambda})$ are for 2-methylphenol + water: Brusset and Gaynès [112]. Diamonds $(\oplus)$ are for 3-methylphenol + water: Klauck et al. [89]. 


\subsubsection{VLE with ketones}

The results for the ketone binaries are presented in Figs. 20 and 21. The predicted pressures of (phenol + acetone) at high $x$ (phenol) are typically lower than the experimental counterparts. The large deviations (up to $70 \%$ ) are caused by either flawed predictions or problematic experimental data. With the current information, neither of the options can be proven. For the other binaries with phenol, the agreement is significantly better.

Several data sets are found to be problematic. Comparison of the pressures of (phenol + acetone) from Ref. [124] and (phenol + butanone) from Ref. [129] with the results from both considered models and other experimental data for these mixtures (Figs. 20a and 20b) indicates that the pressures reported in these works are too low. The (phenol + acetone) pressures and gas-phase compositions at $P \approx 0.1 \mathrm{MPa}$ [127] have large deviation from the other sources reporting the results at this pressure $[125,128]$ and the predicted data. Therefore, these results should be discarded.

The pressures predicted with the two considered models for the binaries with substituted phenols (Fig. 21) are inconsistent. The reason for this discrepancy cannot currently be determined. Another problem to be solved is an unexpectedly large deviation of the gasphase compositions for (2-methylphenol + acetone) [125] from the predictions (Figs. 20c, 20d, 21c, 21d). Similar deviations are observed in the results on (phenol + methanol) and (2methylphenol + methanol) from the same laboratory discussed later. 


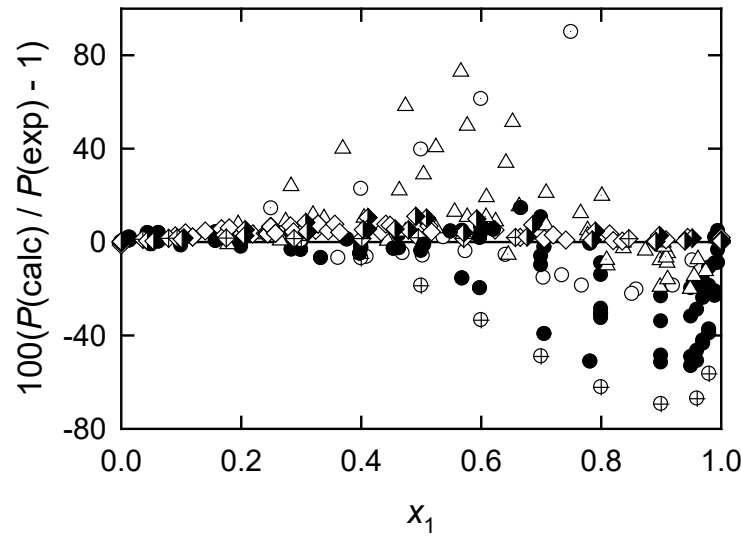

$a$

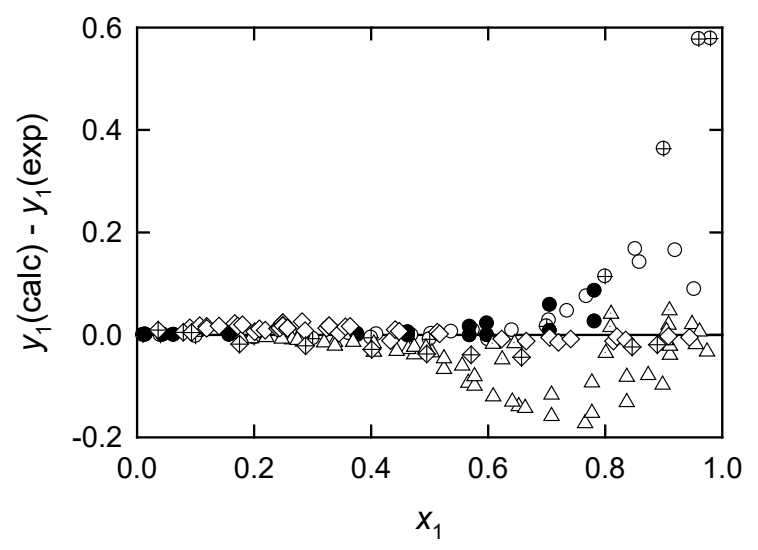

$c$

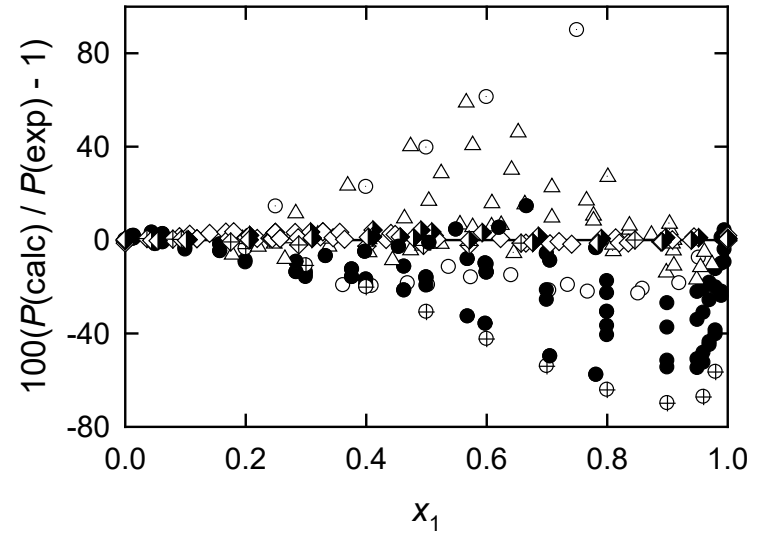

$b$

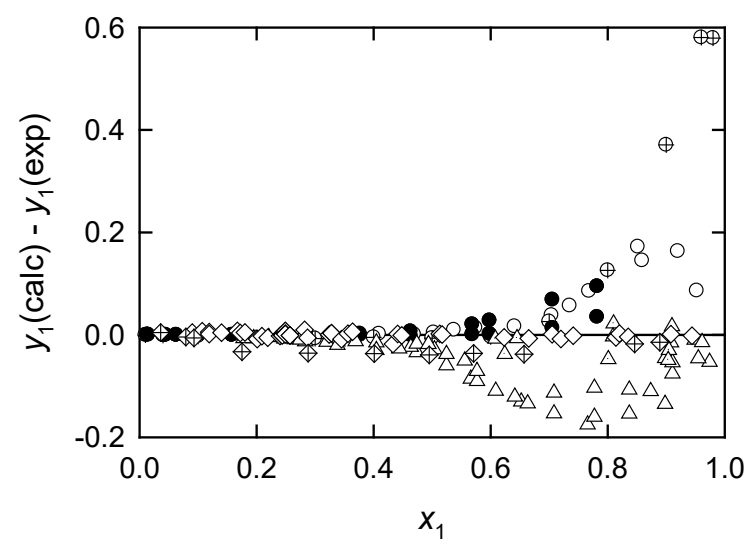

$d$

Fig. 20. Comparison of the predicted and experimental pressures $P$ and first-component mole fractions $y_{1}$ in the gas phase at different first-component mole fractions in the liquid phase $x_{1}$ for the binaries of phenol with ketones: a, c, NIST-COSMO-SAC; b, d: NIST-Modified UNIFAC.

Circles are for phenol + acetone: $\diamond$, Weissenberger et al. [84]; $\odot$, Weissenberger et al. [124]; $\bigcirc$, Chalov et al. [125]; •, Gölles [126]; $\oplus$, Motina et al. [127]; $\mathbf{O}$, Vasil'eva et al. [128]. Triangles are for phenol + butanone: $\triangle$, Byk and Shcherbak [129]; $\triangle$, Oscarson et al. [130]. Diamonds are for phenol + acetophenone: $\diamond$, Fried and Pick [131]; $\diamond$, Aarna and Kaps [132], $\triangleleft$, Giles and Wilson [133]. 


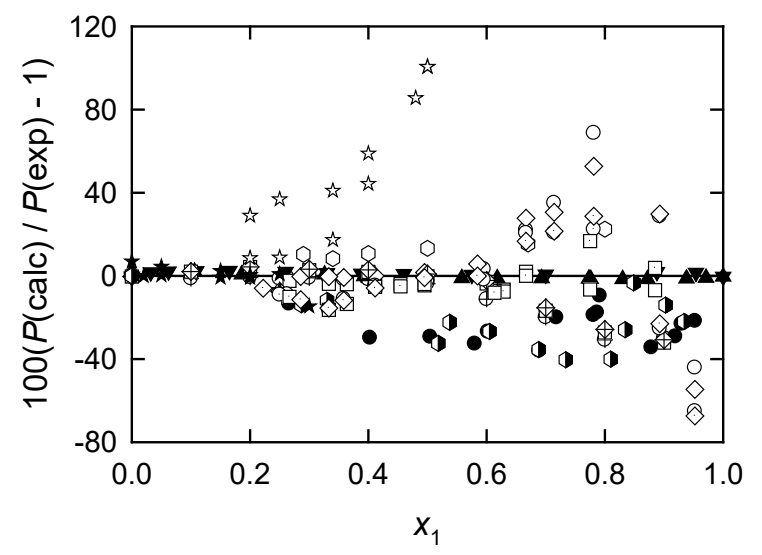

$a$

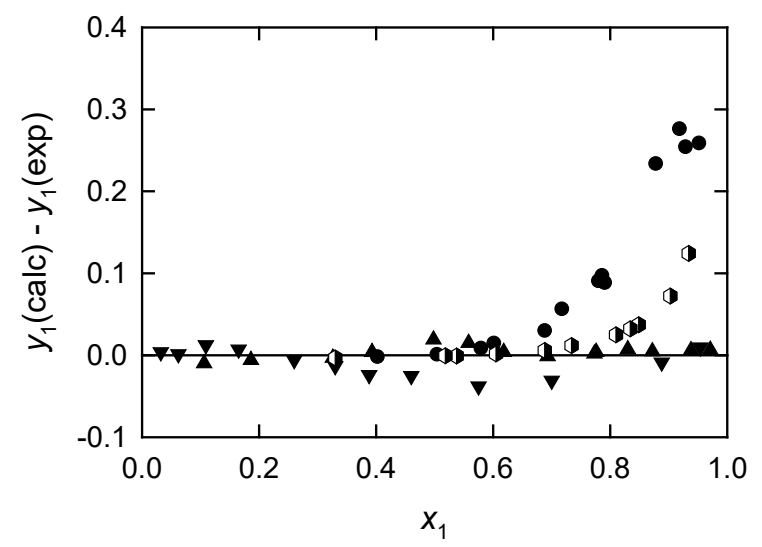

$c$

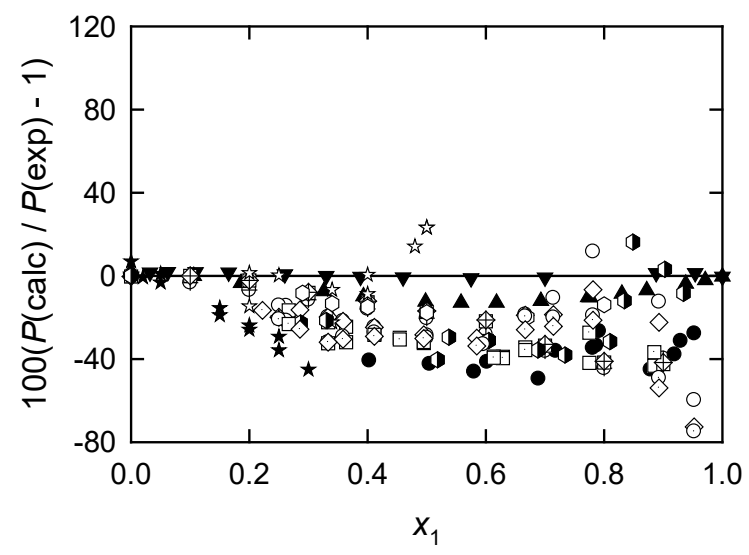

$b$

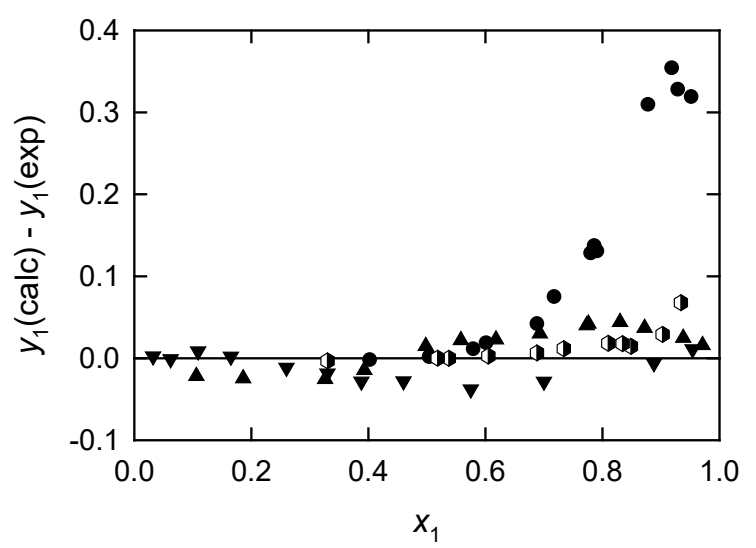

$d$

Fig. 21. Comparison of the predicted and experimental pressures $P$ and first-component mole fractions $y_{1}$ in the gas phase at different first-component mole fractions in the liquid phase $x_{1}$ for the binaries of phenolic compounds with ketones: a, c, NIST-COSMO-SAC; b, d: NISTModified UNIFAC.

Circles are for 2-methylphenol + acetone: $\bigcirc$, Weissenberger and Schuster [134]; $\odot$, Weissenberger and Piatti [135]; $\oplus$, Piatti [136]; •, Chalov et al. [125].

Triangles $(\mathbf{\Delta})$ are for 2-methylphenol + 2-octanone: filled, Aarna and Kaps [132] Triangles down $(\boldsymbol{\nabla})$ are for 2-methylphenol + acetophenone, Aarna and Kaps [132].

Squares are for 3-methylphenol + acetone: $\square$, Weissenberger and Schuster [134]; $\square$, Weissenberger and Piatti [135]; 田, Piatti [136].

Diamonds are for 4-methylphenol + acetone: $\diamond$, Weissenberger and Schuster [134]; $\diamond$, Weissenberger and Piatti [135]; $\oplus$, Piatti [136].

Stars are for 1,3-benzenediol + acetone: is, Weissenberger et al. [104]; $\star$, Shakhparonov and Martynova [123].

Hexagons are for 2-methoxyphenol + acetone: $\bigcirc$, Weissenberger et al. [104]; Chalov et al. [125]. 


\subsubsection{VLE with alcohols}

For this group of compounds, the values predicted with the models considered are not always consistent. This can be explained by two factors: (i) different treatment of H-bonding, which plays an important part for these systems, and (ii) individual parameters for methanol in NIST-modified UNIFAC.

For (phenol + alcohols), a good consistency of the experimental VLE pressures with the ones predicted with the NIST-COSMO-SAC is observed (Fig. 22a). The predicted values are about $20 \%$ low near $x$ (phenol $)=0.85$. The data scatter for the UNIFAC predictions is larger (Fig. 22b). For the VLE with 2- and 4-methylphenols, the general trend is similar to the one for phenol. The data scatter for the pressures over (3-methylphenol + alcohols) is too large to make any conclusion.

The questionable results of Prasad et al. introduce a significant noise to the graphs. A very large positive deviation from the NIST-COSMO-SAC predictions is observed for the pressures of (2-methylphenol + methanol) [143] (Fig. 23a). The predicted values are consistent with the other two datasets available for this binary $[134,125]$. The results of Prasad et al. with three other alcohols demonstrate the largest negative deviation. The problematic dataset with methanol is not revealed with NIST-modified UNIFAC though, per this model, the datasets for this binary are not consistent (Fig. 23b).

Several vapor pressure datasets for (3-methylphenol + alcohol) reported by Prasad et al. [145] (four for NIST-COSMO-SAC and three for NIST-modified UNIFAC) are inconsistent with the predicted values with the deviations exceeding $150 \%$ (Fig. 24). The results from this laboratory have the largest deviation for (4-methylphenol + methanol, ethanol, and 1butanol) (Fig. 25a). This problem is not revealed by the NIST-modified-UNIFAC predictions because of the significant data scatter (Fig. 25b).

The data scatter and inconsistency between the predicted pressures in Fig. 26 does not allow one to determine a general trend. In the results for 1,4-benzenediol with methanol and ethanol $\left[{ }^{137}\right]$, the mole fractions of the diol are below 0.005 . Thus, the boiling temperatures for these results are very close to those of pure alcohols. Therefore, these data are not shown in Fig. 26 and not used for the statistical analysis.

Some predicted gas-phase compositions have a large (up to 0.45 mole fraction) deviation from the values available in the literature (particularly, $[125,138]$ ). We believe this is partially caused by the model limitations. However, the gas-phase compositions of (phenol + methanol) at $x_{1}>0.9$ reported in these works differ by about 0.15 mole fraction. The limited available information does not allow one to find a reason of this discrepancy. New VLE measurements should be carried out for all systems considered in Refs. [125] and [138].

The statistical summary is presented in Table 3 . The average standard deviations are significantly larger than for the furan derivatives that characterizes the overall data quality. Unlike the results for the furan derivatives, those for the subset without water do not change much. Removal of the questionable data significantly decreases the standard deviations. The NIST-COSMO-SAC is again more sensitive to this dataset quality improvement than NISTmodified UNIFAC. 


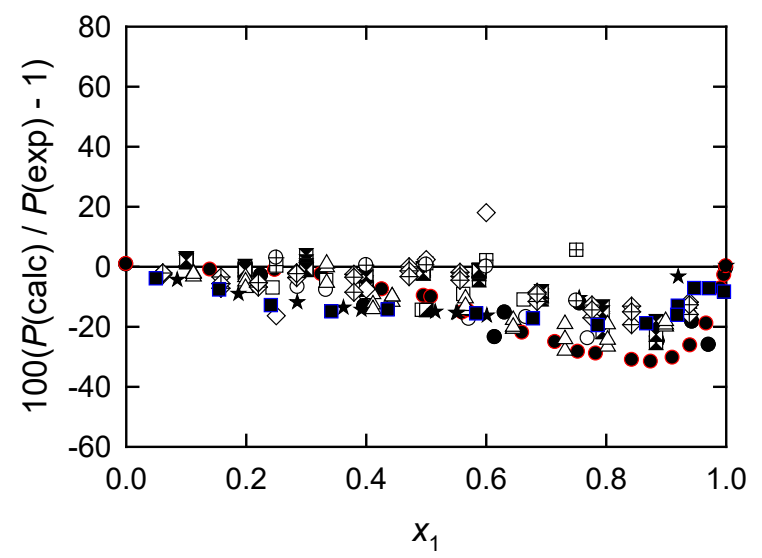

$a$

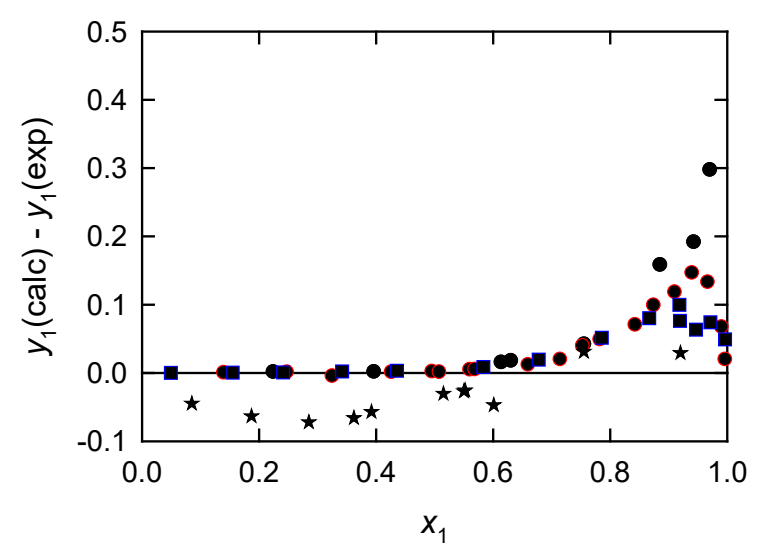

$c$

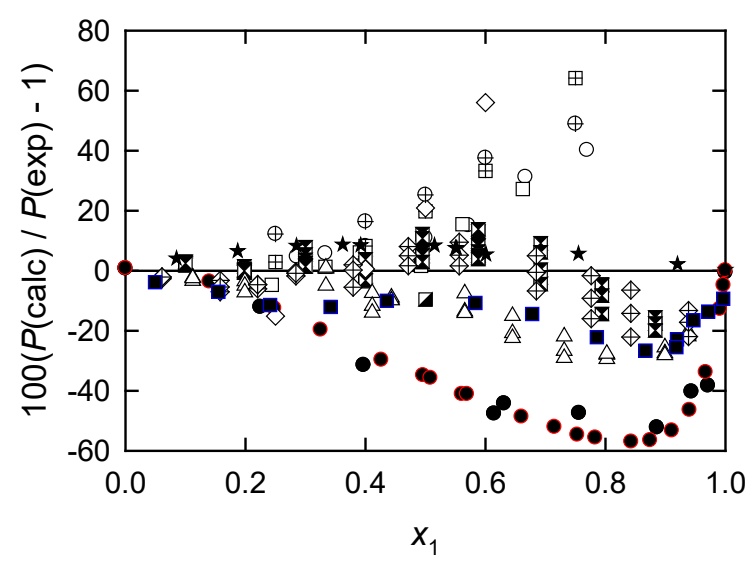

$b$

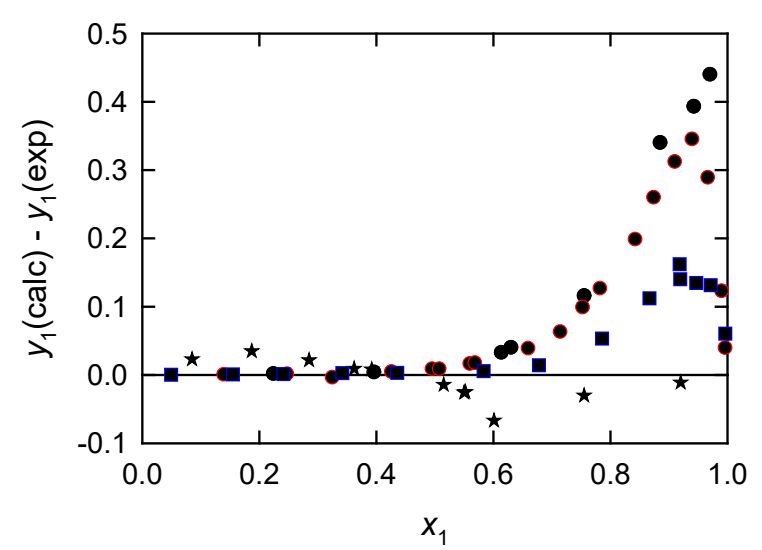

$d$

Fig. 22. Comparison of the predicted and experimental pressures $P$ and first-component mole fractions $y_{1}$ in the gas phase at different first-component mole fractions in the liquid phase $x_{1}$ for the binaries of phenol with alcohols: a, c, NIST-COSMO-SAC; b, d: NIST-Modified UNIFAC.

Circles are for phenol + methanol: $\bigcirc$, Weissenberger et al. [84]; $\oplus$, Weissenberger et al. [124]; $\mathbf{O}$, Chalov et al. [125]; $\bullet$, Hu et al. [138].

Squares are for phenol + ethanol: $\square$, Weissenberger et al. [84]; $\boxplus$, Weissenberger et al. [124]; $\mathbf{Z}$, Garner and Ellis [36]; $\mathbf{\square}$, Chou et al. [121]; $\mathbf{D}$, Cesari et al. [139].

Triangles $(\triangle)$ are for phenol + 1-propanol, Ravikumar et al. [140].

Diamonds are for phenol + 2-propanol: $\diamond$, Weissenberger et al. [124] (the experimental value at $x=0.75$ has a large deviation and is not shown); $\oplus$, Veeranna et al. [141].

Stars $(\star)$ are for phenol $+1,2$-ethanediol, Brusset et al. [142]. 


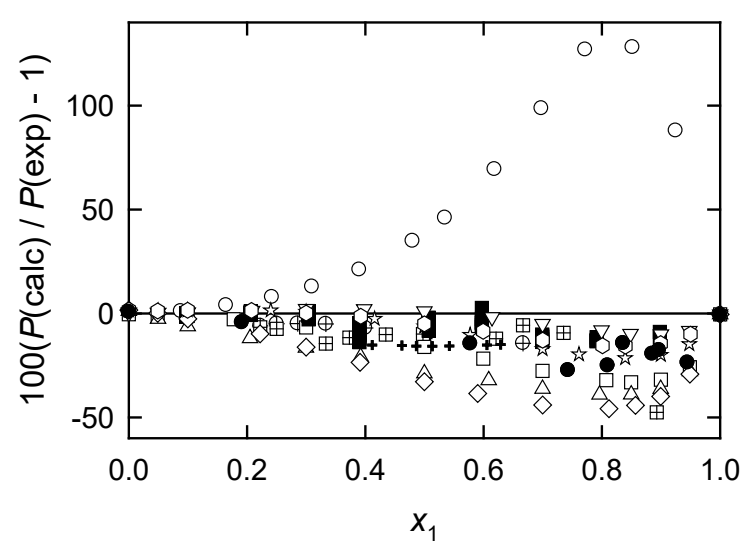

$a$

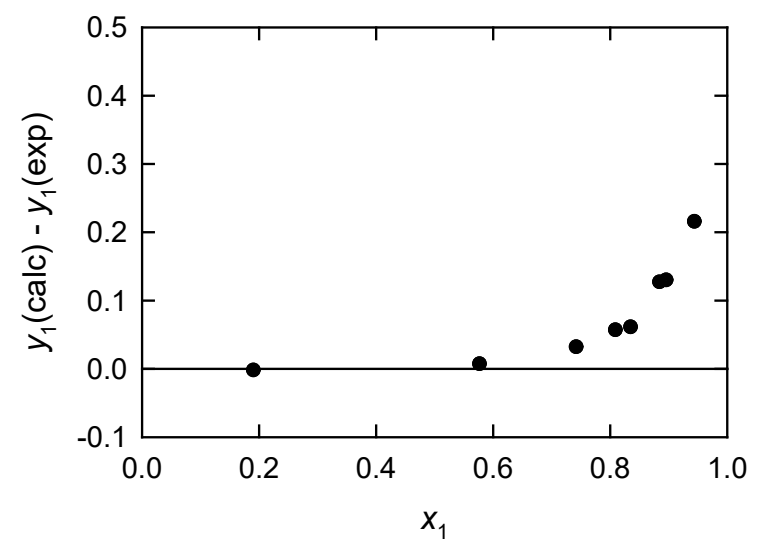

$c$

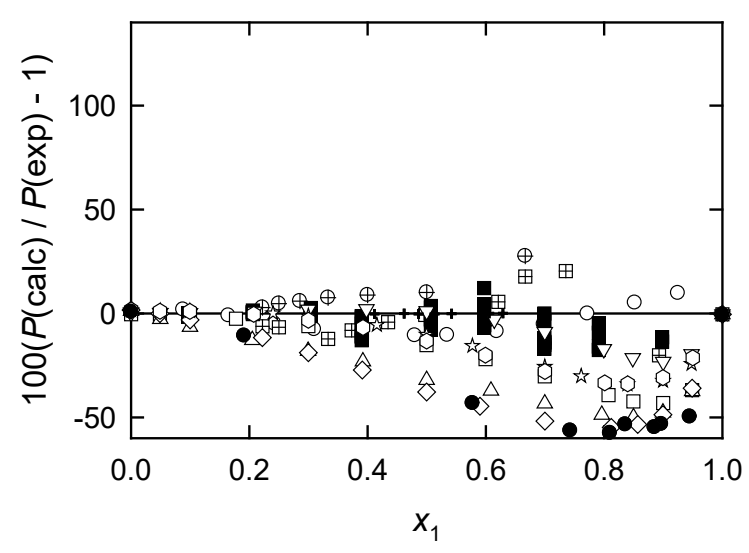

$b$

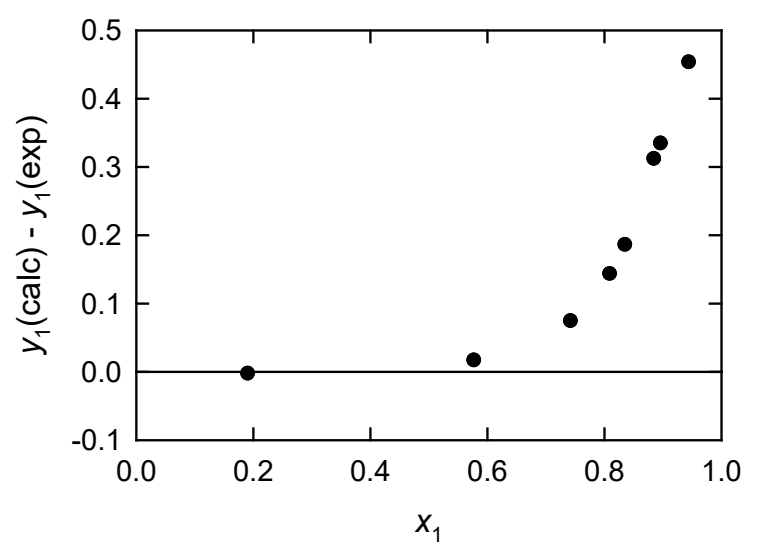

$d$

Fig. 23. Comparison of the predicted and experimental pressures $P$ and first-component mole fractions $y_{1}$ in the gas phase at different first-component mole fractions in the liquid phase $x_{1}$ for the binaries of 2-methylphenol with alcohols: a, c, NIST-COSMO-SAC; b, d: NISTModified UNIFAC.

Circles are for 2-methylphenol + methanol: $\oplus$, Weissenberger and Schuster [134]; $\mathbf{\oplus}$, Chalov et al. [125]; O, Prasad et al. [143].

Squares are for 2-methylphenol + ethanol: $\boxplus$, Weissenberger and Piatti [135]; $\square$, Prasad et al. [143]; $\mathbf{\square}$, Cesari et al. [139].

Triangles $(\triangle)$ are for 2-methylphenol + 1-propanol, Prasad et al. [143].

Triangles down $(\nabla)$ are for 2-methylphenol + 2-propanol, Prasad et al. [143].

Diamonds $(\diamond)$ are for 2-methylphenol + 1-butanol, Prasad et al. [143].

Stars (论) are for 2-methylphenol + 2-butanol, Prasad et al. [143].

Hexagons $(\bigcirc)$ are for 2-methylphenol + 2-methyl-1-propanol, Prasad et al. [143].

Pluses (+) are for 2-methylphenol + 1,2-ethanediol, Kurtyka [144]. 


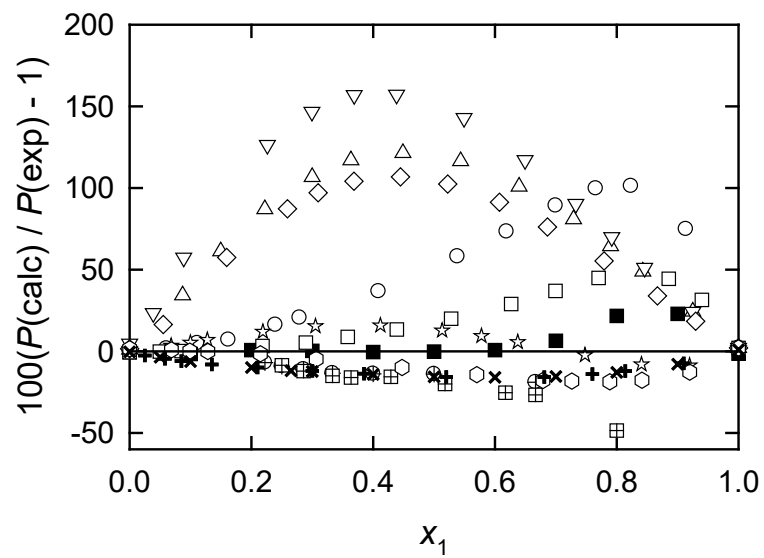

$a$

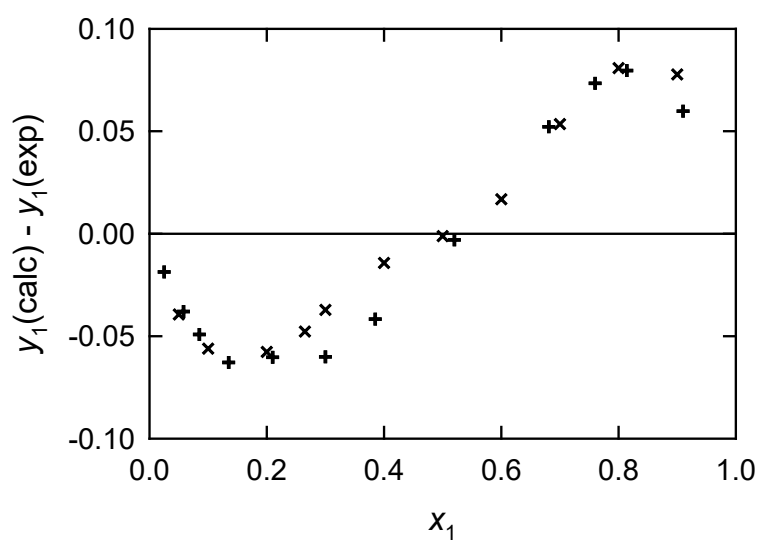

$c$

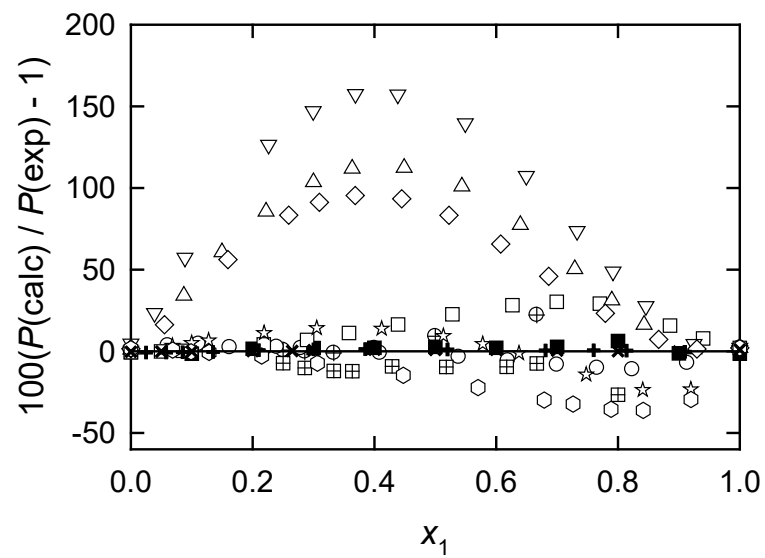

$b$

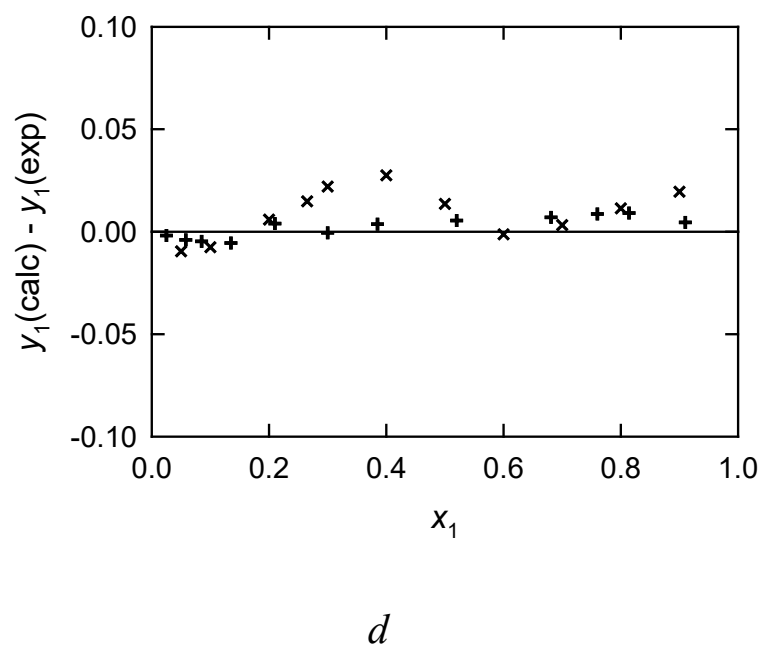

Fig. 24. Comparison of the predicted and experimental pressures $P$ and first-component mole fractions $y_{1}$ in the gas phase at different first-component mole fractions in the liquid phase $x_{1}$ for the binaries of 3-methylphenol with alcohols: a, c, NIST-COSMO-SAC; b, d: NISTModified UNIFAC.

Circles are for 3-methylphenol + methanol: $\oplus$, Weissenberger et al. [94]; O, Prasad et al. [145].

Squares are for 3-methylphenol + ethanol: $\boxplus$, Weissenberger and Piatti [135]; $\mathbf{\square}$, Piatti [146]; $\square$, Prasad et al. [145].

Triangles $(\triangle)$ are for 3-methylphenol + 1-propanol, Prasad et al. [145].

Triangles down $(\nabla)$ are for 3-methylphenol + 2-propanol, Prasad et al. [145].

Diamonds $(\diamond)$ are for 3-methylphenol + 1-butanol, Prasad et al. [145].

Stars (论) are for 3-methylphenol + 2-butanol, Prasad et al. [145].

Hexagons $(\bigcirc)$ are for 3-methylphenol + 2-methyl-1-propanol, Prasad et al. [145].

3-methylphenol + 1,2-ethanediol: $\times$, Othmer et al. [100]; +, Brusset et al. [142]. 


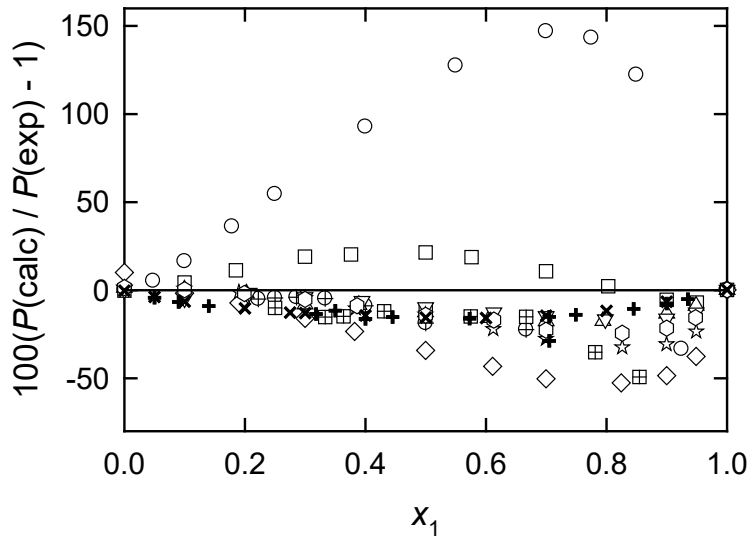

$a$

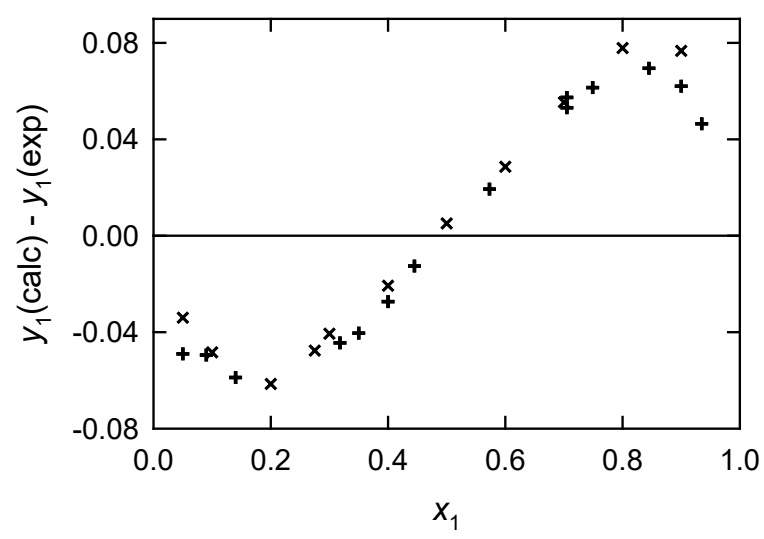

$c$

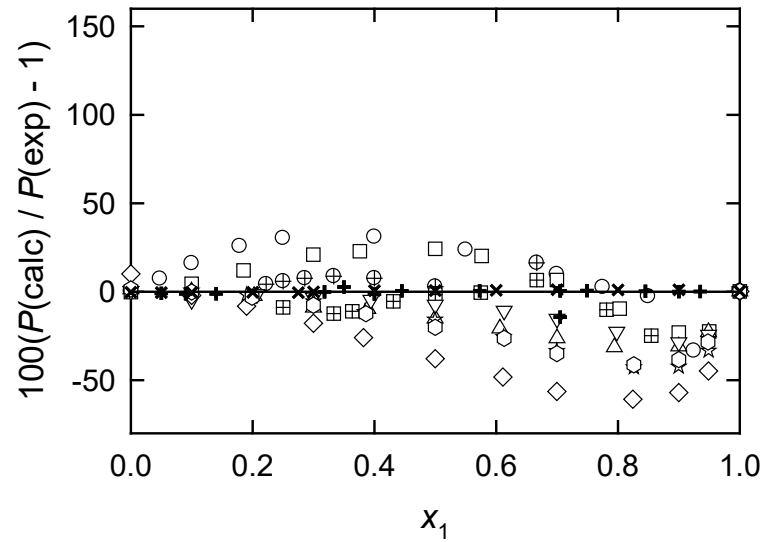

$b$

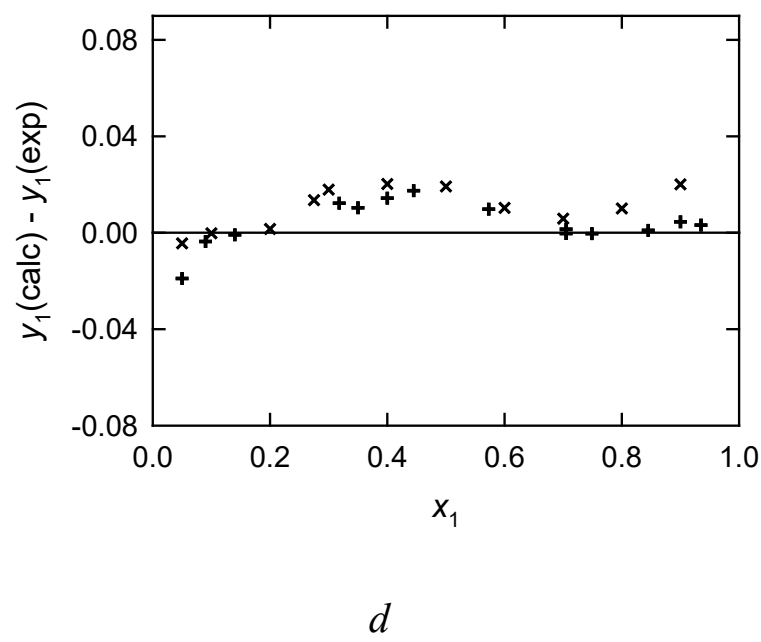

Fig. 25. Comparison of the predicted and experimental pressures $P$ and first-component mole fractions $y_{1}$ in the gas phase at different first-component mole fractions in the liquid phase $x_{1}$ for the binaries of 4-methylphenol with alcohols: a, c, NIST-COSMO-SAC; b, d: NISTModified UNIFAC.

Circles are for 4-methylphenol + methanol: $\oplus$, Weissenberger et al. [94]; O, Prasad et al. [143].

Squares are for 4-methylphenol + ethanol: $\boxplus$, Weissenberger and Piatti [135]; $\square$, Prasad et al. [143].

Triangles $(\triangle)$ are for 4-methylphenol + 1-propanol, Prasad et al. [143].

Triangles down $(\nabla)$ are for 4-methylphenol + 2-propanol, Prasad et al. [143].

Diamonds $(\diamond)$ are for 4-methylphenol + 1-butanol, Prasad et al. [143].

Stars (ㄴ) are for 4-methylphenol + 2-butanol, Prasad et al. [143].

Hexagons $(\bigcirc)$ are for 4-methylphenol + 2-methyl-1-propanol, Prasad et al. [143].

4-methylphenol + 1,2-ethanediol: $\times$, Othmer et al. [100]; +, Brusset et al. [142]. 


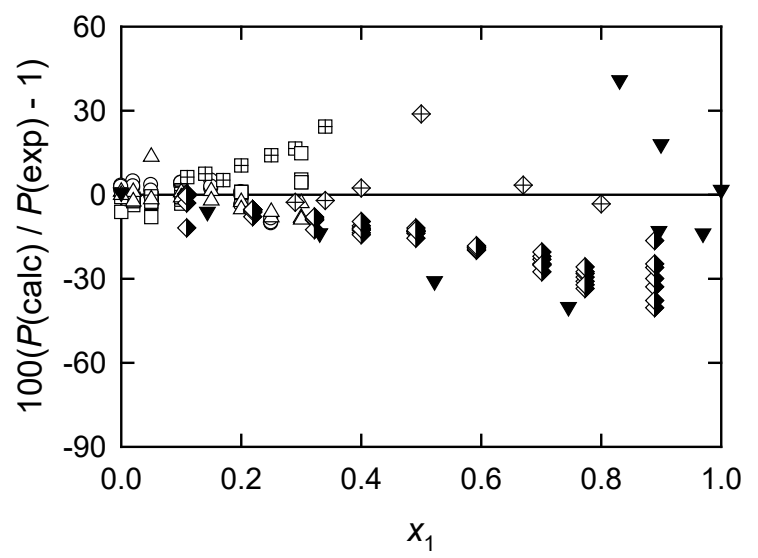

$a$

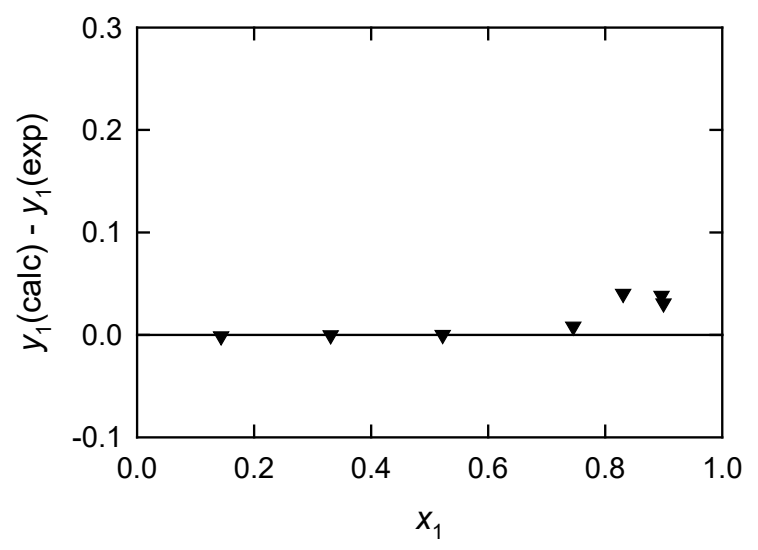

$c$

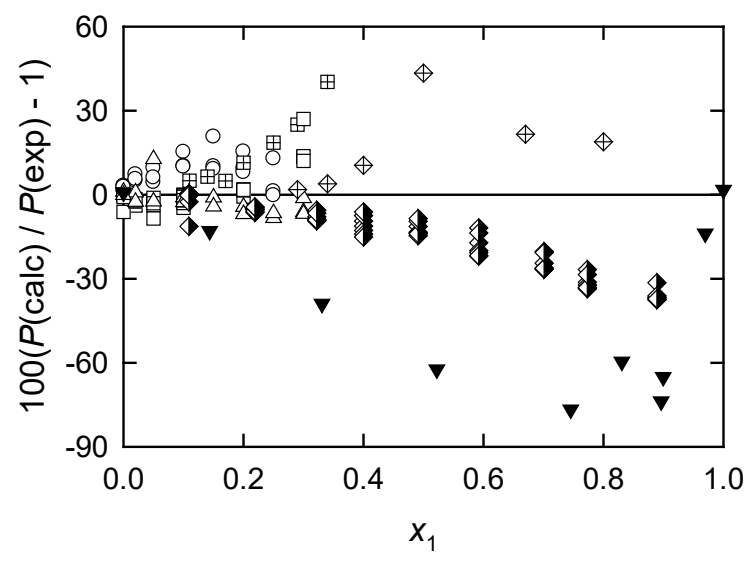

$b$

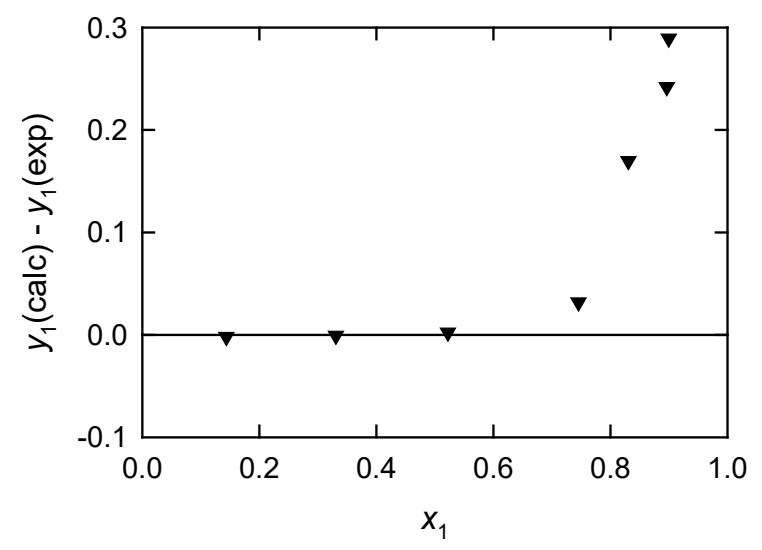

$d$

Fig. 26. Comparison of the predicted and experimental pressures $P$ and first-component mole fractions $y_{1}$ in the gas phase at different first-component mole fractions in the liquid phase $x_{1}$ for the binaries of 1,3-benzenediol and 2-methoxyphenol with alcohols: a, c, NIST-COSMOSAC; $b$, d: NIST-Modified UNIFAC.

Circles (O) are for 1,3-benzenediol + methanol, Shakhparonov and Martynova [123].

Squares are for 1,3-benzenediol + ethanol: $\boxplus$, Weissenberger et al. [104]; $\square$, Shakhparonov and Martynova [123].

Triangles $(\triangle)$ are for 1,3-benzenediol + 1-butanol, Shakhparonov and Martynova [123].

Triangles down $(\boldsymbol{\nabla})$ are for 2-methoxyphenol + methanol, Chalov et al. [125].

Diamonds are for 2-methoxyphenol + ethanol: $\triangleleft$, Weissenberger et al. [104]; $\triangleleft$, Cesari et al. [139]. 


\section{Conclusion}

The experimental VLE data for the binary mixtures relevant to the catalytic fast pyrolysis of biomass have been collected. Two models based on fundamentally different approaches, NIST-COSMO-SAC and NIST-modified UNIFAC, were applied to predict equilibrium pressures and gas-phase compositions for these mixtures. If the predicted values significantly deviated from the experimental data or the experimental results were mutually inconsistent, they were analyzed using different criteria to detect problems in the theory and experimental data. Also, the mixtures were identified for which new experimental results are required to resolve the existing inconsistencies.

The main components were divided into two groups: furan derivatives and phenolic compounds. For the first group, the overall data quality is good; and more experimental data are needed to resolve inconsistencies between the experimental data, primarily, for (furan + 2-furaldehyde) and (2-furaldehyde + water). The VLE data predicted with NIST-COSMOSAC and NIST-modified UNIFAC for phenolic compounds have a significantly worse agreement with the experimental values. Analysis of these inconsistencies in chemical series (isomers, homologs) revealed that about half of the experimental values in this group are questionable. These data are available from a single laboratory for many binaries; that is why it is especially important to be careful if the results are to be used for process simulation or model parameterization. There is a need for reliable experimental data for VLE of phenolic compounds to replace the doubtful results.

For many systems, both models behave in a similar way. Significant inconsistencies between the results of the two models occur for the binaries with alcohols, especially, methanol. The NIST-COSMO-SAC results seem to be preferable because this model has a few empirical parameters compared to the large number of group-specific ones in NIST-modified UNIFAC. However, further studies are required to improve the understanding of this problem.

Removal of the suspicious experimental data from the considered dataset decreases the relative standard deviation between the experimental pressures and NIST-COSMO-SAC predictions by about a factor of two. This effect is significantly weaker for the results from NIST-modified UNIFAC. It is probably caused by limitations of the training set and the empirical nature of the model.

\section{Acknowledgments}

This work was authored in part by the National Renewable Energy Laboratory, operated by Alliance for Sustainable Energy, LLC, for the U.S. Department of Energy (DOE) under Contract No. DE-AC36-08GO28308. Funding provided by U.S. Department of Energy Office of Energy Efficiency and Renewable Energy Bioenergy Technologies Office. 


\section{References}

[1] Collard F, Blin J (2014) A review on pyrolysis of biomass constituents:

Mechanisms and composition of the products obtained from the conversion of cellulose, hemicelluloses and lignin. Renewable and Sustainable Energy Reviews 38:594-608. https://doi.org/10.1016/j.rser.2014.06.013

[2] Mohan D, Pittman CU, Steele PH (2006) Pyrolysis of Wood/Biomass for Bio-oil: A Critical Review. Energy Fuels 20:848-889. https://doi.org/10.1021/ef0502397

[3] Bridgwater AV (2012) Review of fast pyrolysis of biomass and product upgrading. Biomass and Bioenergy 38:68-94. https://doi.org/10.1016/j.biombioe.2011.01.048

[4] Oasmaa A, Peacocke C (2010) Properties and Fuel Use of Biomass Derived Fast Pyrolysis Liquids: A Guide (VTT, Finland), VTT Publication 731. http://www.vtt.fi/Documents/P731.pdf

[5] Venderbosch RH (2015) A Critical View on Catalytic Pyrolysis of Biomass. ChemSusChem 8:1306-1316. https://doi.org/10.1002/cssc.201500115

[6] Diebold JP, Scahill JW (1988) Conversion of Wood to Aromatic Gasoline with Zeolite Catalysts. Energy Progress 8(1):59-66.

[7] Anellotech (2018) Commercializing bio-paraxylene to make 100\% bio-based PET bottles a reality. European Bioplastics Conference (Berlin, Germany). Accessed Jan 15, 2020:

https://www.anellotech.com/sites/default/files/Anellotech $\% 20$ Presentation $\% 20 \mathrm{EUB}$ P FINAL.pdf

[8] Ruddy DA, Schaidle JA, Ferrell III JR, Wang J, Moens L, Hensley JE (2014) Recent advances in heterogeneous catalysts for bio-oil upgrading via "ex situ catalytic fast pyrolysis": catalyst development through the study of model compounds. Green Chem. 16:454-490. https://doi.org/10.1039/C3GC41354C

[9] Nimlos M (2019) Performance Advantaged Bioproducts from Catalytic Fast Pyrolysis. Performance-Advantaged Bioproducts and Separations Consortium. DOE BETO Peer Review (Denver, CO). Accessed on Nov 30, 2019, at: https://www.energy.gov/sites/prod/files/2019/04/f61/Analysis $\% 20 \mathrm{in} \% 20$ support $\% 2$ 0of $\% 20$ performance $\% 20$ advantaged $\% 20$ bioproducts $\% 20$ from $\% 20$ catalytic $\% 20$ fast $\% 20$ pyrolysis_NL0034074.pdf

[10] Dutta A, Sahir A, Tan E, Humbird D, Snowden-Swan L, Meyer P, Ross J, Sexton D, Yap R, Lukas J (2015) Process Design and Economics for the Conversion of Lignocellulosic Biomass to Hydrocarbon Fuels - Thermochemical Research Pathways with in situ and ex situ Upgrading of Fast Pyrolysis Vapors (NREL, USA), NREL/TP-5100-62455, PNNL-23823. https://www.nrel.gov/docs/fy15osti/62455.pdf

[11] Dutta A, Schaidle J, Humbird D, Baddour F, Sahir A (2016) Conceptual Process Design and Techno-Economic Assessment of Ex Situ Catalytic Fast Pyrolysis of Biomass: A Fixed Bed Reactor Implementation Scenario for Future Feasibility. Topics in Catalysis 59:2-18. https://doi.org/10.1007/s11244-015-0500-Z

[12] Griffin MB, Iisa K, Wang H, Dutta A, Orton KA, French RJ, Santosa DM, Wilson N, Christensen E, Nash C, Van Allsburg KM, Baddour FG, Ruddy DA, Tan ECD, Cai H, Mukarakate C, Schaidle JA (2018) Driving towards cost-competitive biofuels through catalytic fast pyrolysis by rethinking catalyst selection and reactor 
configuration. Energy Environ. Sci. 11:2904-2918.

http://doi.org/10.1039/C8EE01872C

[13] Iisa K, French RJ, Orton KA, Dutta A, Schaidle JA (2017) Production of lowoxygen bio-oil via ex situ catalytic fast pyrolysis and hydrotreating. Fuel 207:413422. https://doi.org/10.1016/j.fuel.2017.06.098

[14] Jasperson LV, McDougal RJ, Diky V, Paulechka E, Chirico RD, Kroenlein K, Iisa K, Dutta A (2017) Liquid-Liquid Equilibrium Measurements for Model Systems Related to Catalytic Fast Pyrolysis of Biomass. J. Chem. Eng. Data 62:243-252. https://doi.org/10.1021/acs.jced.6b00625

[15] Ille Y, Sánchez FA, Dahmen N, Pereda S (2019) Multiphase Equilibria Modeling of Fast Pyrolysis Bio-Oils. Group Contribution Associating Equation of State Extension to Lignin Monomers and Derivatives. Ind. Eng. Chem. Res. 58:73187331. https://doi.org/10.1021/acs.iecr.9b00227

[16] Hansen HK, Rasmussen P, Fredenslund A, Schiller M, Gmehling J (1991) Vaporliquid equilibria by UNIFAC group contribution. 5. Revision and extension. Ind. Eng. Chem. Res. 30:2352-2355. https://doi.org/10.1021/ie00058a017

[17] Klamt A, Schüürmann G (1993) COSMO: A New Approach to Dielectric Screening in Solvents with Explicit Expressions for the Screening Energy and its Gradient. J. Chem. Soc., Perkin Trans. 2:799-805. https://doi.org/10.1039/P29930000799

[18] York DM, Karplus M (1999) A Smooth Solvation Potential Based on the Conductor-Like Screening Model. J. Phys. Chem. A 103:11060-11079. https://doi.org/10.1021/jp9920971

[19] Klamt A, Jonas V, Burger T, Lohrenz JCW. Refinement and Parametrization of COSMO-RS. J. Phys. Chem. A 102:5074-5085. https://doi.org/10.1021/jp980017s

[20] Lin ST, Sandler SI (2002) A Priori Phase Equilibrium Prediction from a Segment Contribution Solvation Model. Ind. Eng. Chem. Res. 41:899-913. https://doi.org/10.1021/ie001047w

[21] Holderbaum T, Gmehling J (1991) PSRK: A Group Contribution Equation of State Based on UNIFAC. Fluid Phase Equilib. 70:251-265. https://doi.org/10.1016/0378-3812(91)85038-V

[22] Gros HP, Bottini S, Brignole EA (1996) A group contribution equation of state for associating mixtures. Fluid Phase Equilib. 116:537-544. https://doi.org/10.1016/0378-3812(95)02928-1

[23] Paulechka E, Diky V, Kazakov A, Kroenlein K, Frenkel M (2015) Reparameterization of COSMO-SAC for Phase Equilibrium Properties Based on Critically Evaluated Data. J. Chem. Eng. Data 60:3554-3561. https://doi.org/10.1021/acs.jced.5b00483

[24] Kang JW, Diky V, Frenkel M (2015) New modified UNIFAC parameters using critically evaluated phase equilibrium data. Fluid Phase Equilib. 388:128-141. https://doi.org/10.1016/j.fluid.2014.12.042

[25] Frisch MJ, Trucks GW, Schlegel HB, Scuseria GE, Robb MA, Cheeseman JR, Scalmani G, Barone V, Mennucci B, Petersson GA, et al. (2013) Gaussian 09, Revision D.01 (Gaussian Inc., Wallingford, CT). 
[26] Frenkel M, Chirico RD, Diky V, Xinjian Y, Qian D, Muzny C (2005) ThermoData Engine (TDE): Software Implementation of the Dynamic Data Evaluation Concept. J. Chem. Inf. Model. 45:816-838. https://doi.org/10.1021/ci050067b

[27] Frenkel M, Chirico RD, Diky V, Yan X, Dong Q, Muzny C (2005) ThermoData Engine (TDE): Software Implementation of the Dynamic Data Evaluation Concept. J. Chem. Inf. Model. 45:816-838. https://doi.org/10.1021/ci050067b

[28] Diky V, Chirico RD, Muzny CD, Kazakov AF, Kroenlein K, Magee JW, Abdulagatov I, Frenkel M (2013) ThermoData Engine (TDE): Software Implementation of the Dynamic Data Evaluation Concept. 9. Extensible Thermodynamic Constraints for Pure Compounds and New Model Developments. J. Chem. Inf. Model. 53:3418-3430. https://doi.org/10.1021/ci4005699

[29] Weidlich U, Gmehling J (1987) A Modified UNIFAC Model. 1. Prediction of VLE, $h^{\mathrm{E}}$, and $\gamma^{\circ}$. Ing. Eng. Chem. Res. 26:1372-1381. https://doi.org/10.1021/ie00067a018

[30] Nala M, Auger E, Gedik I, Ferrando N, Dicko M, Paricaud P, Volle F, Passarello JP, de Hemptinne JC, Tobaly P, Stringari P, Coquelet C, Ramjugernath D, Naidoo P, Lugo R (2013) Vapour-liquid equilibrium (VLE) for the systems furan $+n-$ hexane and furan + toluene. Measurements, data treatment and modeling using molecular models. Fluid. Phase Equilib. 337:234-245. https://doi.org/10.1016/j.fluid.2012.08.005

[31] Thévaneau P, Valtz A, Coquelet C (2017) Vapor Liquid Equilibrium Data for the Furan-Toluene Binary System between 313.02 and 352.99 K. J. Chem. Eng. Data 62:1168-1172. https://doi.org/10.1021/acs.jced.6b00424

[32] Krevor DH, Prausnitz JM (1986) Vapor-Liquid Equilibria for Model Mixtures of Coal-Derived Liquids. 1. Binary Systems with 2-Methylfuran. J. Chem. Eng. Data 31:349-353. https://doi.org/10.1021/je00045a027

[33] Thornton JD, Garner FH (1951) Vapour-liquid equilibria in hydrocarbon-nonhydrocarbon systems. I. The system benzene-cyclohexane-furfuraldehyde. J. Appl. Chem. 1:S61-S68.

[34] Kenny JW (1957) Prediction of ternary liquid-liquid equilibrium from binary data (for the system furfural-iso-octane-benzene). Chem. Eng. Sci. 6:116-122. https://doi.org/10.1016/0009-2509(57)85004-0

[35] Stephenson RW, Van Winkle M (1962) Modification of Relative Volatilities by Addition of Solvent. J. Chem. Eng. Data 7:510-516. https://doi.org/10.1021/je60015a021

[36] Garner FH, Ellis SRM (1951) Applicability of vapour-liquid equilibrium relationships to extractive distillation. Trans. Inst. Chem. Eng. 29:45-62.

[37] Thornton JD, Garner FH. Vapour-liquid equilibria in hydrocarbon-nonhydrocarbon systems. III. The system isooctane-toluene-furfuraldehyde. J. Appl. Chem. 1:S74-S80.

[38] Garner FH, Hall RTW (1955) Vapour-liquid equilibria of $\mathrm{C}_{7}$-hydrocarbon-furfural systems. Part I. Binary and ternary data for the system methylcyclohexane-toluenefurfural. J. Inst. Petroleum 41:1-18.

[39] Rivenq F (1973) Ébulliométrie des mélanges toluene-furfural, (Note de Laboratoire). Bull. Soc. Chim. Fr. (9):2645-2656. 
[40] Puri PS, Raju KSN (1970) Vapor-Liquid Equilibria. Systems $p$-Xylene-Furfural and Ethylbenzene-Furfural. J. Chem. Eng. Data 15:480-483. https://doi.org/10.1021/je60047a021

[41] Tai WP, Lee HY, Lee MJ (2014) Isothermal vapor-liquid equilibrium for binary mixtures containing furfural and its derivatives. Fluid Phase Equilib. 384: 134-142. https://doi.org/10.1016/j.fluid.2014.10.037

[42] Auger E, Coquelet C, Valtz A, Nala M, Naidoo P, Ramjugernath D (2016) Equilibrium data and GC-PC SAFT predictions for furanic extraction. Fluid Phase Equilib. 430:57-66. https://doi.org/10.1016/j.fluid.2016.09.019

[43] Chen Q, Zhang L, Zhang H, Wang X, Liu A, Chen H, Zhang L, Zhu D, Gao D (2020) Measurements and Correlation of Isobaric Vapor-Liquid Equilibrium Data for Binary Mixtures of Furan, Oxolane, and Furan-2-Carbaldehyde and Application of the Binary Model Parameters for Further Prediction of the Ternary System. $J$. Chem. Eng. Data 65:2583-2596. https://doi.org/10.1021/acs.jced.9b01210

[44] Holdren RF, Hixon RM (1946) Vapor Pressure and Vapor-Liquid Equilibria in the System Furfural-2-Methylfuran. Ind. Eng. Chem. 38:1061-1062. https://doi.org/10.1021/ie50442a024

[45] Negadi L, Mokbel I, Chiali-Baba-Ahmed N, Kara-Zaitri L (2014) Phase equilibrium properties of binary mixtures containing 2,5-dimethylfuran and furfuryl alcohol or methyl isobutyl ketone at several temperatures. J. Chem. Thermodyn. 70: 233-238. https://doi.org/10.1016/j.jct.2013.10.039

[46] Myles MG, Wingard RE (1961) Calculating Activity Coefficients. Ind. Eng. Chem. 53:219-222. https://doi.org/10.1021/ie50615a029

[47] Tsirlin YA, Vasil'eva VA (1971) Liquid-vapor phase equilibrium in binary mixtures of furfural with furan alcohols under reduced pressure. Zh. Prikl. Khim. 44: 1121-1126.

[48] Pokki JP, Lê HQ, Uusi-Kyyny P, Sixta H, Alopaeus V (2018) Isobaric VaporLiquid Equilibrium of Furfural $+\gamma$-Valerolactone at $30 \mathrm{kPa}$ and Isothermal LiquidLiquid Equilibrium of Carbon Dioxide $+\gamma$-Valerolactone + Water at $298 \mathrm{~K} . J$. Chem. Eng. Data 63:4381-4391. https://doi.org/10.1021/acs.jced.8b00451

[49] Zheng H, Luo X, Yin G, Chen J, Zhao S (2018) Vapor Pressure and Isobaric Vapor-Liquid Equilibrium for Binary Systems of Furfural, 2-Acetylfuran, and 5Methylfurfural at 3.60 and $5.18 \mathrm{kPa}$. J. Chem. Eng. Data 63:49-56. https://doi.org/10.1021/acs.jced.7b00574

[50] Fele L, Grilic V (2003) Separation of Furfural from Ternary Mixtures. J. Chem. Eng. Data 48:564-570. https://doi.org/10.1021/je020117y

[51] Ma Y, Gao J, Li M, Zhu Z, Wang Y (2018) Isobaric vapour-liquid equilibrium measurements and extractive distillation process for the azeotrope of $(N, N$ dimethylisopropylamine + acetone). J. Chem. Thermodyn. 122:154-161. https://doi.org/10.1016/j.jct.2018.03.019

[52] Hauschild T, Wu HS, Sandler SI (1987) Vapor-liquid equilibrium of the mixtures 2-furaldehyde/1-butanol and 2-furaldehyde/4-methyl-2-pentanone. J. Chem. Eng. Data 32:226-229. https://doi.org/10.1021/je00048a028

[53] Zaitseva A, Laavi H, Pokki JP, Uusi-Kyyny P, Alopaeus V (2014) Isothermal vapor-liquid equilibrium and excess molar enthalpies of the binary mixtures 
furfural + methyl isobutyl ketone, +2-butanol and +2-methyl-2-butanol. Fluid Phase Equilib. 372:85-99. https://doi.org/10.1016/j.fluid.2014.03.033

[54] Smith AS, Labonte JF (1952) Dehydration of Aqueous Methyl Ethyl Ketone with 2Methyl Furan. Ind. Eng. Chem. 44:2740-2743. https://doi.org/10.1021/ie50515a064

[55] Dudutkina IV, Lutugina NV (1981) Study of phase equilibria in the binaries containing furfuryl alcohol. Sovremennye Problemy Fizicheskoy Khimii Rastvorov, Part 2, pp 40-46. Deposited in ONIITEKhIM (Cherkassy, USSR), \#916 KhP-D81.

[56] Hickman JB, Hall JL (1950) Liquid-Vapor Equilibria, Refractive Indices and Freezing Points in the System: 2-Methylfurane-Methanol. Proc. W. Va. Acad. Sci. 22:72-79.

[57] Mejía A, Segura H, Cartes M (2013) Isobaric Vapor Liquid Equilibrium and Isothermal Interfacial Tensions for the System Ethanol + 2,5-Dimethylfuran. 58: 3226-3232. https://doi.org/10.1021/je400683g

[58] Ni X, Wang Z (1987) Studies on VLE of Carbinol-Furfual-Water-Acetic Acid. Huaxue Gongcheng. (3):50-58.

[59] Staroske J, Figurski G (1992) Das Dampf-Flüssigkeits-Gleichgewicht des ternären Systems Furfural-Ethylacetat-Methanol und dessen binäre Randsysteme bei 298,15 K. Chem. Tech. 44:64-66.

[60] Kharin SE, Perelygin VM, Polyanskii KK (1970) Liquid-vapor phase equilibrium in the water-furfural and ethanol-furfural systems. Gidroliznaya I Lesokhimicheskaya Promyshlennost' 23:15-16.

[61] Havasi D, Pátzay G, Kolarovszki Z, Mika LT (2016) Isobaric Vapor-Liquid Equilibria for Binary Mixtures of $\gamma$-Valerolactone + Methanol, Ethanol, and 2Propanol. J. Chem. Eng. Data 61:3326-3333. https://doi.org/10.1021/acs.jced.6b00384

[62] Rigamonti R, Spaccamela Marchetti E (1955) Estrazione del furfurolo dale soluzioni acquose diluite - Nota II. Chim. Ind. 37:1039-1044.

[63] Mains GH (1922) The System Furfural-Water - I. Chem. Metal. Eng. 26:779-784.

[64] Pearce EJ, Gerster JA (1950) Furfural-Water System - Experimental and Theoretical Vapor-Liquid Relationships. Ind. Eng. Chem. 42:1418-1424. https://doi.org/10.1021/ie50487a043

[65] Tsirlin YA. (1962) Liquid-vapour equilibrium in the furfural-water system at reduced pressures. Russ. J. Phys. Chem. 36:903-905.

[66] Staroske J, Schuberth H (1988) Das Phasengleichgewichtsverhalten des ternären Systems Furfural/Ethylacetat/Wasser (1/2/3) bei $25^{\circ}$ C. Z. Phys. Chem. 2690:572575. https://doi.org/10.1515/zpch-1988-26961

[67] Sunder MS, Prasad DHL (2003) Phase Equilibria of Water + Furfural and Dichloromethane + n-Hexane. J. Chem. Eng. Data 48:221-223. https://doi.org/10.1021/je020053r

[68] Boldyrev AV, Komarov VM, Krichevtsov BK (1972) Liquid-vapor equilibrium in the system water-furfuryl alcohol. Zh. Prikl. Khim. 46:2338-2339.

[69] Dudkina IV, Lutugina NV, Syrovarova TK (1982) Liquid-vapor equilibrium in the water-ethanol-acetone-methyl ethyl ketone-furfural system and its binary and ternary subsystems. Vestn. Leningr. Univ., Ser. 4: Fiz. Khim. (10):101-104. 
[70] Havasi D, Mizsey P, Mika LT (2016) Vapor-Liquid Equilibrium Study of the Gamma-Valerolactone-Water Binary System. J. Chem. Eng. Data 61:1502-1508. https://doi.org/10.1021/acs.jced.5b00849

[71] Zaitseva A, Pokki JP, Le HQ, Alopaeus V, Sixta H (2016) Vapor-Liquid Equilibria, Excess Enthalpy, and Density of Aqueous $\gamma$-Valerolactone Solutions. J. Chem. Eng. Data 61:881-890. https://doi.org/10.1021/acs.jced.5b00724

[72] Fox JJ, Barker MF (1917) Determination of phenol in commercial cresylic acid. $J$. Soc. Chem. Ind. (London) 36:842-845.

[73] Schneider KW, Oberkobusch R. (1951) Die Analyse von Phenolgemischen unter Anwendung der Rektifikation und Chromatographie. Brennst.-Chem. 32:110-117.

[74] Vostrikova VN, Komarova TV, Reshetov SA (1981) Study of liquid-vapor equilibrium in phenol-o-cresol and styrene-benzaldehyde binary systems at reduced pressures. Zh. Prikl. Khim. 54:1178-1179.

[75] Clausse D, Lambert JP, Guigon P, Boudehen-Boiveaut A (1988) Determination d'equilibres liquid-vapeur et liquid-liquide pour l'elaboration de procedes industriels. Calorim. Anal. Therm. 19:C21.1-C21.9.

[76] Selvam SP, Dutt NVK, Balkishan Rao I, Subba Rao YV (1992) Isobaric VLE data for the binary systems phenol $+\mathrm{O}$-cresol, phenol + p-cresol, O-cresol + P-cresol and P-cresol + 2,4-xylenol. Fluid Phase Equilib. 78:261-267. https://doi.org/10.1016/0378-3812(92)87040-T

[77] Vostrikova VN, Komarova TV, Reshetov SA, Vinogradova VV (1978) Liquidvapor equilibrium in the binary systems found in products from the oxidative methylation of toluene. Khimicheskaya Promyshlennost' (5):345-346.

[78] Cepeda E, Gonzalez C, Resa JM, Ortiz de Salido C (1989) Isobaric vapor-liquid equilibrium for the cumene- $m$-cresol and phenol- $m$-cresol systems at $13.33 \mathrm{kPa} . J$. Chem. Eng. Data 34:429-431. https://doi.org/10.1021/je00058a017

[79] Hwang SM, Lee MJ, Lin H (2000) Isothermal vapor-liquid equilibria for mixtures of 4-methoxyphenol, catechol, and p-cresol. Fluid Phase Equilib. 172:183-196. https://doi.org/10.1016/S0378-3812(00)00370-8

[80] Shi X, Qi M, Zhang Q, Zhou W, Lu M (2000) Measurement and Prediction of VLE of Catechol System. J. East China Univ. Sci. Technol. 26:236-239.

[81] Wang J, Ou J, Sun X, Huang C, Sun J, Shao H, Leng Y (2018) Measurement and correlation of isobaric vapour-liquid equilibrium for systems of $o$-cresol, $m$-cresol and 2,6-dimethylphenol at $20.0 \mathrm{kPa}$. Fluid Phase Equilib. 459:44-50. https://doi.org/10.1016/j.fluid.2017.12.011

[82] Vostrikova VN, Komarova TV, Sobolev OB (1980) Vapor-liquid equilibrium under vacuum in binary systems containing styrene, benzaldehyde, and $p$ - and $o$ cresols. Zh. Prikl. Khim. 53:2118-2119.

[83] Ye R, Xia MS, Yu D, Liu H, Hu Y (1998) Isobaric Vapor-Liquid Equilibria for 2Methylphenol-2,6-Dimethylphenol-2,4,6-Trimethylphenol Ternary System. Chin. J. Chem. Eng. 6:183-188.

[84] Weissenberger G, Schuster F, Schuler K (1924) Über die Molekülverbindungen der Phenole. IV. Das Verhalten der binären Systeme mit Phenol und Phenoläthern. Monatsh. Chem. 45:425-435. https://doi.org/10.1007/BF01521924 
[85] Martin AR, George CM. 330. Partial vapour pressures and refractivities of mixtures of benzene with nitrobenzene, phenol, benzyl alcohol, or $p$-dichlorobenzene. $J$. Chem. Soc. 1413-1416. https://doi.org/10.1039/JR9330001413

[86] Gmehling J (1982) Phase Equilibria in Binary Systems Formed by Phenol with Benzene, $n$-Octane, and n-Decane. J. Chem. Eng. Data 27:371-373. https://doi.org/10.1021/je00030a002

[87] Nienhaus B, Limbeck U, Bölts R, de Haan AB, Niemann SH, Gmehling J (1998) Vapor-Liquid Equilibria at 413.65 K and Excess Enthalpies at 323.15, 363.15, and 413.15 K for Mixtures of Benzene, Toluene, Phenol, and Benzaldehyde. J. Chem. Eng. Data 43:941-948. https://doi.org/10.1021/je980116z

[88] Drickamer HG, Brown GG, White RR (1945) Vapor-Liquid Equilibria in PhenolHydrocarbon Systems. Trans. Am. Inst. Chem. Eng. 41:555-605.

[89] Klauck M, Grenner A, Taubert K, Martin A, Meinhardt R, Schmelzer J (2008) Vapor-Liquid Equilibria in Binary Systems of Phenol or Cresols + Water, + Toluene, and + Octane and Liquid-Liquid Equilibria in Binary Systems of Cresols + Water. Ind. Eng. Chem. Res. 47:5119-5126. https://doi.org/10.1021/ie071214t

[90] Anderko A (1989) (Vapour+liquid) equilibria of (phenol + butylbenzene or propylbenzene or isopropylbenzene or 1,2,4-trimethylbenzene or ethylbenzene) at 393.15 and 403.15 K. J. Chem. Thermodyn. 21:731-738. https://doi.org/10.1016/0021-9614(89)90056-6

[91] Byk SS, Stroiteleva RG (1956) Phase equilibria in the phenol + isopropylbenzene system in the presence of $\alpha$-methylstyrene. Zh. Fiz. Khim. 30: 2451-2455.

[92] Cepeda E, Gonzalez C, Resa JM (1989) Isobaric Vapor-Liquid Equilibrium for the Cumene-Phenol System. J. Chem. Eng. Data 34:270-273. https://doi.org/10.1021/je00057a004

[93] Weissenberger G, Piatti L (1924) Über die Molekülverbindungen der Phenole. II. Das Verhalten der Kresole gegen aromatische Kohlenwasserstoffe. Monatsh. Chem. 45:281-285. https://doi.org/10.1007/BF01524670

[94] Weissenberger G, Schuster F, Wojnoff K (1925) Über die Molekülverbindungen der Phenole. VII. Das Verhalten der hydrierten Kresole und verwandter Verbindungen. Monatsch. Chem. 46:1-8. https://doi.org/10.1007/BF01525485

[95] Prasad TEV, Harish G, Krupavaram N, Prasad S, Jaiswal A, Prasad DHL (2005) Bubble points of some binary mixtures formed by $o$-cresol at $95.75 \mathrm{kPa}$. Fluid Phase Equilib. 238:45-51. https://doi.org/10.1016/j.fluid.2005.09.012

[96] Prasad TEV, Vasavi M, Jyotsna M, Jhansi V, Smitha G, Prasad DHL (2008) Bubble point measurements of binary mixtures formed by ethyl benzene with selected compounds at $95.35 \mathrm{kPa}$. J. Chem. Thermodyn. 40:1418-1421. https://doi.org/10.1016/j.jct.2008.05.002

[97] Savitt SA, Othmer DF (1952) Separation of $m$ - and $p$-Cresols from Their Mixtures. Ind. Eng. Chem. 44:2428-2431. https://doi.org/10.1021/ie50514a041

[98] Sartakova OY, Krut'ko OM, Khristenko MS, Kormina LA (1996) Design of flow diagrams for the separation of toluene-diglyme mixtures with the use of additional components. Zh. Prikl. Khim. 69:1077-1080.

[99] Prasad TEV, Reddy NM, Kiran NA, Prasad DHL (2006) Activity coefficients of binary mixtures of $m$-cresol + selected compounds at $95.5 \mathrm{kPa}$. Phys. Chem. Liq. 44:227-231. https://doi.org/10.1080/00319100500329077 
[100] Othmer DF, Savitt SA, Krasner A, Goldberg AM, Markowitz D (1949) Composition of Vapors from Boiling Binary Solutions. Systems with $m$ - or $p$ Cresol as One Component. Ind. Eng. Chem. 41:572-574. https://doi.org/10.1021/ie50471a028

[101] Schmelzer J, Niederbroeker H, Partzsch S, Voeckler R, Meinhardt R (1996) Isothermal vapor-liquid equilibria in binary mixtures containing hydrocarbons (nonane, decane, dodecane, butylbenzene, or 2-methylnaphthalene) and phenol or cresols (2-methylphenol or 3-methylphenol) at 373 and 453 K. ELDATA: Int. Electron. J. Phys.-Chem. Data 2:153-162.

[102] Marks DE, Wingard RE (1960) Vapor-Liquid Equilibrium in the Toluene- $p$-Cresol System. J. Chem. Eng. Data 5:416-419. https://doi.org/10.1021/je60008a004

[103] Prasad TEV, Venkanna N, Kumar YN, Ashok K, Sirisha NM, Prasad DHL. Activity coefficients and excess Gibbs' free energy of some binary mixtures formed by $p$-cresol at $95.23 \mathrm{kPa}$. J. Chem. Thermodyn. 39:1022-1026. https://doi.org/10.1016/j.jct.2006.12.017

[104]Weissenberger G, Hencke R, Bregmann L (1925) Zur Kenntnis organischer Molekülverbindungen. XVI. Zweiwertige Phenole und ihre Äther. Monatsh. Chem. 46:471-482. https://doi.org/10.1007/BF01525702

[105]Lebedeva AA, Kiva VN, Pariychuk LV (1970) Vapor-liquid equilibrium in mixtures of anisole, phenol, and o-cresol. Trudy, Nauchno-Issledovatel 'skii Institut Neftekhimicheskikh Proizvodstv 2:92-95.

[106]Li H, Xia S, Ma P, Yan F, Yang Z, Li Y (2014) Isobaric (vapour + liquid) equilibria for three binary systems (toluene + anisole, $n$-butylbenzene + anisole, and guaiacol + anisole) at $101.33 \mathrm{kPa}$. Fluid Phase Equilib. 369:109-114. https://doi.org/10.1016/j.fluid.2014.02.025

[107] Schreinemakers FAH (1900) Dampfdrucke binärer und ternärer Gemische. Z. Phys. Chem. 35U:459-479. https://doi.org/10.1515/zpch-1900-3530

[108] Schükarew A (1910) Über die Eigenschaften der Lösungen bei ihrer kritischen Lösungstemperatur. Z. Phys. Chem. 71U:90-108. https://doi.org/10.1515/zpch$\underline{1910-7107}$

[109]Rhodes FH, Wells JH, Murray GW (1925) Vapor Composition Relationships in the Systems Phenol-Water and Phenol-Cresol. Ind. Eng. Chem. 17:1199-1201. https://doi.org/10.1021/ie50191a044

[110]Ferguson JB (1927) The System Water-Phenol. J. Phys. Chem. 31:757-763. https://doi.org/10.1021/j150275a013

[111] Campbell AN, Campbell AJR (1937) Concentrations, Total and Partial Vapor Pressures, Surface Tensions and Viscosities, in the Systems Phenol-Water and Phenol-Water-4\% Succinic Acid. J. Am. Chem. Soc. 59:2481-2488. https://doi.org/10.1021/ja01291a001

[112]Brusset H, Gaynès J (1953) Courbes d'ébullition et de rosée des systems binaires eau-phénol et eau-orthocrésol. C. R. Hebd. Seances Acad. Sci. 236:1563-1565.

[113] Markuzin NP (1961) Equilibrium between solution and vapor in the system triethylamine-phenol and phenol-water at $15^{\circ}$. Zh. Prikl. Khim. 34:1175-1176.

[114] Weller R, Schuberth H, Leibnitz E (1963) Die Phasengleichgewichte dampfförmig/flüssig des Systems Phenol $/ n$-Butylacetat/Wasser bei $44,4^{\circ} \mathrm{C}$. $J$. Prakt. Chem. 21:234-249. 
[115]Kliment V, Fried V, Pick J (1964) Gleichgewicht Flüssigkeit-Dampf XXXIII. Systeme Butylacetat-Phenol und Wasser-Phenol. Collect. Czech. Chem. Commun. 29:2008-2015. https://doi.org/10.1135/cccc19642008

[116]Kiva VN, Lebedeva AA, Kirichenko GA, Mozgovaya VP (1970) Study of azeotropy in some ternary mixtures of the decomposition products of cumene hydroperoxide. Document \# 2270-70 deposited in VINITI.

[117]Kolyuchkina GY, Timofeev VS, Serafomov LA (1971) Study of phase equilibrium in the heptane-phenol-water system. Uch. Zap., Mosk. Inst. Tonkoi Khim. Tekhnol. 1(3):78-87.

[118]Hakuta T (1975) Vapor-liquid equilibria of pollutants in sea water. II. Vapor-liquid equilibria of phenolic substance-water systems. Nippon Kaisui Gakkaishi 28: 379385.

[119]Karavaeva AP, Koshel' GN, Galiaskarova LM (1975) Mutual solubility and liquidvapor equilibrium in the cyclohexanone-phenol-water ternary. Osnovn. Org. Sint. Neftekhim. 3:98-104.

[120]Lyzlova RV, Susarev MP (1982) Phase equilibria in the water-hydrogen chloridephenol ternary. Zh. Prikl. Khim. 55:261-265.

[121]Chou CH, Perng JL, Lee MD, Chen YP (1987) Vapor-liquid equilibrium measurements of the ternary system of ethanol, water and phenol at $760 \mathrm{mmHg} . J$. Chin. Inst. Chem. Eng. 18:393-399.

[122] Tabai S, Rogalski M, Solimando R, Malanowski SK (1997) Activity Coefficients of Chlorophenols in Water at Infinite Dilution. J. Chem. Eng. Data 42: 1147-1150. https://doi.org/10.1021/je960336h

[123] Shakhparonov MI, Martynova ME (1953) On the theory of the thermodynamic properties of solutions. VII. Vapor pressure of resorcinol solutions in various solvents. Zh. Fiz. Khim. 27:197-205.

[124] Weissenberger G, Hencke R, Sperling E (1925) Zur Kenntnis organischer Molekülverbindungen. XVII. Das Verhalten des Dekahydronaphthalins. Monatsh. Chem. 46:483-497. https://doi.org/10.1007/BF01526344

[125] Chalov NV, Goryachikh EF, Vodolazova LK (1955) Study of the liquid-vapor compositions in binary solutions of phenol. Gidroliznaya I Lesokhimicheskaya Promyshlennost' 8:11-12.

[126]Gölles F (1963) Zur Ermittlung und rechnerischen Überprüfung thermodynamischer Daten aus experimentell gefundenen Werten, 4. Mitt.: Zur Bestimmung der Partialdrucke im System Phenol(2)-Aceton(3). Monatsh. Chem. 94:1108-1117. https://doi.org/10.1007/BF00905699

[127] Motina GL, Tentser NZ, Aerov ME (1968) Liquid-vapor equilibrium in the system phenol-acetone and phenol-acetone-water. Zh. Prikl. Khim. 41:1048-1055.

[128] Vasil'eva II, Gryaznov AK, Zakoshanskiy VM, Naumova AA, Polyakov AA (1991) Study of the liquid-vapor equilibrium in the acetone-phenol system. $Z h$. Prikl. Khim. 64:444-448.

[129]Byk SS, Shcherbak LI (1956) Liquid-vapor equilibrium in the phenol-methyl ethyl ketone system. Zh. Fiz. Khim. 30:56-60.

[130] Oscarson JL, Lundell SO, Cunningham JR (1987) Phase equilibria for ten binary systems. AIChE Symp. Ser. 83:1-17. 
[131]Fried V, Pick J (1961) Liquid-vapor equilibria. XXV. System phenolacetophenone at reduced pressures. Collect. Czech. Chem. Commun. 26:954-960. https://doi.org/10.1135/cccc19610954

[132] Aarna A, Kaps T (1974) Vapor-liquid isobaric equilibrium in phenol + oxygencompound binary mixtures. Eesti NSV Tead. Akad. Toim., Keem., Geol. 23:16-21.

[133] Giles NF, Wilson GM (2006) Vapor-Liquid Equilibria on Seven Binary Systems: Ethylene Oxide + 2-Methylpropane; Acetophenone + Phenol; cis-1,3-

Dichloropropene + 1,2-Dichloropropane; 1,5-Hexadiene + Allyl Chloride; Isopropyl Acetate + Acetonitrile; Vinyl Chloride + Methyl Chloride; and 1,4Butanediol $+\gamma$-Butyrolactone. J. Chem. Eng. Data 51:1954-1962. https://doi.org/10.1021/je050317k

[134] Weissenberger G, Schuster F (1924) Über die Molekülverbindungen der Phenole. V. Zur Kenntnis der Dampfdruckkurven. Monatsh. Chem. 45:437-448. https://doi.org/10.1007/BF01524551

[135] Weissenberger G, Piatti L (1925) Über die Molekülverbindugen der Phenole. I. Das Verhalten Kresole gegen Alkohol, Äther und Aceton. Monatsh. Chem. 45:187-206. https://doi.org/10.1007/BF01524660

[136]Piatti L (1936) Zur Kenntnis binärer Gemische IV. Angew. Chem. 49:77-78. https://doi.org/10.1002/ange.19360490304

[137] Kodama D, Tanaka H, Kato M (2002) Vapor-Liquid Equilibrium of 1,4Dihydroxybenzene in Methanol or Ethanol. J. Chem. Eng. Data 47:91-92. https://doi.org/10.1021/je010158e

[138] Hu WM, Shen LM, Zhao LJ (2004) Measurement of vapor-liquid equilibrium for binary mixtures of phenol-dimethyl carbonate and phenol-methanol at $101.3 \mathrm{kPa}$. Fluid Phase Equilib. 219:265-268. https://doi.org/10.1016/j.fluid.2004.01.023

[139]Cesari L, Namysl S, Canabady-Rochelle L, Mutelet F (2017) Phase equilibria of phenolic compounds in water or ethanol. Fluid Phase Equilib. 453:58-66. https://doi.org/10.1016/j.fluid.2017.09.008

[140] Ravikumar YVL, Ramakrishna M, Veeranna D (1991) Bubble Temperature Data for Phenol-n-Propanol System. Phys. Chem. Liq. 23:109-114. https://doi.org/10.1080/00319109108030640

[141] Veeranna D, Ravi Kumar YVL, Ramakrishna M (1989) Bubble Temperature Data for Phenol-Alcohol Systems 1. Phenol-i-Propanol System. Phys. Chem. Liq. 19:17-22. https://doi.org/10.1080/00319108908028404

[142]Brusset H, Kaiser L, Hocquel J (1968) Étude de quelques systems binaires du glycol. Chim. Ind. Genie Chim. 99:207-219.

[143] Prasad TEV, Jaiswal A, Prasad S, Harish G, Krupavaram N, Sirisha NM, Ashok K, Kumar YN, Venkanna N, Prasad DHL (2006) Activity coefficients of the binary mixtures of $o$-cresol or $p$-cresol with $\mathrm{C}_{1}-\mathrm{C}_{4}$ aliphatic alcohols near ambient pressure. Fluid Phase Equilib. 244:86-98. https://doi.org/10.1016/j.fluid.2006.03.018

[144] Kurtyka Z (1956) The Positive-Negative Azeotrope: Glycol-o-Cresol-2,4,6Collidine. XXIII. Bull. Acad. Pol. Sci., Cl. III 4:49-53.

[145] Prasad TEV, Kiran NA, Reddy NM, Prasad DHL (2006) (Vapor + liquid) equilibria of the binary mixtures of $m$-cresol with $\mathrm{C}_{1}-\mathrm{C}_{4}$ aliphatic alcohols at $95.5 \mathrm{kPa} . J$. Chem. Thermodyn. 38:1696-1700. https://doi.org/10.1016/j.jct.2006.03.006 
[146]Piatti L (1931) Zur Kenntnis binärer Gemische. Z. Phys. Chem. 152A:36-46. https://doi.org/10.1515/zpch-1931-15204 